\title{
Sequestering Carbon Dioxide in Coalbeds
}

\author{
Technical Progress Report
}

Reporting Period

from September 28, 2000 to October 28, 2001

\author{
K. A. M. Gasem \\ R. L. Robinson, Jr. \\ Oklahoma State University \\ School of Chemical Engineering \\ Stillwater, Oklahoma 74078-0537 \\ L. R. Radovic \\ Pennsylvania State University \\ Department of Energy and \\ Geo-Environmental Engineering \\ University Park, PA 16802 \\ PREPARED FOR THE UNITED STATES \\ DEPARTMENT OF ENERGY \\ DE-FC26-98FT40426
}




\section{DISCLAIMER}

This report was prepared as an account of work sponsored by an agency of the United States Government. Neither the United States Government nor any agency thereof, nor any of their employees, makes any warranty, express or implied, or assumes any legal liability or responsibility for the accuracy, completeness, or usefulness of any information, apparatus, product, or process disclosed or represents that its use would not infringe privately owned rights. Reference herein to any specific commercial product, process, or service by trade name, trademark, manufacturer, or otherwise does not necessarily constitute or imply its endorsement, recommendation, or favoring by the United States Government or any agency thereof. The views and opinions of authors expressed herein do not necessarily state or reflect those of the United States Government or any agency thereof. 


\section{ABSTRACT}

The authors' long term goal is to develop accurate prediction methods for describing the adsorption behavior of gas mixtures on solid adsorbents over complete ranges of temperature, pressure and adsorbent types. The major objectives of the project are to

- measure the adsorption behavior of pure $\mathrm{CO}_{2}$, methane, nitrogen and their binary and ternary mixtures on several selected coals having different properties at temperatures and pressures applicable to the particular coals being studied,

- $\quad$ generalize the adsorption results in terms of appropriate properties of the coals to facilitate estimation of adsorption behavior for coals other than those studied experimentally,

- delineate the sensitivity of the competitive adsorption of $\mathrm{CO}_{2}$, methane and nitrogen to the specific characteristics of the coal on which they are adsorbed; establish the major differences (if any) in the nature of this competitive adsorption on different coals, and

- test and/or develop theoretically-based mathematical models to represent accurately the adsorption behavior of mixtures of the type for which measurements are made.

The specific accomplishments of this project during this reporting period are summarized below in three broad categories outlining experimentation, model development, and coal characterization.

\section{Experimental Work}

Pure-Gas Adsorption: Adsorption isotherms for pure $\mathrm{CO}_{2}$, methane, and nitrogen on wet Lower Basin (LB) Fruitland coal were measured at $319.3 \mathrm{~K}\left(115^{\circ} \mathrm{F}\right)$ and pressures to $12.4 \mathrm{MPa}$ (1800 psia). The LB Fruitland coal adsorption measurements are a new addition to the existing database. All adsorption measurements for methane, nitrogen, and $\mathrm{CO}_{2}$ on LB Fruitland coal indicate hat it has the lowest adsorption capacity of the four coals we have studied thus far. The amount adsorbed on the LB Fruitland coal is about one half that of Fruitland coal at the same conditions for methane and nitrogen. This difference in the adsorptive capacity is mainly due to the high ash content of LB Fruitland coal. Specifically, the ash content of LB Fruitland coal is roughly twice that of Fruitland coal. For $\mathrm{CO}_{2}$, two replicate isotherms show an anomalous bump near 1400 psia. The low-sorbing nature of LB Fruitland coal and the increased uncertainty of the $\mathrm{CO}_{2}$ bulk density at these near-critical-point conditions amplify the expected uncertainty in temperature and pressure measurements. The methane and nitrogen absolute adsorption isotherms are well represented by Type I adsorption. $\mathrm{CO}_{2}$ isotherm data can be represented adequately by Type I adsorption, but the isotherm does not appear to be adequately described by Langmuir-type behavior. Nevertheless, the new measurements agree with the previous ones in the relative amounts of methane and nitrogen adsorbed, which are in the approximate ratio of 2.5:1. 
Adsorption isotherms for pure $\mathrm{CO}_{2}$, methane, and nitrogen on dry activated carbon (Filtrasorb-400) were measured at $327.6 \mathrm{~K}\left(130^{\circ} \mathrm{F}\right)$ and pressures to $12.4 \mathrm{MPa}(1800$ psia). The expected uncertainties are within $2 \%$. These data complement our previous measurements on activated carbon. The results at $130{ }^{\circ} \mathrm{F}$ show $10 \%$ lower adsorption capacity for the activated carbon than observed at $113^{\circ} \mathrm{F}$. The relative affinity of the various gases (as determined at 1000 psia in reference to nitrogen) adsorbed is approximately 2.3:1.5:1 for $\mathrm{CO}_{2}$, methane and nitrogen, respectively.

Binary Adsorption: Binary adsorption of methane/nitrogen, methane/ $\mathrm{CO}_{2}$, and nitrogen $/ \mathrm{CO}_{2}$ at a series of compositions has been measured on wet Illinois-6 coal at $319.3 \mathrm{~K}\left(115^{\circ} \mathrm{F}\right)$ and pressures to $12.4 \mathrm{MPa}(1800 \mathrm{psia})$. The nominal molar feed compositions of these mixtures are $20,40,60$, and $80 \%$. The uncertainties for the binary mixtures vary with compositions. In general, the expected uncertainty in the amounts of individual-component adsorption from the methane/nitrogen mixtures is 2 $10 \%$. The total adsorption of the various binary mixtures is bounded by the respective pure-component data.

A second experimental apparatus was set up for multicomponent adsorption measurements, and gas chromatograph calibrations were conducted to support the adsorption measurements. In addition, binary adsorption of methane/nitrogen, and methane $/ \mathrm{CO}_{2}$ on dry activated carbon was measured for the nominal molar feed compositions of $20,40,60$, and $80 \%$. In general, the expected uncertainties in the amounts of individual-component adsorption from these binary mixtures are $2-8 \%$. The present results for activated carbon show similar behavior to comparable binary adsorption on Fruitland coal (albeit, differing in the amount adsorbed). Further, the component absolute adsorption for these binary mixtures on activated carbon is well represented by Type I adsorption. These newly-acquired data represent a valuable addition to the currently limited database on high-pressure adsorption.

\section{Model Development}

Various adsorption models, including the Langmuir/loading ratio correlation, ZhouGasem-Robinson (ZGR) and Park-Gasem-Robinson (PGR) two-dimensional equations of state (EOS), and the modified simplified local density model (SLD-PR) have been used to analyze our adsorption data. Model parameters have been obtained for the systems studied.

The ZGR EOS was used to correlate our adsorption data for pure methane, nitrogen, and $\mathrm{CO}_{2}$ on dry activated carbon, wet Fruitland, wet Illinois-6 and wet Lower Basin Fruitland coals. Also, a new robust initialization method was developed for the ZGR EOS to improve its computational efficiency. The results obtained demonstrate the ability of the ZGR EOS to represent the systems considered within their expected experimental uncertainties. The ZGR EOS describes the adsorption on dry activated carbon within $0.8 \%$ AAD (absolute average deviation), wet Fruitland coal within $2 \%$, wet Lower Basin Fruitland coal within 2\%, and wet Illinois-6 within 4\%. 
In addition, by introducing the adsorbed-phase density as a model parameter in to the ZGR EOS, we now are able to use the model to correlate the experimental Gibbs adsorption data directly. Comparable representation is observed for both absolute and Gibbs adsorption data within $1.5 \%$. More importantly, we can now fit the isotherms exhibiting a maximum excess Gibbs adsorption; thus, gaining the ability to expand the 2-D ZGR correlative capability to cover the full pressure range considered (up to 2000 psia for the $\mathrm{CO}_{2}$ isotherms).

Our results for the different binary mixtures on wet Illinois-6 coal show that the LRC model can describe component adsorption data for some compositions within 5\%; however, deviations as large as $30 \%$ are observed for the individual component adsorption in nitrogen $/ \mathrm{CO}_{2}$ mixture. In comparison, the ZGR EOS can correlate the total mixture adsorption of all the mixtures considered within 5\%. For the component adsorption predicted by ZGR, nitrogen $/ \mathrm{CO}_{2}$ shows the worst results. This may attributed to the large difference between the ZGR pure-fluid parameters, indicating that this system is more non-ideal than the other systems and larger errors are expected.

We have modified the simplified local density model (SLD) to improve its predictive capability, especially when dealing with near-critical and supercritical adsorption behavior. Various forms of the SLD model were evaluated and generalizations of the various models were explored. Our results indicate that increasing the Peng-Robinson covolume by $55 \%$ improves significantly the quality of the fit for all isotherms.

The modified SLD model represents the adsorption behavior of all fluids considered within $6 \% \mathrm{AAD}$, including the near-critical behavior of carbon dioxide beyond $8.3 \mathrm{MPa}$ (1200 psia). Specifically, the modified SLD-PR model represents the adsorption of pure methane, nitrogen and $\mathrm{CO}_{2}$ on dry activated carbon within 2\% AAD, on wet Fruitland coal within 4\%, wet Lower Basin Fruitland coal within 6\%, and on wet Illinois-6 coal within $4 \%$. These results indicate that the modified model is capable of representing these within about twice their expected experimental uncertainties.

\section{Coal Characterization}

At Pennsylvania State University, we performed additional studies designed to assess the role of coal surface chemistry in determining the relative adsorption uptakes of carbon dioxide vs. methane. Detailed electrophoresis experiments with coals ranging in rank from lignite to low volatile bituminous were carried out. Electrophoretic mobilities (EM) were measured on powdered samples as a function of $\mathrm{pH}$. Some samples exhibited rather complex shapes, rather than monotonic EM changes with $\mathrm{pH}$. For comparison, the same experiments were carried out using an activated carbon and graphite. The isoelectric points (IEP) were all in the acidic range, ranging from 1.0 to 4.9. Upon coal demineralization, the mobility curves were very different, indicating that a large portion of the measured response was due to the presence of inorganic constituents in coal.

Experiments that are complementary to electrophoresis were carried out with the same coals: mass titrations and determination of the point of zero charge (PZC). In the 
absence of specific adsorption, the point of zero charge (obtained as an asymptotic value from the titration curve) should be identical to the isoelectric point (obtained from electrophoresis). In all cases, however, the PZC was much larger than the IEP. Thus, for example, the values for the Pocahontas low-volatile bituminous coal were 8.3 and 3.5, respectively, while those for the Beulah lignite were 6.4 and 1.8. These differences are due, at least in part, to the fact that the PZC is a response of the entire pore surface (both internal and external), while the IEP is a response only of the external particle surface. Therefore, in agreement with similar studies using activated carbons (for the Calgon Carbon BPL sample, the corresponding values were 7.8 and 5.0), the external surface of all the coals is enriched in acidic functional groups (e.g., $\mathrm{COOH}$ ). Part of the difference may also be due to the heterogeneous distribution of mineral matter in the coals. The implications of these findings for $\mathrm{CO}_{2}$ sequestration in coal mines need to be evaluated carefully.

Plans were developed to set up an adsorption breakthrough experiment, which will allow us to evaluate directly the dynamic and competitive $\mathrm{CO}_{2}$ and methane adsorption characteristics of the coals. A fixed-bed column connected to a gas chromatograph will be used. Combining these results with the static adsorption isotherms, and with the physical and chemical characteristics of the coals, will allow us to identify the key parameters that determine the $\mathrm{CO}_{2}$ sequestration potential of the various coalbeds. 


\section{TABLE OF CONTENTS}

A. Executive Summary $\quad 8$

$\begin{array}{ll}\text { B. Experimental Work } & 13\end{array}$

$\begin{array}{ll}\text { 1. Experimental Facility } & 13\end{array}$

2. Experimental Methods and Procedures 13

$\begin{array}{ll}\text { C. Results and Discussion } & 18\end{array}$

$\begin{array}{ll}\text { 1. Experimental Data } & 18\end{array}$

2. Model Development 22

D. Penn State Collaboration 35

$\begin{array}{ll}\text { E. Conclusions } & 36\end{array}$

$\begin{array}{ll}\text { F. References } & 38\end{array}$

$\begin{array}{ll}\text { G. Tables } & 40\end{array}$

$\begin{array}{ll}\text { H. Figures } & 69\end{array}$ 


\section{A. Executive Summary}

During the present reporting period (September 2000 - October 2001), complementary tasks involving experimentation, model development, and coal characterization were undertaken to meet our project objectives. Following is a summary of our major accomplishments:

\section{Experimental Work}

1. Adsorption isotherms for pure $\mathrm{CO}_{2}$, methane, and nitrogen on wet Lower Basin (LB) Fruitland coal were measured at $319.3 \mathrm{~K}\left(115{ }^{\circ} \mathrm{F}\right)$ and pressures to 12.4 MPa (1800 psia). The LB Fruitland coal adsorption measurements are a new addition to the existing database.

All adsorption measurements on LB Fruitland coal indicate that it has the lowest adsorption capacity of the coals we have studied thus far. For methane and nitrogen, the amount adsorbed on the LB Fruitland coal is about one half that of Fruitland coal at the same conditions. This difference in the adsorptive capacity is due mainly to the high ash content of LB Fruitland coal. Specifically, the ash content of LB Fruitland coal is roughly twice that of Fruitland coal. For $\mathrm{CO}_{2}$, two replicate isotherms show an anomalous bump near 1400 psia. The low-sorbing nature of LB Fruitland coal and the increased uncertainty of the $\mathrm{CO}_{2}$ bulk density at these near-critical-point conditions amplify the expected uncertainties in temperature and pressure measurements. The methane and nitrogen absolute adsorption isotherms are well represented by Type I adsorption. $\mathrm{CO}_{2}$ can also be represented adequately by Type I adsorption, but the isotherm does not appear to be adequately described by Langmuir-type behavior. Nevertheless, the new measurements agree with the previous ones in the relative amounts of methane and nitrogen adsorbed, which are in the approximate ratio of 2.5:1.

2. Adsorption isotherms for $\mathrm{CO}_{2}$, methane, and nitrogen on activated carbon (Filtrasorb-400) were measured at $327.6 \mathrm{~K}\left(130^{\circ} \mathrm{F}\right)$ and pressures to $12.4 \mathrm{MPa}$ (1800 psia). The expected uncertainties are within $2 \%$. These data complement our previous measurements on activated carbon at $130{ }^{\circ} \mathrm{F}$. The results show $10 \%$ lower adsorption capacity for the activated carbon than observed at $113^{\circ} \mathrm{F}$. The relative affinity of the various gases (as determined at 1000 psia in reference to nitrogen) adsorbed is approximately 2.3:1.5:1 for $\mathrm{CO}_{2}$, methane and nitrogen, respectively.

3. Binary adsorption of methane and nitrogen at a series of compositions has been measured on wet Illinois- 6 coal at $319.3 \mathrm{~K}\left(115^{\circ} \mathrm{F}\right)$ and pressures to $12.4 \mathrm{MPa}$ (1800 psia). The nominal molar feed compositions of these mixtures are 20, 40, 60 and $79 \%$ methane. The uncertainties for the binary mixtures vary with compositions. In general, the expected uncertainty in the amounts of individualcomponent adsorption from the methane/nitrogen mixtures is $2-10 \%$. 
Our methane/nitrogen binary mixture adsorption results indicate that methane is more strongly adsorbed than nitrogen, as is the case for pure adsorption. For feed compositions of 79,60 , and $40 \%$, methane has higher absolute adsorption than nitrogen. However, for a feed composition of $20 \%$ methane, nitrogen has higher adsorption than methane. The total adsorption of methane/nitrogen binary mixture is bounded by the pure nitrogen and pure methane data.

4. Binary adsorption of methane and $\mathrm{CO}_{2}$ at a series of compositions has been measured on wet Illinois- 6 coal at $319.3 \mathrm{~K}\left(115^{\circ} \mathrm{F}\right)$ and pressures to $12.4 \mathrm{MPa}$ (1800 psia). The nominal feed compositions of these mixtures are 23, 40, 60, and $77 \%$ methane. The uncertainties for binary mixtures vary with composition. In general, the expected uncertainty in the amounts of individual-component adsorption from the methane/ $\mathrm{CO}_{2}$ mixtures is $3-10 \%$.

Our methane/ $\mathrm{CO}_{2}$ binary mixture adsorption results indicate that $\mathrm{CO}_{2}$ is more strongly adsorbed than methane, as is the case for pure adsorption. The total adsorption of methane/ $\mathrm{CO}_{2}$ binary mixture is bounded by the pure methane and pure $\mathrm{CO}_{2}$ data.

5. Binary adsorption of nitrogen and $\mathrm{CO}_{2}$ at a series of compositions has been measured on wet Illinois- 6 coal at $319.3 \mathrm{~K}\left(115^{\circ} \mathrm{F}\right)$ and pressures to $12.4 \mathrm{MPa}$ (1800 psia). The nominal feed compositions of these mixtures are 20, 42, 60 and $82 \%$ nitrogen. The uncertainties for the binary mixtures vary with composition. In general, the expected uncertainty in the amounts of individual-component adsorption from the nitrogen/ $\mathrm{CO}_{2}$ mixtures is $2-10 \%$.

Our nitrogen $/ \mathrm{CO}_{2}$ binary mixture adsorption results indicate that $\mathrm{CO}_{2}$ is more strongly adsorbed than nitrogen, as is the case for pure-fluid adsorption. The total adsorption of nitrogen/ $\mathrm{CO}_{2}$ binary mixture is bounded by the pure nitrogen and pure $\mathrm{CO}_{2}$ data.

6. Our second experimental apparatus was set up for multicomponent adsorption measurements, and gas chromatograph calibrations were conducted to support the adsorption measurements. In addition, binary adsorption of methane/nitrogen, and methane/ $\mathrm{CO}_{2}$ on dry activated carbon was measured for the nominal molar feed compositions of $20,40,60$, and $80 \%$ methane. In general, the expected uncertainty in the amounts of individual-component adsorption from the methane/nitrogen mixtures is $2-8 \%$. The present results for activated carbon show similar behavior to comparable binary adsorption on Fruitland coal (albeit, differing in the amount adsorbed). Further, the component absolute adsorption for these binary mixtures on activated carbon is well represented by Type I adsorption. These newly-acquired data represent a valuable addition to the currently limited database on high-pressure adsorption. These data, on a well-defined adsorbent matrix, facilitate evaluations of proposed models without the added complexity associated with coal characterization. 


\section{Model Development}

7. Various adsorption models, including the Langmuir/loading ratio correlation, Zhou-Gasem-Robinson (ZGR) and Park-Gasem-Robinson (PGR) twodimensional equations of state (EOS), and the modified simplified local density model (SLD-PR) have been used to analyze our adsorption data. Model parameters have been obtained for the systems studied.

The ZGR EOS was used to correlate our adsorption data for pure methane, nitrogen, and $\mathrm{CO}_{2}$ on dry activated carbon, wet Fruitland, wet Illinois-6 and wet Lower Basin Fruitland coals. The model parameters were determined by minimizing the sum of squares of percentage absolute errors in the calculated amounts of pure-gas adsorption. Also, a new robust initialization method was developed for the ZGR EOS to improve its computational efficiency.

The results obtained demonstrate the ability of the ZGR EOS to represent the systems considered within their expected experimental uncertainties. The ZGR EOS describes the adsorption on dry activated carbon within $0.8 \%$ AAD (absolute average deviation), wet Fruitland coal within 2\%, wet Lower Basin Fruitland coal within $2 \%$, and wet Illinois- 6 within $4 \%$.

8. In addition, by introducing the adsorbed phase density as a model parameter in to the ZGR EOS, we now are able to use the model to correlate the experimental excess Gibbs adsorption data directly. Comparable representation is observed for both absolute and Gibbs adsorption data (within 1.5\%). More importantly, we can now fit the isotherms exhibiting maxima in the excess Gibbs adsorption, thus gaining the ability to expand the 2-D ZGR correlative capability to cover the full pressure range considered (up to 2000 psia for the $\mathrm{CO}_{2}$ isotherms).

Our results for the different binary mixtures on wet Illinois-6 coal show that the LRC model can describe component adsorption data at some compositions within $5 \%$; however, deviations as large as $30 \%$ are observed for the component adsorption in the nitrogen/ $\mathrm{CO}_{2}$ mixture. In comparison, the ZGR EOS can correlate the total mixture adsorption of all the mixtures considered within $5 \%$. For the component adsorption predicted by ZGR, nitrogen/ $\mathrm{CO}_{2}$ shows the worst results. This may attributed to the large difference between the ZGR pure-fluid parameters, indicating that this system is more non-ideal than the other systems and larger errors are expected. The adsorbed phase densities used in the binary calculations are generated from the ZGR pure-gas Gibbs adsorption data regressions by assuming ideal mixing in the adsorbed phase.

9. We have modified the simplified local density model (SLD) to improve its predictive capability for pure-component adsorption, especially when dealing with near-critical and supercritical adsorption behavior. Various forms of the SLD model were evaluated and model generalizations of the various models were explored. Our results indicate that increasing the Peng-Robinson covolume by 
$55 \%$ improves significantly the quality of the fit for all the pure-component isotherms.

The modified SLD model represents the adsorption behavior of all fluids considered within $6 \% A A D$, including the near-critical behavior of carbon dioxide beyond $8.3 \mathrm{MPa}$ (1200 psia). Specifically, the modified SLD-PR model represents the adsorption of pure methane, nitrogen and $\mathrm{CO}_{2}$ on dry activated carbon within $2 \% A A D$, on wet Fruitland coal within 4\%, wet Lower Basin Fruitland coal within $6 \%$, and on wet Illinois-6 coal within $4 \%$. (These errors are about twice the expected experimental uncertainty.)

Pure-gas adsorption isotherm measurements for Lower Basin Fruitland and Illinois-6 were modeled with the SLD-PR model. For these low sorbing coals, the regressed surface areas and well depths are significantly lower than those of activated carbon and about half those of Fruitland coal. The high ash content of $64 \%$ for the Lower Basin Fruitland coal may explain its comparatively lower adsorption than Illinois- 6 and Fruitland coals, which have ash contents of $11 \%$ and $21 \%$, respectively.

\section{Coal Characterization}

10. At Pennsylvania State University, we performed additional studies designed to assess the role of coal surface chemistry in determining the relative adsorption uptakes of carbon dioxide vs. methane. Detailed electrophoresis experiments with coals ranging in rank from lignite to low volatile bituminous were carried out. Electrophoretic mobilities (EM) were measured on powdered samples as a function of $\mathrm{pH}$. Some samples exhibited rather complex shapes, rather than monotonic EM changes with $\mathrm{pH}$. For comparison, the same experiments were carried out using an activated carbon and graphite. The isoelectric points (IEP) were all in the acidic range, ranging from 1.0 to 4.9. Upon coal demineralization, the mobility curves were very different, indicating that a large portion of the measured response was due to the presence of inorganic constituents in coal.

11. Experiments that are complementary to electrophoresis were carried out with the same coals: mass titrations and determination of the point of zero charge (PZC). In the absence of specific adsorption, the point of zero charge (obtained as an asymptotic value from the titration curve) should be identical to the isoelectric point (obtained from electrophoresis). In all cases, however, the PZC was much larger than the IEP. Thus, for example, the values for the Pocahontas lowvolatile bituminous coal were 8.3 and 3.5 , respectively, while those for the Beulah lignite were 6.4 and 1.8. These differences are due, at least in part, to the fact that the PZC is a response of the entire pore surface (both internal and external), while the IEP is a response only of the external particle surface. Therefore, in agreement with similar studies using activated carbons (for the Calgon Carbon BPL sample, the corresponding values were 7.8 and 5.0 ), the external surface of 
all the coals is enriched in acidic functional groups (e.g., $\mathrm{COOH}$ ). Part of the difference may also be due to the heterogeneous distribution of mineral matter in the coals. The implications of these findings for $\mathrm{CO}_{2}$ sequestration in coal mines need to be evaluated carefully.

12. Plans were developed to set up an adsorption breakthrough experiment, which will allow us to evaluate directly the dynamic and competitive $\mathrm{CO}_{2}$ and methane adsorption characteristics of the coals. A fixed-bed column connected to a gas chromatograph will be used. Combining these results with the static adsorption isotherms, and with the physical and chemical characteristics of the coals, will allow us to identify the key parameters that determine the $\mathrm{CO}_{2}$ sequestration potential of the various coalbeds. 


\section{B. Experimental Work}

\section{Experimental Facility}

Currently, we have two experimental facilities dedicated to gas adsorption measurements. The first apparatus was developed in a prior project sponsored by Amoco Corporation and the Oklahoma Center for the Advancement of Science and Technology. As a precursor to the data acquisition, the apparatus was thoroughly retested and revised as necessary for operations in the present project. Details of the equipment design have been described previously [1,2]. A brief description of experimental methods and procedures is given in Section B.2, below.

The second apparatus was assembled from an equipment donation from BP Amoco. The donation consisted of essentially the complete coalbed methane research equipment housed at BP Amoco's Tulsa Technology Center. In August 1999, the second apparatus was reassembled in OSU's new Advanced Technology Research Center, a $\$ 35$ million state-of-the-art complex dedicated to research and technology development. Mr. Don Morgan, who formerly operated the equipment at BP Amoco, served as a consultant in reassembling and validating this apparatus.

The new facility has allowed us to essentially double our rate of data production. Although the efforts in reassembling, testing, and validating the new apparatus may have caused temporary delays in data acquisition on the first apparatus, the overall result was an increase in the total amount of data produced to date.

Recently, we have enhanced our experimental capability to include measuring the adsorption kinetics of systems encountered in coalbed methane production and sequestration of $\mathrm{CO}_{2}$. These measurements will help elucidate the pore structure of the coal matrices under study and improve our predictive capability when used in conjunction with equilibrium isotherms.

\section{Experimental Methods and Procedures}

Our two experimental facilities employ an identical mass balance method, utilizing volumetric accounting principles. The experimental apparatus, shown schematically in Figure 1, has been used successfully in previous measurements [1,2]. A brief description of the experimental apparatus and procedures follows.

The entire apparatus is maintained in a constant temperature air bath. The equilibrium cell (EC, Figure 1) is filled with the adsorbent to be studied, and the cell is placed under vacuum prior to gas injection. The void (gas) volume, $V_{\text {void }}$, in the equilibrium cell is then determined by injecting a known quantity of helium from a calibrated injection pump (Ruska). Since helium is not adsorbed, the void volume can be determined from measured values of the temperature, pressure and amount of helium injected into the cell. The equations are 


$$
\begin{aligned}
& \mathrm{V}_{\text {void }}=\mathrm{n}_{\mathrm{He}}\left(\mathrm{Z}_{\mathrm{He}} R T / p\right)_{\text {cell }} \\
& \mathrm{n}_{\mathrm{He}}=\left(\mathrm{pV} / \mathrm{Z}_{\mathrm{He}} R T\right)_{\text {pump }}
\end{aligned}
$$

In these equations, $\eta_{\mathrm{He}}$ is the number of moles of helium injected into the cell, $V$ is the volume of gas injected from the pump, $Z_{\mathrm{He}}$ is the compressibility factor of helium, $R$ is the universal gas constant, $T$ is the temperature, $p$ is the pressure, and the subscripts "cell" and "pump" refer to conditions in the cell and pump sections of the apparatus, respectively.

The amount of gas (methane, for example) adsorbed at a given pressure can be calculated based on the preliminary calibrations done above. First, a given quantity of methane, $\mathrm{n}_{\text {inj; }}$, is injected into the cell. This amount is determined by an equation analogous to Equation 2, above. A recirculating pump is used to circulate methane over the adsorbent until equilibrium is reached, where no further methane is adsorbed. The amount of unadsorbed methane, $n_{\text {unads }}$, is then determined based on the fact that any unadsorbed methane will remain in the void volume (determined from the helium calibration). The expression for this quantity is

$$
\mathrm{n}_{\text {unads }}=\left(p \mathrm{~V}_{\text {void }} / \mathrm{Z}_{\text {methane }} R T\right)_{\text {cell }}
$$

where the pressure $p$ is measured after equilibrium is reached in the cell. The amount of adsorbed methane, $\mathrm{n}_{\mathrm{ads}}$, is then calculated by difference as

$$
\mathrm{n}_{\mathrm{ads}}=\mathrm{n}_{\text {inj }}-\mathrm{n}_{\text {unads }}
$$

These steps are repeated at sequentially higher pressures to yield a complete adsorption isotherm.

In mixture studies, the procedure is only slightly more complicated. The individual gases can be injected separately (or a gas mixture of known composition can be injected), so the total amount of each gas in the cell is known. The amount of unadsorbed gas at each pressure is calculated by Equation 3 with $Z_{\text {methane }}$ replaced by $Z_{\text {mix }}$, the gas mixture compressibility factor. The composition of the gas mixture in the void volume is determined by chromatographic analysis of a microliter-size sample of the gas mixture captured in a sampling valve $\left(\mathrm{SV}_{1}\right)$. This permits the total amount of unadsorbed gas to be apportioned among the various components according to their mole fractions in the gas. Then, Equation 4 can be applied to each component in the gas mixture. For methane, nitrogen, and $\mathrm{CO}_{2}$ mixtures, the mixture $\mathrm{Z}$ factor is determined accurately from available experimental data and accurate equations of state. 


\section{Relationship between Gibbs and Absolute Adsorption}

The Gibbs adsorption definition considers the gas-phase volume $\left(\mathrm{V}_{\mathrm{c}}\right)$ as the sum of the gas $\left(V_{g}\right)$ and adsorbed-phase $\left(V_{a}\right)$ volumes (ignoring the reduction in gas-phase volume due to presence of the adsorbed-phase volume).

$$
\mathrm{V}_{\mathrm{c}}=\mathrm{V}_{\mathrm{g}}+\mathrm{V}_{\mathrm{a}}=\mathrm{V}_{\text {void }}
$$

The number of moles injected may be determined as follows based on the specific molar volume (of each phase), $v_{g}$ and $v_{a}$ :

$$
\mathrm{n}_{\text {inj }}=\frac{\mathrm{V}_{\mathrm{g}}}{\mathrm{V}_{\mathrm{g}}}+\frac{\mathrm{V}_{\mathrm{a}}}{\mathrm{V}_{\mathrm{a}}}=\frac{\mathrm{V}_{\mathrm{g}}+\mathrm{V}_{\mathrm{a}}}{\mathrm{V}_{\mathrm{g}}}+\frac{\mathrm{V}_{\mathrm{a}}}{\mathrm{V}_{\mathrm{a}}}-\frac{\mathrm{V}_{\mathrm{a}}}{\mathrm{V}_{\mathrm{g}}}
$$

Rewriting the above equation in terms of $\mathrm{V}_{\mathrm{c}}$, then

$$
\mathrm{n}_{\text {inj }}=\frac{\mathrm{V}_{\mathrm{c}}}{\mathrm{v}_{\mathrm{g}}}+\frac{\mathrm{V}_{\mathrm{a}}}{\mathrm{v}_{\mathrm{a}}}\left[1-\frac{\mathrm{v}_{\mathrm{a}}}{\mathrm{v}_{\mathrm{g}}}\right]
$$

This equation is identical to the equation usually used to calculate Gibbs adsorption from experiment (i.e.: Equation 4):

$$
\mathrm{n}_{\mathrm{ads}}^{\text {Gibbs }}=\mathrm{n}_{\mathrm{inj}}-\mathrm{n}_{\text {unads }}
$$

where

$$
\mathrm{n}_{\text {unads }}=\frac{\mathrm{v}_{\mathrm{c}}}{\mathrm{v}_{\mathrm{g}}} \quad \text { and } \quad \mathrm{n}_{\mathrm{ads}}^{\text {Gibbs }}=\frac{\mathrm{v}_{\mathrm{a}}}{\mathrm{v}_{\mathrm{a}}}\left[1-\frac{\mathrm{v}_{\mathrm{a}}}{\mathrm{v}_{\mathrm{g}}}\right] .
$$

Since the absolute adsorption is defined as $n_{a d s}^{A b s}=\frac{V_{a}}{V_{a}}$, then the relation between Gibbs and absolute adsorption is therefore

$$
\mathrm{n}_{\mathrm{ads}}^{\text {Abs }}=\mathrm{n}_{\mathrm{ads}}^{\mathrm{Gibs}} /\left[1-\frac{\mathrm{v}_{\mathrm{a}}}{\mathrm{v}_{\mathrm{g}}}\right]
$$

At low pressures, this correction is negligible, but at higher pressure it becomes significant. Rewriting Equation 7 in term of gas $\left(\rho_{\mathrm{g}}\right)$ and adsorbed $\left(\rho_{\mathrm{a}}\right)$ phase densities:

$$
\mathrm{n}_{\mathrm{ads}}^{\text {Abs }}=\mathrm{n}_{\mathrm{ads}}^{\text {Gibbs }} /\left[1-\frac{\rho_{\mathrm{g}}}{\rho_{\mathrm{a}}}\right]
$$


A common approximation for the density of an adsorbed phase is to use the liquid density at the atmospheric pressure boiling point, as done by Yee [3]. $\mathrm{CO}_{2}$, however, is a solid at its atmospheric boiling point. As a result, the density for a saturated liquid at the triple point was used instead. This work, unless otherwise noted, uses the adsorbed-phase density approximation suggested by Yee. For nitrogen, methane, and carbon dioxide, the densities $0.808 \mathrm{~g} / \mathrm{cc}, 0.421 \mathrm{~g} / \mathrm{cc}$, and $1.18 \mathrm{~g} / \mathrm{cc}$, respectively, are used to estimate the absolute adsorption from Gibbs adsorption data.

For multicomponent systems, the adsorbed-phase molar density $\rho_{a}$ in the Equation 8 is replaced with the mixture adsorbed-phase density which is assumed to be the adsorbed mole fraction weighted average of the pure component phase density $\rho_{\text {ai }}$ values, i.e.:

$$
\rho_{\mathrm{a}}=\frac{1}{\sum \frac{\mathrm{x}_{\mathrm{i}}^{\mathrm{Abs}}}{\rho_{\mathrm{ai}}}}
$$

\section{Component Absolute Adsorption}

The component mole fraction in the adsorbed phase $x_{i}^{\text {Abs }}$ is calculated based on the following derivation.

$$
n_{\text {inj }}(i)=\frac{V_{g}}{v_{g}} y_{i}+\frac{V_{a}}{v_{a}} x_{i}^{A b s}=z_{i} n_{\text {inj }}
$$

where $z_{i}$ is the feed mole fraction, and $y_{i}$ is the gas-phase mole fraction.

Since

$$
\mathrm{V}_{\mathrm{c}}=\mathrm{V}_{\mathrm{g}}+\mathrm{V}_{\mathrm{a}}=\mathrm{V}_{\text {void }}
$$

and substituting for $\mathrm{n}_{\mathrm{ads}}^{\text {Abs }}$ then

$$
n_{\text {inj }}(i)=\left[\frac{\left(V_{c}-V_{a}\right)}{v_{g}}\right] y_{i}+\left[\frac{n_{a d s}^{\text {Gibbs }}}{1-\frac{v_{a}}{v_{g}}}\right] x_{i}^{\text {Abs }}
$$

or

$$
n_{\text {inj }}(i)=\frac{V_{c}}{v_{g}} y_{i}-\frac{V_{a}}{v_{g}} y_{i}+\left[\frac{n_{\text {ads }}^{\text {Gibbs }}}{1-\frac{v_{a}}{v_{g}}}\right] x_{i}^{\text {Abs }}
$$


Noting that

$$
\mathrm{n}_{\mathrm{ads}}^{\text {Gibs }}=\frac{\mathrm{V}_{\mathrm{a}}}{\mathrm{v}_{\mathrm{a}}}\left[1-\frac{\mathrm{v}_{\mathrm{a}}}{\mathrm{v}_{\mathrm{g}}}\right]=\left(\frac{\mathrm{V}_{\mathrm{a}}}{\mathrm{v}_{\mathrm{a}}}-\frac{\mathrm{V}_{\mathrm{a}}}{\mathrm{v}_{\mathrm{g}}}\right),
$$

which upon rearrangement leads to

$$
\frac{v_{a}}{v_{g}}=\frac{n_{a d s}^{\text {Gibbs }}}{\left(1-\frac{v_{a}}{v_{g}}\right)}-n_{\text {ads }}^{\text {Gibs }}=\left[\frac{1}{\left(1-\frac{v_{a}}{v_{g}}\right)}-1\right] n_{\text {ads }}^{\text {Gibbs }}=\left[\frac{\frac{v_{a}}{v_{g}}}{\left(1-\frac{v_{a}}{v_{g}}\right)}\right] n_{\text {ads }}^{\text {Gibbs }}
$$

Therefore, Equation 12 becomes

$$
n_{\text {inj }}(i)-\frac{v_{c}}{v_{g}} y_{i}=-\left[\frac{\frac{v_{a}}{v_{g}}}{\left(1-\frac{v_{a}}{v_{g}}\right)}\right] n_{a d s}^{\text {Gibbs }} y_{i}+\left[\frac{n_{a d s}^{\text {Gibs }}}{1-\frac{v_{a}}{v_{g}}}\right] x_{i}^{\text {Abs }}
$$

or

$$
\left(n_{\text {inj }}(i)-\frac{v_{c}}{v_{g}} y_{i}\right)\left(1-\frac{v_{a}}{v_{g}}\right)=\left[x_{i}^{\text {Abs }}-y_{i}\left(\frac{v_{a}}{v_{g}}\right)\right] n_{\text {ads }}^{\text {Gibbs }}
$$

Since

$$
x_{i}^{\text {Gibbs }}=\frac{\left(n_{\text {inj }}(i)-\frac{v_{c}}{v_{g}} y_{i}\right)}{n_{a d s}^{\text {Gibbs }}}
$$

Then Equation 14 can be written as

$$
x_{i}^{\text {Gibbs }}\left(1-\frac{v_{a}}{v_{g}}\right)=x_{i}^{A b s}-y_{i}\left(\frac{v_{a}}{v_{g}}\right)
$$

For a binary system, Equation 15 becomes two equations:

$$
x_{1}^{\text {Gibbs }}=x_{1}^{\text {Abs }}+\left(x_{1}^{\text {Gibbs }}-y_{1}\right)\left[\frac{v_{a 1}}{v_{g}} x_{1}^{\text {Abs }}+\frac{v_{a 2}}{v_{g}} x_{2}^{\text {Abs }}\right]
$$


and

$$
x_{2}^{\text {Gibbs }}=x_{2}^{\text {Abs }}+\left(x_{2}^{\text {Gibbs }}-y_{2}\right)\left[\frac{v_{a 1}}{v_{g}} x_{1}^{A b s}+\frac{v_{a 2}}{v_{g}} x_{2}^{A b s}\right]
$$

Given the Gibbs adsorbed-phase compositions and the experimental gas-phase compositions, absolute adsorbed-phase compositions are obtained by solving Equations $16 \mathrm{a}$ and $16 \mathrm{~b}$ simultaneously. Once these compositions are obtained, the absolute adsorption of the individual components are calculated as follows:

$$
n_{\text {ads }}^{\text {Abs }}(i)=x_{i}^{A b s} n_{a d s}^{A b s}
$$

\section{Results and Discussion}

\section{Experimental Data}

A summary of the progress of our experimental program is presented in Table 1. Thus far, we have completed pure-gas (methane, nitrogen, ethane, and carbon dioxide) adsorption measurements on four solid matrices comprised of wet Fruitland coal (OSU\#2), wet Lower Basin Fruitland coal (OSU\#3), wet Illinois-6 coal, and dry activated carbon. Tables 23 present the compositional analyses for the various solid matrices considered in this study to date.

Binary mixture adsorption measurements were also completed for three binary systems (methane/ $\mathrm{CO}_{2}$, methane/nitrogen, and nitrogen/ $\mathrm{CO}_{2}$ ) on wet Fruitland coal (OSU\#2), wet Illinois- 6 coal and dry activated carbon. Additional binary mixture measurements on activated carbon are underway and should be completed shortly.

The present measurements are conducted mostly at $115{ }^{\circ} \mathrm{F}$ and cover the pressure range from 100 to 1800 psia. Our error analysis indicates that the average uncertainties for the pure-gas adsorption measurements are approximately $2 \%$. The expected uncertainties for the individual component adsorption from binary mixtures vary from 2 to $10 \%$. These estimates, which are depicted as error bars in some of the figures presented below, were generated by error propagation of uncertainties in all measured quantities. The estimated uncertainties in the experimentally measured quantities are as follows -- temperature: $0.2^{\circ} \mathrm{F}$; pressure: 1.0 psia; injected gas volumes: $0.02 \mathrm{cc}$. The newly acquired data confirm the estimated precision of our measurements and agree well with our previous data [2].

Following is a brief description of our new measurements and the associated analyses.

\section{(a) Pure-Gas Adsorption on Wet Lower Basin Fruitland Coal}

Gas adsorption measurements for pure methane, nitrogen and $\mathrm{CO}_{2}$ have been conducted on wet Lower Basin Fruitland coal at $115^{\circ} \mathrm{F}$ and pressures up to 1800 psia. The results are presented in Tables 4-7 and Figures 2-9. 
Figures 2 and 3 and Table 4 show the adsorption isotherm for pure methane. Replicate runs have been conducted to confirm our measurements. These measurements show good agreement between the replicate runs. The maximum expected difference between these measurements is approximately $7 \%$, as depicted as by the error bar in Figures 2 and 3 . The IUPAC EOS [4] was used to calculate the compressibility factor of methane.

The adsorption isotherm for pure nitrogen is presented in Table 5 and Figures 4 and 5 . As shown in these figures, no significant difference between both replicate runs was evident in these measurements. The maximum uncertainty expected for these measurements is approximately $9 \%$. The IUPAC EOS [4] was used to calculate the compressibility factor of nitrogen.

Both methane and nitrogen adsorption measurements on LB Fruitland coal indicate lower adsorption capacity than Fruitland coal, as reported previously. The measurements on LB Fruitland are about one half that on Fruitland coal, at the same conditions. This difference might be due to variations in coal composition. Ash content in LB Fruitland coal is about twice higher than that in Fruitland coal. In contrast, the carbon content in LB Fruitland coal is about one half that in Fruitland coal (see Table 2). Nevertheless, the new measurements agree with the previous ones in the relative amount of methane and nitrogen adsorbed, which are in the approximate ratio of 2.5:1.

During our adsorption measurements on LB coal, four specific studies were conducted to assess the influence of moisture content, compressibility factor predictions, sample preparation, and sample adsorption history on the adsorption behavior, as described below.

Moisture Content. A slightly different moisture content in each measurement set indicates, as previously reported, that water content values beyond the equilibrium water content do not significantly affect the adsorption behavior. The equilibrium water content of the sample coal used was $4 \%$.

Compressibility Factor Predictions: $\mathrm{CO}_{2}$ adsorption measurements are presented in Table 6 and Figure 6 . Three replicate runs were conducted. The figure shows that for pressures below 1200 psia, the $\mathrm{CO}_{2}$ adsorption measurements show no significant difference among the three runs. However, above 1200 psia the data show greater variations among the three runs, consistent with the larger error bars in that region.

The greater uncertainties in the region above 1200 psia are attributed to the sensitivity of the predicted EOS compressibility factor to changes in temperature and pressure $(\partial Z / \partial P$ and $\partial Z / \partial T)$. To illustrate this sensitivity, two equations of state were used to calculate the compressibility factor of $\mathrm{CO}_{2}$. Figure 6 presents the $\mathrm{CO}_{2}$ adsorption when the Wagner EOS [5] is used and Figure 7 presents variations in the amount of $\mathrm{CO}_{2}$ adsorbed when the IUPAC EOS [4] is used. As shown in Figures 6 and 7, the IUPAC 
EOS gives about 7\% lower adsorption than Wagner EOS at pressures above 1200 psia. At lower pressures, both EOS essentially yielded the same $\mathrm{CO}_{2}$ adsorption.

The same coal matrix was used for the methane, nitrogen and $\mathrm{CO}_{2}$ adsorption measurements where methane adsorption was measured first followed by nitrogen and $\mathrm{CO}_{2}$, respectively. To study the effect of sequential runs on $\mathrm{CO}_{2}$ adsorption, $\mathrm{CO}_{2}$ adsorption has been conducted using fresh coal from the same coal sample. The comparison among the three $\mathrm{CO}_{2}$ adsorption isotherms measured following methane and nitrogen adsorption and that measured on the fresh coal matrix (OSU\#3b) is shown in Figure 8. The figure shows insignificant variations (within the experimental uncertainty) among the measurement sets.

Sample preparation: To investigate the effect of sample preparation on the amount adsorbed, a new sample was prepared from the same LB Fruitland coal and $\mathrm{CO}_{2}$ adsorption measurements were performed. The results are presented in Table 7. Comparison of the $\mathrm{CO}_{2}$ adsorption on the new sample with that on the fresh coal matrix is presented in Figure 9. The figure shows that OSU\#3b has slightly higher adsorption than that of OSU\#3a. However, the difference is still well within the range of experimental uncertainties. This is expected since the two samples have similar compositions, as shown in Table 2. Although the new sample has higher moisture content $(14.8 \%)$, this does not contribute significantly to variation in the $\mathrm{CO}_{2}$ adsorption. (Corrections are made for absorption of gases into any free water above the equilibrium moisture content.)

\section{(b) Pure-Gas Adsorption on Activated Carbon}

Table 8 and Figure 10 present adsorption data for $\mathrm{CO}_{2}$, methane, and nitrogen on activated carbon (Filtrasorb-400) at $130^{\circ} \mathrm{F}$ and pressures to 1800 psia. The expected uncertainties are within $2 \%$. These data complement our previous measurements at $113{ }^{\circ} \mathrm{F}$. The results at $130{ }^{\circ} \mathrm{F}$ show $10 \%$ lower adsorption capacity for the activated carbon than observed at $113^{\circ} \mathrm{F}$. The relative affinity of the various gases adsorbed (at 1000 psia) is approximately 2.5:1.5:1 for $\mathrm{CO}_{2}$ : methane: nitrogen.

\section{(c) Binary Mixture Adsorption on Wet Illinois-6 Coal}

Binary adsorption of methane, nitrogen and $\mathrm{CO}_{2}$ at a series of compositions has been measured on the wet Illinois- 6 coal at $115^{\circ} \mathrm{F}$. Tables 9-11 present the experimental data for four different mixtures. The nominal molar feed compositions of these gas mixtures are $20,40,60$, and $80 \%$ nitrogen. The uncertainties for binary mixtures vary for different compositions and different mixtures. In general, the expected uncertainty the individual-component adsorption from these mixtures is $2-10 \%$, with the higher uncertainties applying to the least sorbed components.

As shown in Figures 11-19, the component absolute adsorption for all the binary mixtures is well represented by Type I adsorption. Specifically, the methane/nitrogen binary mixture adsorption results are shown in Figures 11-13. Pure methane has higher 
adsorption than pure nitrogen. In the methane/nitrogen binary mixture adsorption, methane is also more strongly adsorbed. At mixture compositions of 79,60 , and $40 \%$ methane, methane has higher absolute adsorption than nitrogen. However, at a composition of $20 \%$ methane, nitrogen has higher adsorption than methane.

Methane/carbon dioxide binary mixture adsorption results are shown in Figures 14-16. Pure carbon dioxide has higher adsorption than pure methane. In the methane/carbon dioxide binary mixture adsorption, carbon dioxide is also more strongly adsorbed. With the composition of methane from 23 to $77 \%$, carbon dioxide has higher adsorption than methane.

Nitrogen/carbon dioxide binary mixture adsorption results are shown in Figures 17-19. For pure gas adsorption, carbon dioxide has much higher adsorption than nitrogen. With the composition of nitrogen from 20 to $82 \%$, carbon dioxide has higher adsorption than nitrogen.

As shown in Figures 13, 16, and 19, for all binary systems the mixture adsorption isotherms are bounded by the pure component isotherms.

\section{(d) Binary Mixture Adsorption on Dry Activated Carbon}

The second apparatus has been set up for multicomponent adsorption measurements. Gas chromatograph calibrations were conducted to support the measurements. Subsequently, binary adsorption of methane/nitrogen and methane/ $\mathrm{CO}_{2}$ on dry activated carbon at $113^{\circ} \mathrm{F}$ has been completed using this second apparatus.

Tables 12-13 present the experimental data of methane/nitrogen and methane/ $\mathrm{CO}_{2}$ adsorption at nominal molar feed gas compositions of 20,40, 60 and $80 \%$ methane. The uncertainties for these binary mixtures vary for different pressure and compositions. In general, the expected uncertainty in the amounts of individual-component adsorption from the methane/nitrogen mixtures is about $2 \%$; however, higher uncertainties (up to 7 $\%)$ are observed at lower composition of the less-adsorbed gas, i.e., nitrogen in methane-nitrogen system and methane in methane/ $\mathrm{CO}_{2}$ system.

Figure 20 shows the total Gibbs adsorption of the methane/nitrogen binary. The total adsorption increases when more methane is in the mixture. As expected, it is greater than the absolute amount of pure nitrogen but less than the absolute adsorption of pure methane. Figures 21 and 22 show the component Gibbs adsorption for this binary mixture. For comparison, pure methane adsorption is presented in Figure 21 and pure nitrogen adsorption is presented in Figure 22.

Figures 23-25 show the absolute adsorptions for the methane/nitrogen system. As indicated by the figures, methane has higher adsorption than nitrogen. In the methane/nitrogen binary adsorption, methane is more strongly adsorbed at methane feed compositions of 80,60 and 40\%; however, for a feed composition of $20 \%$ methane, nitrogen has higher adsorption than methane. This result shows similar 
behavior to the methane/nitrogen binary adsorption on Fruitland coal, as reported previously.

Figure 26 shows the total Gibbs adsorption of methane/ $\mathrm{CO}_{2}$ system. As expected, the total adsorption increases when more $\mathrm{CO}_{2}$ is in the mixture and higher than the pure methane adsorption. Beyond the maximum excess Gibbs, the amount adsorbed decreases with increasing pressure for all compositions. Figure 27-28 shows the component Gibbs adsorption data for this binary mixture, which are consistent in trend with the pure-component adsorption, as indicated by Figures 27 and 28 for methane and $\mathrm{CO}_{2}$, respectively.

Figures 29-31 show the absolute adsorptions for the methane $/ \mathrm{CO}_{2}$ system. As indicated by the figures, $\mathrm{CO}_{2}$ has higher adsorption than methane. In the methane/CO binary adsorption, $\mathrm{CO}_{2}$ is also more strongly adsorbed at $\mathrm{CO}_{2}$ feed compositions of 80 , 60 and 40\%; however, for a feed composition of $20 \% \mathrm{CO}_{2}$, methane has higher adsorption than $\mathrm{CO}_{2}$.

In both the above binaries, the absolute adsorptions were calculated by assuming ideal solution additive volumes in the condensed phase; i.e., the mixture volume is the mole fraction weighted-average pure component phase volumes.

\section{Model Development}

We are currently investigating five avenues for representing adsorption equilibrium. These include (a) enhanced forms of the Langmuir-type isotherms (see, e.g., [6]), (b) two-dimensional equations of state, (c) simplified local density models, (d) use of twodimensional analogs of the activity coefficients used in vapor-liquid equilibrium calculations, and (e) treating adsorption as a constrained form of vapor-liquid equilibrium [3]. In so doing, our objective is to develop reliable, simple analytic models capable of describing multilayer adsorption of near-critical and supercritical components on heterogeneous surfaces.

In the following, we briefly outline the first three methods and discuss the quality of their representation of the methane, nitrogen, ethane and $\mathrm{CO}_{2}$ pure-fluid adsorption.

\section{(a) Langmuir Models}

Historically, simple models have been used to represent the behavior of pure and mixed gas adsorption on coal. The extended Langmuir model is used almost exclusively in literature studies [e.g., 6], although the Ideal Adsorbed Solution (IAS) model [7] has also been employed [8]. Both these models work well for essentially ideal adsorbed solutions, but neither is capable of handling nonidealities in the adsorbed phase with any accuracy. The extended Langmuir model is shown below as an illustration of the simple modeling approach used in most previous studies. For mixtures, it takes the form 


$$
\theta_{i}=\frac{\omega_{i}}{L_{i}}=\frac{B_{i} P y_{i}}{1+\sum_{j} B_{j} P y_{j}}
$$

where $\omega_{\mathrm{j}}$ is the amount of component "i" adsorbed (moles of "i" adsorbed per unit mass of coal), $L_{i}$ and $\mathrm{B}_{i}$ are Langmuir constants for "i", $P$ is pressure, and $y_{i}$ is the mole fraction of " $i$ " in the gas phase. This relation allows mixture adsorption to be calculated from pure-component data, since values of $L_{i}$ and $B_{i}$ may be determined from the purecomponent form of Equation 18.

The combined Langmuir-Freundlick adsorption isotherm, expressed in terms of $\omega_{\mathrm{i}}$, yields the loading ratio correlation (LCR) for mixtures

$$
\theta_{i}=\frac{\omega_{i}}{L_{i}}=\frac{B_{i}\left(P y_{i}\right)^{\eta_{i}}}{1+\sum_{j} B_{j}\left(P y_{j}\right)^{\eta_{i}}}
$$

The additional parameter in the LRC $\left(\eta_{i}\right)$ lends the Langmuir model more flexibility. Although the simplicity of Langmuir models is attractive, our data show that they are inadequate to represent the behavior of mixtures of the gases $\mathrm{CO}_{2}$, methane, and nitrogen. In fact, previously we found errors greater than $100 \%$ when the extended Langmuir model was applied to our data on the adsorption of nitrogen from nitrogen + $\mathrm{CO}_{2}$ mixtures [2].

\section{(b) Equation-of-State Models}

Simulations of coalbed gas recovery and $\mathrm{CO}_{2}$ sequestering require reliable, yet simple analytic models beyond Langmuir-type correlations. Equation-of-state (EOS) frameworks offer an attractive potential for such requirements.

In our previous annual report, we presented a generalized form of the 2-D EOS. Our recent EOS studies focused on developing a 2-D analog to the Park-Gasem-Robinson (PGR) EOS. This new EOS offers two advantages: (a) the PGR EOS has a more accurate repulsive term, which is essential for reliable adsorption predictions, and (b) it is a segment-segment interactions model, which more closely depict the realities of gascoal interactions during the adsorption process. Following is a brief description of both equations.

\section{D ZGR EOS}

A general form of the popular three-dimensional equation of state can be expressed by [9]:

$$
\left[P+\frac{a \rho^{2}}{1+U b \rho+W(b \rho)^{2}}\right][1-b \rho]=\rho R T
$$


where $a$ and $b$ are the traditional EOS parameters, and numerical values of $U$ and $W$ may be specified to give various forms of three-dimensional equations of state. An even more general two-dimensional analog can be written as follows (by introducing an additional coefficient, $\mathrm{m}$ ):

$$
\left[A \pi+\frac{\alpha \omega^{2}}{1+U \beta \omega+W(\beta \omega)^{2}}\right]\left[1-(\beta \omega)^{m}\right]=\omega R T
$$

where $A$ is the specific surface area, $\pi$ is the spreading pressure, $\omega$ is the specific amount adsorbed, and $\alpha, \beta$ and $\mathrm{m}$ are model parameters. The model coefficients, $\mathrm{U}$, $\mathrm{W}$, and $\mathrm{m}$ must be specified to obtain a specific form of the 2-D EOS for application. For example, an analog of the van der Waals (VDW) EOS is obtained by setting $m=1$ and $U=W=0$, similarly for the Soave-Redlich-Kwong (SRK) $(m=U=1$ and $W=0)$, the Peng-Robinson (PR) $(m=1, U=2$, and $W=-1)$, and the Eyring $(m=1 / 2$ and $U=W$ $=0)$ EOS.

This general 2-D EOS can be used to investigate EOS behaviors by specifying various combinations of model coefficients. Selection of the model coefficient $m$ is the most important among the EOS model coefficients, because it has a significant effect on the shape of the pure adsorption isotherm. If $U$ and $W$ are equal to zero, then by setting $m$ to values of $\infty, 1$, and 1/2, we obtain the 2-D ideal gas law, the VDW EOS, and the Eyring EOS, respectively. Actually, the pure gas isotherms vary considerably in shape and we have found that it is sometimes desirable to select an $\mathrm{m}$ value even smaller than $1 / 2$ to describe pure isotherms. We have determined that an equation with $m=1 / 3$ and $\mathrm{U}=\mathrm{W}=0$ (the ZGR EOS) is promising [9]. The 2-D EOS can be applied to adsorbed phases containing mixtures by utilizing the traditional mixing rules (where $\mathrm{x}$ is the mole fraction in the adsorbed phase):

$$
\begin{aligned}
& \alpha=\sum_{i} \sum_{j} x_{i} x_{j} \alpha_{i j} \\
& \beta=\sum_{i} \sum_{j} x_{i} x_{j} \beta_{i j}
\end{aligned}
$$

along with the non-traditional combination rules [9],

$$
\begin{aligned}
& \alpha_{i j}=\left(1-C_{i j}\right)\left(\alpha_{i}+\alpha_{j}\right) / 2 \\
& \beta_{i j}=\sqrt{\beta_{i} \beta_{j}}
\end{aligned}
$$

where $\mathrm{C}_{\mathrm{ij}}$ is the EOS binary interaction parameter.

\section{D PGR EOS}

This new 2-D EOS is expressed as follows: 


$$
A \pi=\omega R T+\operatorname{cRT} \omega\left(\frac{\beta_{1} \tau L \omega}{1-\beta_{2} \tau L \omega}-\frac{Z_{M} \mathrm{YL} \omega}{1+U \mid \omega+W(L \omega)^{2}}-\frac{Q_{1} Z_{M} \mathrm{YL} \omega}{1+Q_{2} L \omega}\right)
$$

where

$$
\begin{aligned}
& \mathrm{Y}=\exp \left(\mathrm{F}_{\mathrm{t}}\right)-1 \\
& \mathrm{~F}_{\mathrm{t}}=\omega_{1}\left(\frac{1}{2 \tilde{\mathrm{T}}}\right)^{1 / 2}+\omega_{2}\left(\frac{1}{2 \tilde{\mathrm{T}}}\right)+\omega_{3}\left(\frac{1}{2 \tilde{\mathrm{T}}}\right)^{3 / 2}+\omega_{4}\left(\frac{1}{2 \tilde{\mathrm{T}}}\right)^{2} \\
& \tilde{\mathrm{T}}=\frac{\mathrm{T}}{\mathrm{T}^{*}}
\end{aligned}
$$

where $\omega$ is the absolute adsorption and $L=V^{*} / A$. The other universal EOS constants and the component parameters are listed in Tables 14 and 15. Further details are given elsewhere [10].

\section{2-D EOS Initialization}

The initial guesses for $\alpha, \beta$ and $k$ are critical to the 2-D EOS parameters regression. Beyond the EOS parameters $\alpha, \beta$, initial guesses are required for $k$, which represents the slope of the isotherm at the origin [11]. To improve the reliability of EOS calculations, an improved initialization technique was implemented in this study. Specifically, we recommend the following initial guesses for $\alpha, \beta$ and $k$, which are generated from the Langmuir model parameters of the same isotherm:

$$
\begin{aligned}
& \alpha=200 \\
& \beta=1 / 2 L \\
& k=5 L B
\end{aligned}
$$

where $L$ and $B$ are the Langmuir model constants.

\section{(c) The Simplified Local Density Model}

Our experience to date indicates that the 2-D EOS approach is, in general, superior to the more widely-used theories such as the Ideal Adsorbed Solution (IAS) and extended Langmuir isotherm. However, present applications of this approach are inherently deficient in representing multilayer adsorption, especially when it is applied to heterogeneous surfaces as in the case of coal. 
Therefore, we are currently attempting to augment the EOS framework and render it useful for adsorption behavior beyond Type I isotherms by (a) using solid-fluid site characterization based on characteristic curves similar to those generated by the Polanyi potential theory (see, e. g., [12]), and (b) superimposing the fluid-solid potential on an improved EOS phase description to predict the near-critical adsorption behavior. The latter is well exemplified by the simplified local density (SLD) model (see, e.g., Lira and coworkers [13]). We believe such developments will facilitate the use of highly efficient EOS computational frameworks for representing adsorption behavior, as well as improving our understanding of the phenomenon.

The SLD model is a compromise between the traditional empirical / semi-empirical methods, which are computationally less demanding but are unable to account for the various adsorption isotherms seen near the critical region, and the computationally intensive molecular simulation methods. In applying the SLD adsorption model, the fluid-solid potential is superimposed on an equation of state (EOS) and the configurational energy integral in the inhomogeneous fluid phase is simplified with a local density approximation [13].

In this study, we evaluated the predictive capability of the SLD model for the supercritical adsorption systems encountered in $\mathrm{CO}_{2}$ sequestering and coalbed methane recovery. Specifically, we correlated the experimental data on the adsorption of methane, nitrogen and carbon dioxide on wet coals and dry activated carbon using flat-surface and slit forms of the SLD. The SLD model predictions were then compared to predictions from the Langmuir, LRC, and the 2-D EOS models.

\section{Flat-Surface SLD Model}

The SLD model is formulated in terms of the surface excess adsorption $\left(\Gamma^{e x}\right)$, defined as the excess number of moles per unit area of adsorbent, or

$$
\Gamma^{\mathrm{ex}}=\int_{z_{0}}^{\infty}\left(\rho(z)-\rho_{\text {bulk }}\right) d z
$$

For a flat surface geometry, the lower limit of integration is the surface of the solid and is taken as the plane at $z_{o}=\sigma_{\mathrm{ff}} / 2$, where $\sigma_{\mathrm{ff}}$ is the molecular distance between two solid molecules.

As indicated by Equation 26, the SLD theory predicts Gibbs excess, not absolute adsorption. To calculate the absolute adsorption, one must estimate a value for the adsorbed phase density.

In flat-surface adsorption, the SLD model asserts that the equilibrium chemical potential at any point $\mathrm{z}$ above the adsorbent surface is equal to the bulk phase chemical potential. Accordingly, the equilibrium chemical potential is calculated by contributions from fluid-fluid and fluid-solid interaction as 


$$
\mu=\mu_{\text {bulk }}=\mu_{\mathrm{ff}}(\mathrm{z})+\mu_{\mathrm{fs}}(\mathrm{z})
$$

where the subscript bulk refers to the bulk fluid, ff refers to fluid-fluid interactions, and fs refers to the fluid-solid interactions.

The fluid-solid potential at a given point $z$ is independent of temperature and the number of molecules at and around that point. The fluid-solid potential is given in terms of the molecular interactions potential $\psi(\mathrm{z})$ and $\mathrm{N}_{\mathrm{A}}$ (Avogadro's Number) as

$$
\mu_{\mathrm{fs}}=\mathrm{N}_{\mathrm{A}} \Psi(\mathrm{z})
$$

Lee's partially integrated 10-4 Lennard-Jones potential [14] is used to describe the adsorbate-adsorbent interactions

$$
\Psi(\mathrm{z})=4 \pi \rho_{\mathrm{atom}} \varepsilon_{\mathrm{fs}} \sigma_{\mathrm{fs}}^{6}\left(\frac{\sigma_{\mathrm{fs}}^{6}}{5 \mathrm{x}_{\mathrm{i}}^{10}}-\frac{1}{2} \sum_{\mathrm{i}=1}^{4} \frac{1}{\mathrm{x}_{\mathrm{i}}^{4}}\right)
$$

where $\varepsilon_{\mathrm{fs}}$ is the fluid-solid interaction energy parameter, $\rho_{\text {atom }}=0.382 \AA^{2}, x_{i}$ is the intermolecular distance between fluid-molecule centers and the ith plane of solid molecules, $\sigma_{\mathrm{fs}}$ is taken as the arithmetic mean of the fluid and solid diameters. As indicated by Equation 29, the interactions are truncated at the fourth plane of solid atoms with an interplanar spacing of $3.35 \AA$.

The fluid-fluid potential is then calculated as

$$
\mu_{\mathrm{ff}}=\mu_{\text {bulk }}-\mathrm{N}_{\mathrm{A}} \Psi(\mathrm{z})
$$

where

$$
\begin{aligned}
& \mu_{\text {bulk }}=\mu_{\circ}+\mathrm{RT} \ln \left(\mathrm{f}_{\text {bulk }} / \mathrm{f}_{\mathrm{o}}\right) \\
& \mu_{\mathrm{fff}}=\mu_{\circ}+\mathrm{RT} \ln \left(\mathrm{f}_{\mathrm{fff}}(\mathrm{z}) / \mathrm{f}_{\mathrm{o}}\right)
\end{aligned}
$$

After rearrangement this leads to

$$
f_{f f}(z)=f_{\text {bulk }} \exp [-\Psi(z) /(k T)]
$$

In this study, we have used the PR and PGR equations of state to determine the fluid and the bulk fugacities. The fugacity expressions for the PR EOS are (similar expressions for the PGR EOS are given elsewhere [10])

$$
\ln f_{b}=\frac{b \rho_{b}}{1-b \rho_{b}}-\frac{a_{b} \rho_{b}}{R T\left(1+2 b \rho_{b}-b^{2} \rho_{b}^{2}\right)}-\ln \left(\frac{1-b \rho_{b}}{R T \rho_{b}}\right)-\frac{a_{b}}{2 \sqrt{2} b R T} \ln \left(\frac{1+b(1+\sqrt{2}) \rho_{b}}{1+b(1+\sqrt{2}) \rho_{b}}\right)
$$




$$
\ln \mathrm{f}_{\mathrm{ff}}(\mathrm{z})=\frac{\mathrm{b} \rho(\mathrm{z})}{1-\mathrm{b} \rho(\mathrm{z})}-\frac{\mathrm{a}(\mathrm{z}) \rho(\mathrm{z})}{\mathrm{RT}\left(1+2 \mathrm{~b} \rho(\mathrm{z})-\mathrm{b}^{2} \rho^{2}(\mathrm{z})\right)}-\ln \left(\frac{1-\mathrm{b} \rho(\mathrm{z})}{\mathrm{RT} \rho(\mathrm{z})}\right)-\frac{\mathrm{a}(\mathrm{z})}{2 \sqrt{2} \mathrm{bRT}} \ln \left(\frac{1+\mathrm{b}(1+\sqrt{2}) \rho(\mathrm{z})}{1+\mathrm{b}(1+\sqrt{2}) \rho(\mathrm{z})}\right)
$$

where $a_{b}$ is the PR EOS constant, and $a(z)$ is evaluated as follows

$$
\begin{aligned}
& a(z)=a_{b}\left(\frac{5}{16}+\frac{6}{16} \frac{z}{\sigma_{f f}}\right) \text { for } 0.5 \leq \frac{z}{\sigma_{f f}} \leq 1.5 \\
& a(z)=a_{b}\left[1-\frac{1}{8\left(\frac{z}{\sigma_{f f}}-\frac{1}{2}\right)^{3}}\right] \text { for } 1.5 \leq \frac{z}{\sigma_{f f}}<\infty
\end{aligned}
$$

Once the fugacity at the local point is determined, the EOS is used to calculate the corresponding local density $\rho(z)$. To apply the PR-SLD model, we have assumed that (a) the pure fluids are adsorbed on flat, homogenous coal surface, and (b) the coal has pseudo-crystalline structure. Details of our calculation procedure are given elsewhere [10].

\section{Slit SLD Model}

We also have evaluated a slit form of the SLD model, where the adsorbed fluid resides within a slit instead of residing near a flat surface. That is, in contrast to Equation 26, a slit width $L$ is used to determine excess adsorption:

$$
\Gamma^{\mathrm{ex}}=\int_{\sigma_{\mathrm{ff}} / 2}^{\mathrm{L}-\sigma_{\mathrm{ff}} / 2}\left[\rho(z)-\rho_{\mathrm{b}}\right] \cdot d z
$$

The value of slit width $L$ is regressed from experimental data. Details for applying the slit theory are given elsewhere [15].

In this case, the adsorbed molecule has fluid-solid interactions with two surfaces, or

$$
\mu_{\mathrm{ts}}(\mathrm{z})=\mu_{\mathrm{fs} 1}(\mathrm{z})+\mu_{\mathrm{fs} 2}(\mathrm{~L}-\mathrm{z})
$$

The fluid-solid potential, represented by $\Psi(\mathrm{z})$, is defined on a molecular basis by

$$
\Psi(z)=4 \pi \rho_{\text {atoms }} \varepsilon_{\mathrm{ts}} \sigma_{\mathrm{ts}}^{2}\left(\frac{\sigma_{\mathrm{ts}}^{10}}{5\left(z^{\prime}\right)^{10}}-\frac{1}{2} \sum_{\mathrm{i}=1}^{4} \frac{\sigma_{\mathrm{ts}}^{4}}{\left(z^{\prime}+(i-1) \cdot \sigma_{\mathrm{ss}}\right)^{4}}\right)
$$


where $\varepsilon_{\mathrm{fs}}$ is the fluid-solid interaction energy parameter and $\rho_{\text {atom }}=0.382 \mathrm{~A}$. The molecular diameter of the adsorbate and the carbon interplanar distance are $\sigma_{\mathrm{ff}}$ and $\sigma_{\mathrm{ss}}$, respectively. Molecular diameters were obtained from Reid [16] and are presented in Table 17. Following Chen [15], the interplanar spacing is $0.335 \mathrm{~nm}$.

Two other definitions are needed for convenience:

$$
\begin{aligned}
& \sigma_{\mathrm{fs}}=\frac{\sigma_{\mathrm{ff}}+\sigma_{\mathrm{ss}}}{2} \\
& z^{\prime}=z+\sigma_{\mathrm{ss}} / 2
\end{aligned}
$$

The potential energy is related to the fugacity, as

$$
f_{f f}(z)=f_{b} \exp \left(-\frac{\Psi(z)+\Psi(L-z)}{k T}\right)
$$

The fugacity expressions for the PR EOS are given by Equations 32 and 33 . The parameter $\mathrm{a}(\mathrm{z})$ in the PR EOS is a function of position within the slit when calculating the local phase density for that position. Chen and coworkers [17] provide equations that describe how ' $a$ ' changes with position; Table 16 provides these equations, which are necessarily case-dependent on the ratio of the slit length and the fluid molecular diameter $\sigma_{\mathrm{ff}}$. To obtain these formulas, one integrates the sum of all the two body interactions between an arbitrarily selected central molecule and all the other molecules around it.

After the density profile along the slit is computed, the Gibbs adsorption $\Gamma$ is numerically integrated, as expressed by Equation 36. Specifically, half of the slit was subdivided into 50 intervals and Equation 36 was solved for each interval. The amount adsorbed was calculated by numerically integrating with Simpson's rule. Table 17 presents the PR-SLD pure-fluid physical properties used in this study.

A key feature of SLD theory is that it predicts the Gibbs excess, not absolute adsorption. To calculate the absolute adsorption, one must assume the adsorbed phase density or volume. Past researchers have assumed that the phase density is close to the van der Waals co-volume. This assumption creates uncertainty in the absolute adsorption, especially at high pressure. In comparison, SLD uses only the Gibbs excess, which does not rely on phase density assumptions, to obtain model parameters. Furthermore, SLD may be used to predict an average adsorbed phase density as a function of pressure:

$$
\bar{\rho}_{\mathrm{ads}}=\frac{\Gamma^{\mathrm{ex}}}{\left(\mathrm{L}-\sigma_{\mathrm{ff}}\right)}+\rho_{\mathrm{b}}
$$


This average adsorbed phase density can be applied then to calculate the absolute adsorption:

$$
\mathrm{n}_{\mathrm{abs}}=\frac{\Gamma^{\mathrm{ex}}}{\left(1-\frac{\rho_{\text {bulk }}}{\bar{\rho}_{\mathrm{ads}}}\right)}
$$

\section{(d) Model Evaluation Results}

\section{Pure-Gas Adsorption}

Tables 18-29 present a summary of our model evaluation results for five models we have used to correlate the present adsorption data for methane, nitrogen, and $\mathrm{CO}_{2}$ on dry activated carbon, wet Fruitland and Illinois-6 coals, respectively. The models include the LRC correlation, the ZGR and PGR 2-D EOS, and the modified PR-SLD model. The model parameters, shown in Tables 18-29, were determined by minimizing the sum of squares of percentage absolute errors in the calculated adsorption, $\omega$, for the pure gas of interest. The quality of the fit, expressed in terms of the absolute average deviation (\%AAD), is also given for the various models.

LRC Model: Table 18 presents our results for the LRC fitted with a common exponent $\left(\eta_{i}=0.87\right)$ for the all systems considered. The results indicate that the LRC produces better quality fit than the Langmuir correlation (not shown here) for the three gases studied. This in part reflects the added flexibility gained by the additional parameter $\left(\eta_{\mathrm{i}}\right)$ in the regressions. AADs of 0.5 to $5 \%$ were obtained for the systems considered with an overall $A A D$ of about $2 \%$. As expected, the $\mathrm{CO}_{2}$ data yielded greater deviations than methane and nitrogen. To further improve the quality of LRC representation, a systemspecific exponent was regressed for the various isotherms. Detailed LRC correlation results for dry activated carbon, wet Fruitland and Illinois-6 coals are given in Table 19. In general, minor improvement was realized using this strategy.

ZGR and PGR EOS: Tables 20 and 21 present a summary of our model evaluation results for the ZGR and PGR EOS. These results reveal the ability of the both EOS to represent the adsorption of $\mathrm{CO}_{2}$, methane and nitrogen on dry activated carbon, Fruitland, Illinois-6 and Lower Basin Fruitland coals within their expected experimental uncertainties. Overall AAD of about $2 \%$ has been observed. Specifically, the ZGR EOS represent the adsorption on dry activated carbon within $0.8 \%$, wet Fruitland coal within $2.0 \%$, wet lower basin Fruitland coal within $2.2 \%$ and yields slightly worse fit (3.6\%) for wet Illinois-6. The model parameters are shown in Tables 20 and 21. Figures 32-35 illustrate the abilities of the ZGR EOS to describe the present pure-fluid adsorption data; similar results were obtained using the PGR EOS.

In addition, our results indicate that the proposed EOS initialization technique is robust and leads to viable computations. 
ZGR Representation of Gibbs Adsorption: By introducing the adsorbed phase density as a model parameter into the ZGR EOS, we are able to use the model to correlate the experimental Gibbs adsorption data directly. Table 22 presents the regression results for the Gibbs data. Comparable representation (deviations within $1.5 \%$ ) is observed for both the absolute (as shown in Table 20) and Gibbs data. More importantly, we can now fit the isotherms exhibiting a maximum excess Gibbs adsorption, thus gaining the ability to expand the 2-D ZGR correlative capability to cover the full pressure range considered (up to 2000 psia for the $\mathrm{CO}_{2}$ isotherms). Figures 3639 illustrate the quality of representation produced by the ZGR EOS for the $\mathrm{CO}_{2}$, methane, and nitrogen adsorption on the activated carbon and Illinois-6 coal. The ZGR EOS was used to provide the adsorbed-phase density for Figures 36-39.

SLD Model: Previously, we have reported our results for the flat-surface PR-SLD model, which represented methane adsorption with accuracy comparable to the LRC but exhibits larger deviations for nitrogen and $\mathrm{CO}_{2}$. In addition, we have presented our modeling efforts for the slit geometry which, in contrast to other models, including the flat-surface PR-SLD, correlates the adsorption data over the full range pressure, including $\mathrm{CO}_{2}$ and ethane. (A schematic representation of the flat surface and slit versions of the SLD model appears in Figure 40.)

Therefore, we have embarked on further developing the slit-SLD model to improve its predictions for highly non-ideal, near-critical adsorption systems, such as $\mathrm{CO}_{2}$. Specifically, we anticipate significant gains by (a) accounting more accurately for coal heterogeneity and structural complexity, (b) incorporating an equation of state capable of producing accurate phase densities predictions, and (c) modifying the local attractive parameter $\mathrm{a}(\mathrm{z})$. Following are our modeling efforts addressing the first two issues.

$\mathrm{CO}_{2}$, methane, nitrogen, and methane were first modeled in accordance to the SLD theory by Chen and coworkers [17]. Their model contains three regressed parameters: the surface area SA, the slit length $L$, and the solid well depth $\varepsilon$. In addition to this model, we will compare results for two other model modifications: (1) a swelling coefficient that allows the slit length to change with bulk gas density, and (2) a correction $(\Delta)$ in the PR covolume for the fluid-fluid fugacity expression. Unlike the attractive term $\mathrm{a}(\mathrm{z})$, the modified covolume does not change with position.

$$
\begin{aligned}
& \mathrm{L}=\mathrm{L}_{\mathrm{A}}\left(1+\mathrm{L}_{\mathrm{S}} \cdot \rho_{\text {bulk }}\right) \\
& \mathrm{b}_{\text {modified }}=\mathrm{b}_{\text {original }} \cdot \Delta
\end{aligned}
$$

As shown in Table 23 under the heading "Original", $\mathrm{CO}_{2}$ has poor regression results (AAD of 14.9\%) when no modifications are undertaken. Similar results occur for ethane in Table 24 (AAD of 29.7\%). These results are poor because the SLD model cannot quantitatively fit adsorption data beyond the maximum Gibbs adsorption. Chen and others [17] have had similar modeling difficulties for $\mathrm{CO}_{2}$ adsorption on another activated carbon. If the parameters are regressed for pressures below the maximum 
Gibbs adsorption ("Low Pressure" in Tables 23 and 24), the results are much better (AAD of $1.3 \%$ for $\mathrm{CO}_{2}$ and $2.1 \%$ for ethane). Methane and nitrogen have excellent regression results (Tables 25 and 26 ) due to the lack of a pronounced adsorption maximum in the data. Therefore, the slit length and PR covolume were modified to effectively model over the entire pressure regime for $\mathrm{CO}_{2}$ and ethane.

Modification of Slit Length: The swelling phenomenon of coals suggests a variation in the pore volume with density. The extent of the swelling phenomenon has been documented to increase with the percent huminite composition of the coal [18]. The slitSLD model is very simplistic in the representation of the coal structure. The surface area and the effective slit length are the only two geometric descriptors of the coal. In reality, the structure can be described as highly cross-linked with entangled networks of macromolecular chains of irregular structure [19]. The pore structure consists of macropores ( $>500 \mathrm{~A})$, mesopores (20-500 A), micropores (8-20 A), and submicropores $(<8 \mathrm{~A})$. By interaction with the closed pores, the sorbate opens up the micropores that would not be normally accessible for a sorbate molecule of its size [20]. This theoretically increases the amount adsorbed by increasing the available pore volume.

Swelling induced by adsorption at high pressures is not well understood. However, inferences of swelling can be made based on observations on coal volumetric strain measurements and pore volume. Hapalani [21] measured the volumetric strain of coal $\Delta \mathrm{V} / \mathrm{V}$ and found it increased linearly up to a pressure of 900 psia (the highest point measured). Upon desorption, the strain was higher and concave down to the pressure ordinate (see Figure 41). The permeability also increased with pressure, although the curve is slightly concave upward (see Figure 42). Upon desorption to a pressure of 400 psia, the permeability was shown to be close but slightly higher than the adsorption permeability. Lowering the pressure beyond 400 psia dramatically increased the coal's permeability. The increasing volumetric strain and permeability with adsorption suggest an enhanced adsorption effect. The linearity of the volumetric strain with pressure implies a linear model of the surface area or slit length with pressure or density.

Following the work of Tomasko [22,23], the actual pore volume can be regressed from the adsorption isotherm data for $\mathrm{CO}_{2}$ and ethane. For these near-critical systems, the excess Gibbs adsorption for a given isotherm decreases nearly linearly with bulk density beyond the Gibbs Excess maximum. This experimental evidence would suggest that

$$
\frac{\mathrm{d}\left(\mathrm{V} \rho_{\mathrm{a}}\right)}{\mathrm{dP}} \approx 0 \text { and } \quad \frac{\mathrm{dV}}{\mathrm{dP}} \approx 0 \text { in linear region beyond the maximum Gibbs excess }
$$

adsorption. Thus

$$
\frac{\mathrm{dn}_{\text {Gibbs }}}{\mathrm{d} \rho_{\mathrm{b}}}=-\mathrm{V}
$$

As depicted in Figure 43, the slope in this linear region determines the adsorbed phase volume $\mathrm{V}$ (or pore volume) of the adsorbing fluid at high pressures. The phase volume is related to the SLD model surface area and slit length: 


$$
\mathrm{V}=\mathrm{A} / 2 \cdot\left(\mathrm{L}-\mathrm{s}_{\mathrm{ff}}\right)
$$

If no swelling occurs, then the downward slope of an isotherm should have no concavity at high densities. Figure 44 shows the effect of variation of the swelling coefficient $L_{s}$ on the shape of the calculated adsorption isotherm. Up to a density of $0.50 \mathrm{~g} / \mathrm{cm}^{3}$ (about 1450 psia at $113^{\circ} \mathrm{F}$ ), a larger swelling coefficient results in larger Gibbs excess. However, at higher densities, the larger swelling coefficient increases the magnitude of the slope thereby lowering the Gibbs excess. A negative swelling coefficient will be concave up from the density ordinate, effectively increasing the Gibbs excess at sufficiently high densities.

The swelling coefficient can have a relatively large influence on the Gibbs excess and the location of the Gibbs maximum while producing minor differences in the slope. Figure 44 shows that for values of $L_{s}$ ranging from 0.0 to $-20.0 \mathrm{~cm}^{3} / \mathrm{mol}$ the slopes are similar enough as to fall within the experimental uncertainty. The swelling coefficient $L_{s}$ may offset small errors in the bulk density at high pressure. This factor questions the physical meaning derived from the value $L_{s}$ unless a highly accurate equation of state is used in the SLD model and the swelling is significant enough to be experimentally discernible. Nevertheless, the simple swelling model chosen can significantly improve the modeling for $\mathrm{CO}_{2}$ and ethane. As shown in Tables 23 and 24, both $\mathrm{CO}_{2}$ and ethane significantly improve in terms of their regression fits over the original option. All four gases have negative values of $L_{\delta}$, implying an inhibition of adsorption. The negative $L_{s}$ values are more likely accommodating for small errors in the Peng-Robinson bulk density.

Modification of Covolume: An accurate EOS is required for correlating near-critical and supercritical adsorption data precisely. At a minimum, an EOS with an accurate repulsive term should be used to represent the adsorption phenomenon. Following this strategy, Soule [24] modeled adsorption with the ESD (Elliot, Suresh, Donohue) EOS. This resulted in better representation of adsorption with temperature, but no modeling results were shown depicting isotherms with data significantly past the Gibbs excess maximum. Alternatively, one may modify the PR EOS repulsive term by adjusting the covolume empirically (as shown in Equation 45) for screening purposes. Pursuing such a strategy, the modeling fits of $\mathrm{CO}_{2}$ and ethane on dry activated carbon were improved dramatically. The AAD of $\mathrm{CO}_{2}$ drops from $14.9 \%$ to $2.2 \%$ when the covolume is increased by a factor of 1.54 . Likewise, the AAD for ethane drops from $29.7 \%$ to $5.6 \%$ with a factor of 1.59 . Figure 45 shows the improved behavior of the model isotherm if the covolume is varied.

This improvement may be attributed to fact that improved EOS high-density predictions leads to more accurate representation of the adsorption densities. This observation is confirmed by the local density predictions for $\mathrm{CO}_{2}$, as shown in Figure 46. Specifically, a plot of $\mathrm{CO}_{2}$ local density against the normalized length of the slit reveals that the original covolume produces a local density of $1.6 \mathrm{~g} / \mathrm{cm}^{3}$ at wall. In addition, Figure 46 illustrates that a percentage increase in the covolume, decreases the local density at the wall by about the same amount. Since at high pressures the average local density approaches 
the wall density, the average local density using the original covolume approaches 1.60 $\mathrm{cm}^{3}$. This density estimate is too high, as explained below.

The estimated average local density (ALD) at high pressure can be estimated by extrapolation, as shown in Figure 43. If the Gibbs excess is zero, then the bulk density is equivalent to the ALD. $\mathrm{CO}_{2}$ and ethane have ALDs of 1.02 and $0.44 \mathrm{~g} / \mathrm{cm}^{3}$, respectively. Increasing the covolume by a factor of 1.55 decreases the wall density to about $1.02 \mathrm{~g} / \mathrm{cm}^{3}$, which is the average bcal density where the Gibbs excess is zero. Thus, in Figure 45, the modified covolume fits the experimental data better than the original model because the ALD is set appropriately by the modified covolume.

The modified covolume has a physical meaning similar to the solid well depth. The well depth characterizes the magnitude of the LJ potential between a fluid molecule and the solid adsorbent matrix. The covolume term represents an overall repulsive potential. Thus, if the covolume is increased, the repulsive potential is increased thereby lowering the adsorbate density.

Although varying the covolume enables accurate representation of these isotherms, more information is required for the parameterization of the isotherm. The default SLD model incorporates at most three regressed parameters: the surface area SA, the slit length $\mathrm{L}$, and the solid well depth $\varepsilon_{\mathrm{fs}}$. In cases where isotherm data do not have a Gibbs excess maximum, multiple characterizations of the coal will arise upon the addition of the modified covolume. To alleviate this problem, a correlation was sought between the modified covolume and the three existing parameters.

A linear empirical correlation was optimized to account for the relationship between the solid well depth and the modified covolume for four different adsorbents: activated carbon, Fruitland, Illinois-6, and Lower Basin Fruitland. Tables 25-27 show the regression results for these adsorbents for nitrogen, methane, and $\mathrm{CO}_{2}$. Each isotherm was at first optimized independently. An empirical correlation for each species was found between the solid well depth and the covolume factor. The correlation for each species had nearly identical slopes so this slope was kept as a universal constant (see Figure 47). This correlation enables the modified covolume to be established using a single species-dependent constant.

\section{Binary Mixture Data Correlation}

The results of the binary adsorption data correlation are shown in Tables 28 and 29 and sample illustrations are shown in Figures 48-53. Figures 48-50 compare the correlative capability for the ZGR EOS and the LRC, and Figures 51-53 present a comparison between the ZGR EOS data correlation using regressed interaction parameters (regressed $C_{i j}$ and $\left.D_{i j}\right)$ and ZGR predictions based on pure-fluid parameters $\left(C_{i j}=D_{i j}=0\right)$. Our results for the different binary mixtures show that the LRC model can describe component adsorption data for some compositions within 5\%; however, deviations of up to more than $30 \%$ are observed for the component adsorption in nitrogen/ $\mathrm{CO}_{2}$ mixture. In comparison, the ZGR EOS can correlate the total mixture adsorption of all the mixtures considered within 5\%. For the component adsorption predicted by ZGR, 
nitrogen/ $/ \mathrm{CO}_{2}$ shows the worst results. This is may attributed to the large difference between the ZGR pure-fluid parameters, indicating that this system more non-ideal than the other systems and larger errors are expected.

The adsorbed phase densities used in the binary calculations are generated from the ZGR pure-gas Gibbs adsorption data regressions.

\section{Penn State Collaboration}

The Penn State portion of this progress report (covering Year-3 reporting period September 2000 - October 2001) will submitted separately. 


\section{E. Conclusions}

Following is a summary of our accomplishments and conclusions:

- We have measured the adsorption behavior of pure $\mathrm{CO}_{2}$, methane, ethane, nitrogen and some of their binary mixtures on wet lower Basin Fruitland coal, wet Illinois-6 and dry activated carbon at temperatures at $319.3 \mathrm{~K}\left(115^{\circ} \mathrm{F}\right)$ and pressures to $12.4 \mathrm{MPa}$ (1800 psia). The pure-fluid adsorption isotherms show an expected uncertainty of about $3 \%$, and the binary measurements yield expected uncertainties that vary from 2 to $10 \%$. The current measurements showed good agreement with literature data and with measurements obtained previously.

The newly-acquired data constitute a valuable addition to the literature, especially the Illinois-6 adsorption isotherms and measurements involving ethane, which are a new addition to the existing database.

Our additional adsorption measurements on Fruitland coal and on activated carbon confirm that: (a) the Gibbs adsorption isotherm for $\mathrm{CO}_{2}$ under study exhibits typical adsorption behavior for supercritical gas adsorption, and (b) a slight variation from Type I absolute adsorption may be observed for $\mathrm{CO}_{2}$, but the variation is sensitive to the estimates used for adsorbed-phase density.

- We have evaluated the predictive capabilities of various adsorption models, including the Langmuir/loading ratio correlation, Zhou-Gasem-Robinson (ZGR) and Park-Gasem-Robinson (PGR) two-dimensional equations of state (EOS), and the modified simplified local density model (SLD-PR). These models have been used to analyze our adsorption data. Model parameters have been obtained for the systems studied.

We now are able to correlate the experimental Gibbs adsorption data directly using the ZGR EOS. Comparable representation is observed for both absolute and Gibbs adsorption data. More importantly, we can now fit isotherms exhibiting a maximum excess Gibbs adsorption, thus gaining the ability to expand the 2-D ZGR correlative capability to cover the full pressure range considered (up to 2000 psia for the $\mathrm{CO}_{2}$ isotherms). Also, a new robust initialization method was developed for the ZGR EOS to improve its computational efficiency.

The ZGR EOS was used to correlate our adsorption data for pure methane, nitrogen, and $\mathrm{CO}_{2}$ on dry activated carbon, wet Fruitland, wet Illinois-6 and wet Lower Basin Fruitland coals. The results obtained demonstrate the ability of the ZGR EOS to represent the systems considered almost within their expected experimental uncertainties.

Our results for the different binary mixtures on wet Illinois- 6 coal show that the LRC model can describe component adsorption data for some compositions within 5\%; however, deviations as large as $30 \%$ are observed for the component adsorption in nitrogen/ $\mathrm{CO}_{2}$ mixture. In comparison, the ZGR EOS can correlate the total mixture adsorption of all the mixtures considered within $5 \%$. For the component adsorption 
predicted by ZGR, nitrogen/ $\mathrm{CO}_{2}$ shows the worst results. This may attributed to the large difference between the ZGR pure-fluid parameters, indicating that this system is more non-ideal than the other systems and larger errors are expected.

We have modified the simplified local density model (SLD) to improve its predictive capability, especially when dealing with near-critical and supercritical adsorption behavior. Our results indicate that increasing the Peng-Robinson covolume by $55 \%$ improves significantly the quality of the fit for all isotherms. The modified SLD model represents the adsorption behavior of all fluids considered within $6 \% A A D$, including the near-critical behavior of $\mathrm{CO}_{2}$ beyond $8.3 \mathrm{MPa}(1200$ psia). Specifically, the modified SLD-PR model represents the adsorption of pure methane, nitrogen and $\mathrm{CO}_{2}$ on dry activated carbon within $2 \% \mathrm{AAD}$, on wet Fruitland coal within 4\%, wet Lower Basin Fruitland coal within $6 \%$, and on wet Illinois-6 coal within $4 \%$. These results indicate that the modified model is capable of representing these within about twice their expected experimental uncertainties.

- At Pennsylvania State University, we performed additional studies designed to assess the role of coal surface chemistry in determining the relative adsorption uptakes of $\mathrm{CO}_{2}$ vs. methane. Detailed electrophoresis experiments with coals ranging in rank from lignite to low volatile bituminous were carried out. Electrophoretic mobilities (EM) were measured on powdered samples as a function of $\mathrm{pH}$. Some samples exhibited rather complex shapes, rather than monotonic EM changes with $\mathrm{pH}$. For comparison, the same experiments were carried out using an activated carbon and graphite. The isoelectric points (IEP) were all in the acidic range, ranging from 1.0 to 4.9. Upon coal demineralization, the mobility curves were very different, indicating that a large portion of the measured response was due to the presence of inorganic constituents in coal.

Experiments that are complementary to electrophoresis were carried out with the same coals: mass titrations and determination of the point of zero charge (PZC). In the absence of specific adsorption, the point of zero charge (obtained as an asymptotic value from the titration curve) should be identical to the isoelectric point (obtained from electrophoresis). In all cases, however, the PZC was much larger than the IEP. Thus, for example, the values for the Pocahontas low-volatile bituminous coal were 8.3 and 3.5 , respectively, while those for the Beulah lignite were 6.4 and 1.8. These differences are due, at least in part, to the fact that the PZC is a response of the entire pore surface (both internal and external), while the IEP is a response only of the external particle surface. Therefore, in agreement with similar studies using activated carbons (for the Calgon Carbon BPL sample, the corresponding values were 7.8 and 5.0), the external surface of all the coals is enriched in acidic functional groups (e.g., $\mathrm{COOH}$ ). Part of the difference may also be due to the heterogeneous distribution of mineral matter in the coals. The implications of these findings for $\mathrm{CO}_{2}$ sequestration in coal mines need to be evaluated carefully. 


\section{F. References}

1. Hall, F. E., Zhou, Chunhe, Gasem, K. A. M., and Robinson, Jr., R. L., Adsorption of Pure Methane, Nitrogen, and Carbon Dioxide and their Binary Mixtures on Wet Fruitland Coal, SPE Paper 29194, presented at the 1994 Eastern Regional Conference \& Exhibition, Charleston, West Virginia, November 8-10, 1994.

2. Hall, F. E., Adsorption of Pure and Multicomponent Gases on Wet Fruitland Coal, M. S. Thesis, Oklahoma State University, December 1993.

3. Arri, L. E., and Yee, D., Modeling Coalbed Methane Production With Binary Gas Sorption, SPE Paper 24363, presented at the SPE Rocky Mountain Regional Meeting, Casper, Wyoming, May 18-21, 1992.

4. International Thermodynamic Tables of the Fluid State: Methane, International Union of Pure and Applied Chemistry (1978); International Thermodynamic Tables of the Fluid State: Carbon Dioxide, International Union of Pure and Applied Chemistry (1976); International Thermodynamic Tables of the Fluid State: Nitrogen, International Union of Pure and Applied Chemistry (1977).

5. Span, R. and Wagner; W., A New Equation of State for Carbon Dioxide Covering the Fluid Region from the Triple Point Temperature to $1100 \mathrm{~K}$ at Pressures up to 800 MPa, J. Phys. Chem. Ref. Data, 25, 1509-1590 (1996).

6. Kapoor, A., Ritter, J. A., and Yang, R. T., An Extended Langmuir Model for Adsorption of Gas Mixtures on Heterogeneous Surfaces, Langmuir 6 660-664 (1990).

7. Myers, A. L., and Prausnitz, J. M., Thermodynamics of Mixed-Gas Adsorption, AIChE J. 11 121-129 (1965).

8. Stevenson, M. D., Pinczewski, W. V., Somers, M. L., and Bagio, S. E., Adsorption/Desorption of Multicomponent Gas Mixtures on Coal at In-Seam Conditions, SPE Paper 23026, presented at the SPE Asia-Pacific Conference, Perth, Western Australia, November 4-7, 1991.

9. Zhou, C., Gasem, K. A. M., and Robinson, Jr., R. L., Predicting Gas Adsorption Using Two-Dimensional Equations of State, I\&EC Research 33 1280-1289 (1994).

10. Liang, E., Adsorption of Pure and Multicomponent Gases on Wet Fruitland Coal, M. S. Thesis, Oklahoma State University, July 1999.

11. Zhou, Chunhe, Modeling and Predictions of the Pure and Multicomponent Gas Adsorption, Ph.D. Thesis, Oklahoma State University, Stillwater, OK, 1994.

12. Ross, S., and Oliver, J. P., On Physical Adsorption, Interscience Publ., New York, 1964. 
13. Rangarajan, B., Lira, T. C., and Subramanian, R., Simplified Local Model for Adsorption over Large Pressure Ranges, AIChE J., 41 838-845 (1995).

14. Lee, L.L., Molecular Thermodynamics of non-Ideal Fluids; Butterworth: Stoneham, Massachusetts, 1988.

15. Chen, J. H., et al., Adsorption and Desorption of Carbon Dioxide onto and from Activated Carbon at High Pressures, Ind. Eng. Chem. Res., 36, 2808-2815 (1997).

16. Reid, R. C.; Prausnitz, J. M.; Poling, B. E. The Properties of Gases and Liquids, $4^{\text {th }}$ ed.; McGraw-Hill: New York, 1987.

17. Chen, Jeng Hsin, Wong, David, Subramanian, Ramkumar, and Lira, Carl T., Adsorption and Desorption of Carbon Dioxide onto and from Activated Carbon at High Pressures, Ind. Eng. Chem. Res., 36, 2808-2815 (1997).

18. Gentzis, Thomas, Hirosue, Hideharu, and Sakaki, Tsuyoshi, Relationship between Density and Swelling in a Subbituminous and a High-Volatile Bituminous Coal, Energy Sources, $\underline{8}$, 119-129 (1996).

19. Walker, Philip L., Pore Structure in Coals, Energy and Fuels, $\underline{7}$, 559-560 (1993).

20. Spears, Dennis R., Low Temperature Swelling of Argonne Premium Coal Samples: Effect of Micropore Shape and Size, Fuel, $\underline{71}$, 1003-1014 (1992).

21. Harpalani, Satya and Schraufnagel, Richard, Shrinkage of Coal Matrix with Release of Gas and Its Impact on Permeability of Coal, Fuel, $\underline{69}$, 551-556 (1989).

22. Tomasko, David L., and Humayun, Raashina, Personal Communication; 1999.

23. Humayun, Raashina and Tomasko, David L., High-Resolution Adsorption Isotherms of Supercritical Carbon Dioxide on Activated Carbon, AIChE J., 느, 2065-2075 (2000).

24. Soule, Aaron, Studies of Gas Adsorption on Activated Carbon and Cherry Flavor Recovery From Cherry Pits, M.S. Thesis, Michigan State University, East Lansing, Michigan, 1998. 
Table 1. Status of Experimental Program

\begin{tabular}{|l|c|l|c|l|l|}
\hline Solid Matrix / Gas & $\begin{array}{c}\text { Carbon } \\
\text { Dioxide }\end{array}$ & Methane & Nitrogen & Ethane & Binary Mixtures \\
\hline Fruitland Coal- OSU\#2 & Done & Done & Done & Done & Done \\
\hline $\begin{array}{l}\text { Lower Basin Fruitland } \\
\text { Coal- OSU\#3 }\end{array}$ & Done & Done & Done & ---- & ---- \\
\hline IIlinois-6 Coal & Done & Done & Done & --- & Done \\
\hline Activated Carbon & Done & Done & Done & Done & Underway \\
\hline
\end{tabular}


Table 2. Compositional Analysis of Solid Matrices Used in This Study

\begin{tabular}{|l|c|c|c|c|c|c|c|}
\hline Analysis & $\begin{array}{c}\text { Activated } \\
\text { Carbon }\end{array}$ & $\begin{array}{c}\text { Fruitland } \\
\text { Amoco }\end{array}$ & $\begin{array}{c}\text { Fruitland } \\
\text { OSU \#1 }\end{array}$ & $\begin{array}{c}\text { Fruitland } \\
\text { OSU \#2 }\end{array}$ & Illinois-6 & $\begin{array}{c}\text { Lower } \\
\text { Basin } \\
\text { Fruitland } \\
\text { OSU \#3a }\end{array}$ & $\begin{array}{c}\text { Lower } \\
\text { Basin } \\
\text { Fruitland } \\
\text { OSU \#3b }\end{array}$ \\
\hline Ultimate & & & & & & & \\
\hline Carbon \% & 88.65 & 68.56 & 68.63 & 66.58 & 71.47 & 38.92 & 40.20 \\
\hline Hydrogen \% & 0.74 & 5.74 & 4.27 & 4.23 & 5.13 & 3.08 & 3.10 \\
\hline Oxygen \% & 3.01 & 7.19 & 0.89 & 5.08 & 9.85 & 3.75 & 2.87 \\
\hline Nitrogen \% & 0.40 & 1.40 & 1.57 & 1.47 & 1.46 & 0.87 & 0.89 \\
\hline Sulfur \% & 0.73 & 0.65 & 4.19 & 0.72 & 1.27 & 1.73 & 2.14 \\
\hline Ash \% & 6.46 & 16.45 & 20.45 & 21.92 & 10.81 & 51.66 & 50.81 \\
\hline Proximate & & & & & & & \\
\hline Vol. Matter \% & 3.68 & 19.12 & 20.2 & 20.33 & 30.61 & 20.01 & 14.00 \\
\hline Fixed Carbon \% & 89.86 & 64.42 & 59.35 & 57.75 & 55.90 & 28.33 & 35.19 \\
\hline
\end{tabular}


Table 3. Analysis of BPL Activated Carbon Used in This Study

\begin{tabular}{|l|c|c|c|c|}
\hline \multicolumn{1}{|c|}{ Analysis } & Units & Value & $\begin{array}{c}\text { Lower } \\
\text { Limit }\end{array}$ & $\begin{array}{c}\text { Upper } \\
\text { Limit }\end{array}$ \\
\hline Abrasion Number & & 87 & 75 & - \\
\hline Apparent Density & $\mathrm{g} / \mathrm{cc}$ & 0.53 & 0.44 & - \\
\hline Ash & $\%$ & 7 & - & 9 \\
\hline Effective Size & $\mathrm{mm}$ & 0.64 & 0.55 & 0.75 \\
\hline lodine Number & $\mathrm{mg} / \mathrm{g}$ & 1046 & 1000 & - \\
\hline US Sieve Series on 12 & $\%$ & 1 & - & 5 \\
\hline US Sieve Series -40 Mesh & $\%$ & 1 & - & 4 \\
\hline Fixed Carbon & & 1.7 & - & 1.9 \\
\hline
\end{tabular}


Table 4. Pure Methane Adsorption on Wet Lower Basin Fruitland Coal (OSU\#3a) at $115^{\circ} \mathrm{F}$

\begin{tabular}{|c|c|c|c|c|c|}
\hline \multicolumn{3}{|c|}{ Run 1 (8.0\% Moisture) } & \multicolumn{3}{c|}{ Run 2 (7.9\% Moisture) } \\
\hline $\begin{array}{c}\text { Pressure } \\
\text { (psia) }\end{array}$ & $\begin{array}{c}\text { Gibbs } \\
\text { Adsorption } \\
\text { (mmol/g) }\end{array}$ & $\begin{array}{c}\text { Absolute } \\
\text { Adsorption } \\
\text { (mmol/g) }\end{array}$ & $\begin{array}{c}\text { Pressure } \\
\text { (psia) }\end{array}$ & $\begin{array}{c}\text { Gibbs } \\
\text { Adsorption } \\
\text { (mmol/g) }\end{array}$ & $\begin{array}{c}\text { Absolute } \\
\text { Adsorption } \\
\text { (mmol/g) }\end{array}$ \\
\hline 222.8 & 0.1252 & 0.1281 & 308.8 & 0.1585 & 0.1637 \\
\hline 551.6 & 0.1971 & 0.2091 & 680.8 & 0.2162 & 0.2328 \\
\hline 717.3 & 0.2223 & 0.2405 & 919.6 & 0.2404 & 0.2666 \\
\hline 930.0 & 0.2464 & 0.2737 & 1148.9 & 0.2566 & 0.2933 \\
\hline 1127.5 & 0.2616 & 0.2981 & 1329.5 & 0.2678 & 0.3138 \\
\hline 1359.3 & 0.2776 & 0.3266 & 1568.4 & 0.2855 & 0.3462 \\
\hline 1631.8 & 0.2964 & 0.3628 & 1795.8 & 0.2987 & 0.3747 \\
\hline 1832.7 & 0.2917 & 0.3679 & & & \\
\hline 1985.6 & 0.3021 & 0.3900 & & & \\
\hline
\end{tabular}

Table 5. Pure Nitrogen Adsorption on Wet Lower Basin Fruitland Coal (OSU\#3a) at $115^{\circ} \mathrm{F}$

\begin{tabular}{|c|c|c|c|c|c|}
\hline \multicolumn{3}{|c|}{ Run 1 (7.7\% Moisture) } & \multicolumn{3}{c|}{ Run 2 (7.5\% Moisture) } \\
\hline $\begin{array}{c}\text { Pressure } \\
\text { (psia) }\end{array}$ & $\begin{array}{c}\text { Gibbs } \\
\text { Adsorption } \\
\text { (mmol/g) }\end{array}$ & $\begin{array}{c}\text { Absolute } \\
\text { Adsorption } \\
\text { (mmol/g) }\end{array}$ & $\begin{array}{c}\text { Pressure } \\
\text { (psia) }\end{array}$ & $\begin{array}{c}\text { Gibbs } \\
\text { Adsorption } \\
\text { (mmol/g) }\end{array}$ & $\begin{array}{c}\text { Absolute } \\
\text { Adsorption } \\
\text { (mmol/g) }\end{array}$ \\
\hline 210.2 & 0.0347 & 0.0354 & 231.1 & 0.0400 & 0.0408 \\
\hline 433.0 & 0.0614 & 0.0638 & 553.8 & 0.0742 & 0.0781 \\
\hline 620.2 & 0.0699 & 0.0740 & 805.4 & 0.0865 & 0.0932 \\
\hline 826.4 & 0.0824 & 0.0890 & 1014.2 & 0.0987 & 0.1085 \\
\hline 1023.5 & 0.0951 & 0.1047 & 1237.6 & 0.1109 & 0.1246 \\
\hline 1236.2 & 0.1080 & 0.1214 & 1421.9 & 0.1152 & 0.1318 \\
\hline 1422.3 & 0.1180 & 0.1350 & 1611.3 & 0.1256 & 0.1464 \\
\hline 1631.0 & 0.1283 & 0.1499 & 1806.5 & 0.1366 & 0.1624 \\
\hline 1820.1 & 0.1387 & 0.1650 & & & \\
\hline
\end{tabular}


Table 6a. Pure $\mathrm{CO}_{2}$ on Wet Lower Basin Fruitland Coal (OSU\#3a) at $115^{\circ} \mathrm{F}$ (Wagner Z Factors)

\begin{tabular}{|c|c|c|c|c|c|}
\hline \multicolumn{2}{|c|}{ Run 1 (7.3\% Moisture) } & \multicolumn{2}{c|}{ Run 2 (7.2\% Moisture) } & \multicolumn{2}{c|}{ Run 3 (7.1\% Moisture) } \\
\hline $\begin{array}{c}\text { Pressure } \\
\text { (psia) }\end{array}$ & $\begin{array}{c}\text { Gibbs } \\
\text { Adsorption } \\
\text { (mmol/g) }\end{array}$ & $\begin{array}{c}\text { Pressure } \\
\text { (psia) }\end{array}$ & $\begin{array}{c}\text { Gibbs } \\
\text { Adsorption } \\
\text { (mmol/g) }\end{array}$ & $\begin{array}{c}\text { Pressure } \\
\text { (psia) }\end{array}$ & $\begin{array}{c}\text { Gibbs } \\
\text { Adsorption } \\
\text { (mmol/g) }\end{array}$ \\
\hline 233.3 & 0.3207 & 193.7 & 0.3081 & 115.2 & 0.2153 \\
\hline 434.4 & 0.4151 & 627.9 & 0.4400 & 213.8 & 0.3041 \\
\hline 612.6 & 0.4333 & 815.8 & 0.4444 & 413.1 & 0.3968 \\
\hline 844.9 & 0.4440 & 1012.1 & 0.4334 & 611.6 & 0.4420 \\
\hline 1039.7 & 0.4162 & 1200.8 & 0.4148 & 798.8 & 0.4340 \\
\hline 1197.5 & 0.4050 & 1378.8 & 0.4270 & 1011.7 & 0.4138 \\
\hline 1385.9 & 0.4174 & 1580.3 & 0.3612 & 1202.0 & 0.3968 \\
\hline 1558.2 & 0.3136 & 1778.3 & 0.2402 & 1384.9 & 0.4083 \\
\hline 1789.3 & 0.2699 & & & & \\
\hline
\end{tabular}

Table 6b. Pure $\mathrm{CO}_{2}$ on Wet Lower Basin Fruitland Coal (OSU\#3a) at $115^{\circ} \mathrm{F}$ (IUPAC Z Factors)

\begin{tabular}{|c|c|c|c|c|c|}
\hline \multicolumn{2}{|c|}{ Run 1 (7.3\% Moisture) } & \multicolumn{2}{c|}{ Run 2 (7.2\% Moisture) } & \multicolumn{2}{c|}{ Run 3 (7.1\% Moisture) } \\
\hline $\begin{array}{c}\text { Pressure } \\
\text { (psia) }\end{array}$ & $\begin{array}{c}\text { Gibbs } \\
\text { Adsorption } \\
\text { (mmol/g) }\end{array}$ & $\begin{array}{c}\text { Pressure } \\
\text { (psia) }\end{array}$ & $\begin{array}{c}\text { Gibbs } \\
\text { Adsorption } \\
\text { (mmol/g) }\end{array}$ & $\begin{array}{c}\text { Pressure } \\
\text { (psia) }\end{array}$ & $\begin{array}{c}\text { Gibbs } \\
\text { Adsorption } \\
\text { (mmol/g) }\end{array}$ \\
\hline 233.3 & 0.3208 & 193.7 & 0.3082 & 115.2 & 0.2154 \\
\hline 434.4 & 0.4149 & 627.9 & 0.4397 & 213.8 & 0.3042 \\
\hline 612.6 & 0.4330 & 815.8 & 0.4444 & 413.1 & 0.3966 \\
\hline 844.9 & 0.4440 & 1012.1 & 0.4337 & 611.6 & 0.4417 \\
\hline 1039.7 & 0.4163 & 1200.8 & 0.4112 & 798.8 & 0.4339 \\
\hline 1197.5 & 0.4016 & 1378.8 & 0.4075 & 1011.7 & 0.4140 \\
\hline 1385.9 & 0.3977 & 1580.3 & 0.3437 & 1202.0 & 0.3931 \\
\hline 1558.2 & 0.2964 & 1778.3 & 0.2230 & 1384.9 & 0.3885 \\
\hline 1789.3 & 0.2529 & & & & \\
\hline
\end{tabular}


Table 7. Pure $\mathrm{CO}_{2}$ Adsorption on Wet Lower Basin Fruitland Coal (OSU\#3a $\& \# 3 b$ ) at $115^{\circ} \mathrm{F}$ (IUPAC Z Factors)

\begin{tabular}{|c|c|c|c|}
\hline OSU\#3a (Fresh Matrix, 7\% Moisture) & \multicolumn{2}{|c|}{ OSU\#3b (14.8\% Moisture) } \\
\hline $\begin{array}{c}\text { Pressure } \\
\text { (psia) }\end{array}$ & $\begin{array}{c}\text { Gibbs } \\
\text { Adsorption (mmol/g } \\
\text { coal) }\end{array}$ & $\begin{array}{c}\text { Pressure } \\
\text { (psia) }\end{array}$ & $\begin{array}{c}\text { Gibbs } \\
\text { Adsorption } \\
\text { (mmol/g coal) }\end{array}$ \\
\hline 101.8 & 0.1886 & 107.5 & 0.2032 \\
\hline 211.1 & 0.2903 & 229.6 & 0.3084 \\
\hline 409.1 & 0.3810 & 436.0 & 0.4076 \\
\hline 610.5 & 0.4096 & 609.3 & 0.4438 \\
\hline 804.2 & 0.4084 & 813.9 & 0.4360 \\
\hline 1014.5 & 0.4147 & 1012.7 & 0.4325 \\
\hline 1201.6 & 0.4051 & 1206.4 & 0.4064 \\
\hline 1389.2 & 0.3419 & 1395.5 & 0.3749 \\
\hline 1570.6 & 0.2785 & 1581.6 & 0.2911 \\
\hline 1781.3 & 0.2065 & 1792.2 & 0.2141 \\
\hline
\end{tabular}


Table 8. Pure Gas Adsorption on Activated Carbon at $130^{\circ} \mathrm{F}$

\begin{tabular}{|c|c|c|c|c|c|}
\hline \multicolumn{3}{|c|}{ Methane } & \multicolumn{3}{|c|}{ Nitrogen } \\
\hline $\begin{array}{c}\text { Pressure } \\
\text { (psia) }\end{array}$ & $\begin{array}{c}\text { Gibbs } \\
\text { Adsorption } \\
\text { (mmol/g) }\end{array}$ & $\begin{array}{l}\text { Absolute } \\
\text { Adsorption } \\
\text { (mmol/g) }\end{array}$ & $\begin{array}{c}\text { Pressure } \\
\text { (psia) }\end{array}$ & $\begin{array}{c}\text { Gibbs } \\
\text { Adsorption } \\
\text { (mmol/g) }\end{array}$ & $\begin{array}{l}\text { Absolute } \\
\text { Adsorption } \\
(\mathrm{mmol} / \mathrm{g})\end{array}$ \\
\hline 85.5 & 1.361 & 1.372 & 88.9 & 0.771 & 0.780 \\
\hline 182.9 & 2.053 & 2.090 & 223.8 & 1.439 & 1.485 \\
\hline 375.9 & 2.756 & 2.863 & 413.4 & 2.007 & 2.128 \\
\hline 618.1 & 3.204 & 3.418 & 619.2 & 2.396 & 2.618 \\
\hline 821.8 & 3.370 & 3.681 & 808.1 & 2.654 & 2.984 \\
\hline 1004.3 & 3.457 & 3.861 & 1012.5 & 2.850 & 3.307 \\
\hline 1202.6 & 3.542 & 4.056 & 1214.4 & 2.989 & 3.580 \\
\hline 1412.5 & 3.562 & 4.193 & 1404.8 & 3.092 & 3.818 \\
\hline 1603.0 & 3.567 & 4.310 & 1607.5 & 3.170 & 4.046 \\
\hline 1956.9 & 3.580 & 4.547 & 1828.8 & 3.240 & 4.290 \\
\hline \multicolumn{3}{|c|}{ Carbon Dioxide (Run 1) } & \multicolumn{3}{|c|}{ Carbon Dioxide (Run 2) } \\
\hline $\begin{array}{c}\text { Pressure } \\
\text { (psia) }\end{array}$ & $\begin{array}{c}\text { Gibbs } \\
\text { Adsorption } \\
(\mathrm{mmol} / \mathrm{g})\end{array}$ & $\begin{array}{l}\text { Absolute } \\
\text { Adsorption } \\
\text { (mmol/g) }\end{array}$ & $\begin{array}{c}\text { Pressure } \\
\text { (psia) }\end{array}$ & $\begin{array}{c}\text { Gibbs } \\
\text { Adsorption } \\
\text { (mmol/g) }\end{array}$ & $\begin{array}{l}\text { Absolute } \\
\text { Adsorption } \\
\text { (mmol/g) }\end{array}$ \\
\hline 87.5 & 2.878 & 2.903 & 368.0 & 5.353 & 5.567 \\
\hline 182.6 & 4.037 & 4.111 & 821.7 & 6.351 & 7.071 \\
\hline 342.2 & 5.002 & 5.186 & 1232.0 & 6.311 & 7.836 \\
\hline 554.7 & 5.774 & 6.154 & & & \\
\hline 778.4 & 6.255 & 6.910 & & & \\
\hline 983.2 & 6.407 & 7.382 & & & \\
\hline 1182.8 & 6.339 & 7.731 & & & \\
\hline 1294.5 & 6.226 & 7.931 & & & \\
\hline
\end{tabular}


Table 9. Methane/Nitrogen Mixture Adsorption on Wet Illinois- 6 Coal at $115^{\circ} \mathrm{F}$

\begin{tabular}{|c|c|c|c|}
\hline $\begin{array}{c}\text { Pressure } \\
\text { (psia) }\end{array}$ & $\begin{array}{c}\text { Methane Gas } \\
\text { Mole Fraction }\end{array}$ & $\begin{array}{c}\text { Methane } \\
\text { Adsorption } \\
\text { (mmole/g coal) }\end{array}$ & $\begin{array}{c}\text { Nitrogen } \\
\text { Adsorption } \\
\text { (mmole/g coal) }\end{array}$ \\
\hline \multicolumn{4}{|c|}{ Methane Feed Composition: 20\% (22.8\% moisture) } \\
\hline 101.4 & 0.1784 & 0.0130 & 0.0198 \\
\hline 199.5 & 0.1793 & 0.0218 & 0.0259 \\
\hline 398.7 & 0.1815 & 0.0387 & 0.0493 \\
\hline 627.1 & 0.1823 & 0.0559 & 0.0675 \\
\hline 809.0 & 0.1829 & 0.0672 & 0.0773 \\
\hline 999.3 & 0.1836 & 0.0779 & 0.0908 \\
\hline 1197.6 & 0.1842 & 0.0872 & 0.0999 \\
\hline 1401.6 & 0.1842 & 0.0992 & 0.1057 \\
\hline 1596.5 & 0.1841 & 0.1117 & 0.1151 \\
\hline 1806.2 & 0.1850 & 0.1165 & 0.1276 \\
\hline & Methane Feed Composition: $40 \%(22.7 \%$ moisture) \\
\hline 102.5 & 0.3718 & 0.0263 & 0.0117 \\
\hline 206.0 & 0.3736 & 0.0497 & 0.0215 \\
\hline 405.3 & 0.3785 & 0.0825 & 0.0397 \\
\hline 605.2 & 0.3805 & 0.1089 & 0.0502 \\
\hline 803.7 & 0.3809 & 0.1347 & 0.0549 \\
\hline 1001.2 & 0.3818 & 0.1561 & 0.0603 \\
\hline 1204.1 & 0.3825 & 0.1767 & 0.0639 \\
\hline 1403.0 & 0.3834 & 0.1921 & 0.0683 \\
\hline 1600.5 & 0.3847 & 0.2057 & 0.0812 \\
\hline 1815.7 & 0.3853 & 0.2276 & 0.0951 \\
\hline
\end{tabular}


Table 9. Methane/Nitrogen Mixture Adsorption on Wet Illinois- 6 Coal at $115^{\circ} \mathrm{F}$ - Continued

\begin{tabular}{|c|c|c|c|}
\hline $\begin{array}{c}\text { Pressure } \\
\text { (psia) }\end{array}$ & $\begin{array}{c}\text { Methane Gas } \\
\text { Mole Fraction }\end{array}$ & $\begin{array}{c}\text { Methane } \\
\text { Adsorption } \\
\text { (mmole/g coal) }\end{array}$ & $\begin{array}{c}\text { Nitrogen } \\
\text { Adsorption } \\
\text { (mmole/g coal) }\end{array}$ \\
\hline \multicolumn{4}{|c|}{ Methane Feed Composition: $60 \%(22.7 \%$ moisture) } \\
\hline 101.0 & 0.5743 & 0.0467 & 0.0140 \\
\hline 202.5 & 0.5731 & 0.0827 & 0.0180 \\
\hline 407.2 & 0.5786 & 0.1327 & 0.0286 \\
\hline 601.5 & 0.5810 & 0.1681 & 0.0334 \\
\hline 817.5 & 0.5816 & 0.2060 & 0.0330 \\
\hline 1004.9 & 0.5829 & 0.2315 & 0.0352 \\
\hline 1204.1 & 0.5836 & 0.2604 & 0.0364 \\
\hline 1401.3 & 0.5841 & 0.2826 & 0.0335 \\
\hline 1609.4 & 0.5851 & 0.3064 & 0.0383 \\
\hline 1818.0 & 0.5860 & 0.3313 & 0.0451 \\
\hline & Methane Feed Composition: $79 \%(22.6 \%$ & 0.0075 \\
\hline 99.3 & 0.7731 & 0.0661 & 0.0143 \\
\hline 203.7 & 0.7764 & 0.1193 & 0.0168 \\
\hline 405.3 & 0.7780 & 0.1828 & 0.0190 \\
\hline 610.3 & 0.7799 & 0.2280 & 0.0232 \\
\hline 802.1 & 0.7813 & 0.2715 & 0.0224 \\
\hline 998.6 & 0.7818 & 0.3052 & 0.0209 \\
\hline 1199.2 & 0.7819 & 0.3426 & 0.0180 \\
\hline 1400.7 & 0.7822 & 0.3708 & 0.0233 \\
\hline 1601.6 & 0.7832 & 0.4002 & 0.0225 \\
\hline 1810.1 & 0.7838 & 0.4142 & \\
\hline
\end{tabular}


Table 10. Methane/Carbon Dioxide Mixture Adsorption on Wet Illinois-6 Coal at $115^{\circ} \mathrm{F}$

\begin{tabular}{|c|c|c|c|}
\hline $\begin{array}{c}\text { Pressure } \\
\text { (psia) }\end{array}$ & $\begin{array}{c}\text { Methane Gas } \\
\text { Mole Fraction }\end{array}$ & $\begin{array}{c}\text { Methane } \\
\text { Adsorption } \\
\text { (mmole/g coal) }\end{array}$ & $\begin{array}{c}\text { Carbon Dioxide } \\
\text { Adsorption } \\
\text { (mmole/g coal) }\end{array}$ \\
\hline \multicolumn{4}{|c|}{ Methane Feed Composition: $23 \%(20.9 \%$ moisture) } \\
\hline 103.8 & 0.3745 & 0.0218 & 0.2228 \\
\hline 203.0 & 0.3459 & 0.0344 & 0.3464 \\
\hline 420.9 & 0.3263 & 0.0360 & 0.5272 \\
\hline 609.5 & 0.3016 & 0.0483 & 0.5870 \\
\hline 804.0 & 0.2933 & 0.0483 & 0.6770 \\
\hline 1005.9 & 0.2817 & 0.0554 & 0.7216 \\
\hline 1211.7 & 0.2708 & 0.0614 & 0.7192 \\
\hline 1412.8 & 0.2623 & 0.0795 & 0.7420 \\
\hline 1607.9 & 0.2571 & 0.0798 & 0.7368 \\
\hline 1814.3 & 0.2519 & 0.1038 & 0.7679 \\
\hline & Methane Feed Composition: $40 \%(20.9 \%$ & 0.1665 \\
\hline 103.1 & 0.5793 & 0.0349 & 0.2622 \\
\hline 210.6 & 0.5423 & 0.0531 & 0.3848 \\
\hline 407.0 & 0.5132 & 0.0710 & 0.4841 \\
\hline 612.9 & 0.5003 & 0.0703 & 0.5307 \\
\hline 823.2 & 0.4796 & 0.0863 & 0.5557 \\
\hline 1011.5 & 0.4651 & 0.1022 & 0.5858 \\
\hline 1211.3 & 0.4536 & 0.1253 & 0.6181 \\
\hline 1430.1 & 0.4452 & 0.1418 & 0.6341 \\
\hline 1607.2 & 0.4405 & 0.1425 & 0.6761 \\
\hline 1842.7 & 0.4356 & 0.1557 & \\
\hline
\end{tabular}


Table 10. Methane/Carbon Dioxide Mixture Adsorption on Wet Illinois -6 Coal at $115^{\circ} \mathrm{F}$ - Continued

\begin{tabular}{|c|c|c|c|}
\hline $\begin{array}{c}\text { Pressure } \\
\text { (psia) }\end{array}$ & $\begin{array}{c}\text { Methane Gas } \\
\text { Mole Fraction }\end{array}$ & $\begin{array}{c}\text { Methane } \\
\text { Adsorption } \\
\text { (mmole/g coal) }\end{array}$ & $\begin{array}{c}\text { Carbon Dioxide } \\
\text { Adsorption } \\
\text { (mmole/g coal) }\end{array}$ \\
\hline \multicolumn{4}{|c|}{ Methane Feed Composition: $60 \%(20.8 \%$ moisture) } \\
\hline 108.0 & 0.7795 & 0.0480 & 0.1133 \\
\hline 203.6 & 0.7603 & 0.0727 & 0.1867 \\
\hline 395.5 & 0.7380 & 0.0904 & 0.2927 \\
\hline 621.3 & 0.7096 & 0.1159 & 0.3634 \\
\hline 815.3 & 0.6960 & 0.1327 & 0.4180 \\
\hline 1008.6 & 0.6833 & 0.1551 & 0.4563 \\
\hline 1202.9 & 0.6701 & 0.1726 & 0.4645 \\
\hline 1405.2 & 0.6609 & 0.1863 & 0.4773 \\
\hline 1598.2 & 0.6525 & 0.2016 & 0.4764 \\
\hline 1810.8 & 0.6429 & 0.2290 & 0.4567 \\
\hline & Methane Feed Composition: $77 \%(20.8 \%$ moisture) \\
\hline 131.6 & 0.8817 & 0.0808 & 0.0728 \\
\hline 223.7 & 0.8816 & 0.1046 & 0.1157 \\
\hline 400.8 & 0.8756 & 0.1279 & 0.1838 \\
\hline 612.2 & 0.8479 & 0.1752 & 0.2108 \\
\hline 809.5 & 0.8460 & 0.1826 & 0.2628 \\
\hline 1001.9 & 0.8336 & 0.2072 & 0.2733 \\
\hline 1182.4 & 0.8271 & 0.2249 & 0.2898 \\
\hline 1400.9 & 0.8274 & 0.2264 & 0.3400 \\
\hline 1597.7 & 0.8178 & 0.2521 & 0.3255 \\
\hline 1803.4 & 0.8127 & 0.2714 & 0.3288 \\
\hline
\end{tabular}


Table 11. Nitrogen/Carbon Dioxide Mixture Adsorption on Wet Illinois-6 Coal at $115^{\circ} \mathrm{F}$

\begin{tabular}{|c|c|c|c|}
\hline $\begin{array}{c}\text { Pressure } \\
\text { (psia) }\end{array}$ & $\begin{array}{c}\text { Nitrogen Gas } \\
\text { Mole Fraction }\end{array}$ & $\begin{array}{c}\text { Nitrogen } \\
\text { Adsorption } \\
\text { (mmole/g coal) }\end{array}$ & $\begin{array}{c}\text { Carbon Dioxide } \\
\text { Adsorption } \\
\text { (mmole/g coal) }\end{array}$ \\
\hline \multicolumn{4}{|c|}{ Nitrogen Feed Composition: 82\% (5.7\% moisture) } \\
\hline 139.0 & 0.9387 & 0.0134 & 0.0545 \\
\hline 204.4 & 0.9309 & 0.0171 & 0.0751 \\
\hline 438.5 & 0.9177 & 0.0345 & 0.1434 \\
\hline 601.3 & 0.9090 & 0.0428 & 0.1794 \\
\hline 804.7 & 0.9021 & 0.0538 & 0.2217 \\
\hline 992.0 & 0.8906 & 0.0793 & 0.2399 \\
\hline 1209.6 & 0.8814 & 0.1027 & 0.2581 \\
\hline 1398.7 & 0.8777 & 0.1120 & 0.2801 \\
\hline 1590.4 & 0.8714 & 0.1311 & 0.2874 \\
\hline 1802.9 & 0.8669 & 0.1486 & 0.2995 \\
\hline & Nitrogen Feed Composition: $60 \%(5.7 \%$ moisture) \\
\hline 119.7 & 0.7985 & 0.0103 & 0.1040 \\
\hline 206.2 & 0.7713 & 0.0161 & 0.1570 \\
\hline 398.1 & 0.7449 & 0.0265 & 0.2589 \\
\hline 597.2 & 0.7277 & 0.0308 & 0.3412 \\
\hline 816.2 & 0.7071 & 0.0432 & 0.3981 \\
\hline 998.4 & 0.6970 & 0.0539 & 0.4468 \\
\hline 1202.8 & 0.6812 & 0.0770 & 0.4668 \\
\hline 1390.6 & 0.6731 & 0.0857 & 0.4912 \\
\hline 1597.7 & 0.6635 & 0.1098 & 0.5069 \\
\hline 1798.8 & 0.6591 & 0.1161 & 0.5333 \\
\hline
\end{tabular}


Table 11. Nitrogen/Carbon Dioxide Mixture Adsorption on Wet Illinois-6 Coal at $115^{\circ} \mathrm{F}$ - Continued

\begin{tabular}{|c|c|c|c|}
\hline $\begin{array}{c}\text { Pressure } \\
\text { (psia) }\end{array}$ & $\begin{array}{c}\text { Nitrogen Gas } \\
\text { Mole Fraction }\end{array}$ & $\begin{array}{c}\text { Nitrogen } \\
\text { Adsorption } \\
\text { (mmole/g coal) }\end{array}$ & $\begin{array}{c}\text { Carbon Dioxide } \\
\text { Adsorption } \\
\text { (mmole/g coal) }\end{array}$ \\
\hline \multicolumn{4}{|c|}{ Nitrogen Feed Composition: $42 \%(5.7 \%$ moisture) } \\
\hline 120.9 & 0.6392 & 0.0057 & 0.1659 \\
\hline 214.3 & 0.6076 & 0.0070 & 0.2541 \\
\hline 392.3 & 0.5680 & 0.0109 & 0.3749 \\
\hline 614.4 & 0.5426 & 0.0111 & 0.4925 \\
\hline 810.7 & 0.5205 & 0.0221 & 0.5575 \\
\hline 1001.3 & 0.5083 & 0.0242 & 0.6181 \\
\hline 1206.3 & 0.4948 & 0.0357 & 0.6608 \\
\hline 1396.8 & 0.4833 & 0.0527 & 0.6869 \\
\hline 1603.8 & 0.4709 & 0.0747 & 0.6869 \\
\hline 1823.6 & 0.4671 & 0.0807 & 0.7396 \\
\hline & Nitrogen Feed Composition: $20 \%(5.7 \%$ moisture) \\
\hline 106.1 & 0.3528 & 0.0044 & 0.2190 \\
\hline 203.9 & 0.3171 & 0.0081 & 0.3381 \\
\hline 422.6 & 0.2857 & 0.0070 & 0.5126 \\
\hline 621.2 & 0.2682 & 0.0079 & 0.6228 \\
\hline 806.6 & 0.2566 & 0.0087 & 0.7004 \\
\hline 996.0 & 0.2472 & 0.0110 & 0.7662 \\
\hline 1202.3 & 0.2360 & 0.0241 & 0.8056 \\
\hline 1388.4 & 0.2289 & 0.0349 & 0.8425 \\
\hline 1588.3 & 0.2219 & 0.0480 & 0.8500 \\
\hline 1799.0 & 0.2167 & 0.0591 & 0.8524 \\
\hline
\end{tabular}


Table 12. Methane/Nitrogen Adsorption on Dry Activated Carbon at $113^{\circ} \mathrm{F}$

\begin{tabular}{|c|c|c|c|c|c|}
\hline $\begin{array}{c}\text { Pressure } \\
\text { (psia) }\end{array}$ & \multirow{2}{*}{$\begin{array}{c}\text { Methane Gas } \\
\text { Mole Fraction }\end{array}$} & \multicolumn{2}{c|}{$\begin{array}{c}\text { Methane Adsorption } \\
\text { (mmol/g coal) }\end{array}$} & $\begin{array}{c}\text { Nitrogen Adsorption } \\
\text { (mmol/g coal) }\end{array}$ \\
\cline { 3 - 6 } & \multicolumn{6}{|c|}{ Gibbs } & Absolute & Gibbs & Absolute \\
\hline \multicolumn{7}{|c|}{ Methane Feed Composition: 81.7\% } \\
\hline 94.8 & 0.6492 & 1.5997 & 1.6109 & 0.2268 & 0.2328 \\
\hline 200.9 & 0.6743 & 2.3723 & 2.4088 & 0.2928 & 0.3105 \\
\hline 400.1 & 0.7025 & 3.1929 & 3.2965 & 0.3296 & 0.3735 \\
\hline 610.4 & 0.7214 & 3.5980 & 3.7845 & 0.3089 & 0.3809 \\
\hline 819.8 & 0.7317 & 3.8766 & 4.1557 & 0.2666 & 0.3689 \\
\hline 1006.2 & 0.7441 & 3.9936 & 4.3625 & 0.2567 & 0.3836 \\
\hline 1210.9 & 0.7520 & 4.0822 & 4.5528 & 0.2241 & 0.3793 \\
\hline 1412.5 & 0.7586 & 4.1233 & 4.6972 & 0.1945 & 0.3772 \\
\hline 1603.1 & 0.7627 & 4.1450 & 4.8174 & 0.1557 & 0.3649 \\
\hline 1804.5 & 0.7675 & 4.1317 & 4.9100 & 0.1297 & 0.3654 \\
\hline \multicolumn{7}{|c|}{ Methane Feed Composition: $60.0 \%$} & & \\
\hline 108.8 & 0.3700 & 1.1562 & 1.1627 & 0.4906 & 0.5017 \\
\hline 207.9 & 0.3942 & 1.6916 & 1.7106 & 0.6469 & 0.6761 \\
\hline 391.9 & 0.4235 & 2.3176 & 2.3696 & 0.7635 & 0.8343 \\
\hline 609.6 & 0.4506 & 2.7558 & 2.8584 & 0.8015 & 0.9266 \\
\hline 800.0 & 0.4675 & 3.0057 & 3.1588 & 0.7928 & 0.9672 \\
\hline 1010.6 & 0.4822 & 3.1932 & 3.4071 & 0.7630 & 0.9927 \\
\hline 1212.3 & 0.4906 & 3.3420 & 3.6163 & 0.7018 & 0.9865 \\
\hline 1408.5 & 0.5009 & 3.4053 & 3.7408 & 0.6595 & 0.9939 \\
\hline 1605.1 & 0.5085 & 3.4594 & 3.8580 & 0.6109 & 0.9961 \\
\hline 1802.7 & 0.5132 & 3.5203 & 3.9821 & 0.5413 & 0.9794 \\
\hline
\end{tabular}


Table 12. Methane/Nitrogen Adsorption on Dry Activated Carbon at $113^{\circ} \mathrm{F}$ - Continued

\begin{tabular}{|c|c|c|c|c|c|}
\hline \multirow[t]{2}{*}{$\begin{array}{l}\text { Pressure } \\
\text { (psia) }\end{array}$} & \multirow[t]{2}{*}{$\begin{array}{l}\text { Methane Gas } \\
\text { Mole Fraction }\end{array}$} & \multicolumn{2}{|c|}{$\begin{array}{l}\text { Methane Adsorption } \\
\text { (mmol/g coal) }\end{array}$} & \multicolumn{2}{|c|}{$\begin{array}{l}\text { Nitrogen Adsorption } \\
\text { (mmol/g coal) }\end{array}$} \\
\hline & & Gibbs & Absolute & Gibbs & Absolute \\
\hline \multicolumn{6}{|c|}{ Methane Feed Composition: $40.0 \%$} \\
\hline 111.5 & 0.2036 & 0.7352 & 0.7384 & 0.7307 & 0.7431 \\
\hline 232.7 & 0.2298 & 1.1552 & 1.1667 & 1.0583 & 1.0969 \\
\hline 413.2 & 0.2397 & 1.5933 & 1.6214 & 1.2605 & 1.3498 \\
\hline 603.5 & 0.2513 & 1.9174 & 1.9678 & 1.3430 & 1.4932 \\
\hline 802.4 & 0.2713 & 2.1148 & 2.1947 & 1.4036 & 1.6183 \\
\hline 1012.6 & 0.2843 & 2.2777 & 2.3912 & 1.4079 & 1.6936 \\
\hline 1202.6 & 0.2907 & 2.4154 & 2.5599 & 1.3679 & 1.7207 \\
\hline 1395.2 & 0.2976 & 2.5143 & 2.6922 & 1.3217 & 1.7416 \\
\hline 1596.3 & 0.3054 & 2.5744 & 2.7887 & 1.2774 & 1.7647 \\
\hline 1803.6 & 0.3145 & 2.5925 & 2.8468 & 1.2545 & 1.8086 \\
\hline \multicolumn{6}{|c|}{ Methane Feed Composition: $20.0 \%$} \\
\hline 109.6 & 0.0937 & 0.3264 & 0.3275 & 0.9154 & 0.9269 \\
\hline 217.8 & 0.0997 & 0.5202 & 0.5240 & 1.3482 & 1.3830 \\
\hline 401.8 & 0.1063 & 0.7541 & 0.7645 & 1.7541 & 1.8412 \\
\hline 603.6 & 0.1120 & 0.9419 & 0.9615 & 1.9865 & 2.1415 \\
\hline 805.5 & 0.1191 & 1.0751 & 1.1060 & 2.1157 & 2.3441 \\
\hline 1008.1 & 0.1280 & 1.1577 & 1.2023 & 2.1999 & 2.5037 \\
\hline 1212.1 & 0.1314 & 1.2481 & 1.3060 & 2.2130 & 2.5956 \\
\hline 1406.6 & 0.1374 & 1.2919 & 1.3646 & 2.2310 & 2.6878 \\
\hline 1606.1 & 0.1431 & 1.3173 & 1.4060 & 2.2321 & 2.7635 \\
\hline 1803.7 & 0.1467 & 1.3475 & 1.4516 & 2.2098 & 2.8156 \\
\hline
\end{tabular}


Table 13. Methane/Carbon Dioxide Adsorption on Dry Activated Carbon at $113^{\circ} \mathrm{F}$

\begin{tabular}{|c|c|c|c|c|c|}
\hline $\begin{array}{c}\text { Pressure } \\
\text { (psia) }\end{array}$ & $\begin{array}{c}\text { Methane Gas } \\
\text { Mole Fraction }\end{array}$ & $\begin{array}{c}\text { Methane Adsorption } \\
\text { (mmol/g AC) }\end{array}$ & $\begin{array}{c}\text { Carbon Dioxide } \\
\text { Adsorption } \\
\text { (mmol/g AC) }\end{array}$ \\
\cline { 3 - 6 } & \multicolumn{6}{|c|}{ Gibbs } & Absolute & Gibbs & Absolute \\
\hline \multicolumn{6}{|c|}{ Methane Feed Composition: 80.0\% } \\
\hline 111.7 & 0.8792 & 1.9376 & 1.9678 & 0.5592 & 0.5634 \\
\hline 211.5 & 0.8858 & 2.5149 & 2.5925 & 0.7838 & 0.7938 \\
\hline 407.3 & 0.8839 & 3.0350 & 3.2287 & 1.0571 & 1.0825 \\
\hline 597.7 & 0.8826 & 3.2372 & 3.5630 & 1.2488 & 1.2921 \\
\hline 805.0 & 0.8774 & 3.3167 & 3.7995 & 1.3959 & 1.4634 \\
\hline 1003.5 & 0.8714 & 3.3218 & 3.9656 & 1.4954 & 1.5904 \\
\hline 1203.3 & 0.8657 & 3.2519 & 4.0608 & 1.5615 & 1.6869 \\
\hline 1402.4 & 0.8610 & 3.1664 & 4.1502 & 1.6157 & 1.7746 \\
\hline 1601.7 & 0.8563 & 3.0595 & 4.2224 & 1.6489 & 1.8440 \\
\hline 1800.4 & 0.8519 & 2.9432 & 4.2876 & 1.6644 & 1.8981 \\
\hline \multicolumn{7}{|c|}{ Methane Feed Composition: $60.0 \%$} & \\
\hline 99.2 & 0.7593 & 1.4872 & 1.5115 & 1.1699 & 1.1776 \\
\hline 206.6 & 0.7626 & 1.9546 & 2.0262 & 1.6873 & 1.7096 \\
\hline 401.2 & 0.7664 & 2.2399 & 2.4218 & 2.2749 & 2.3304 \\
\hline 604.8 & 0.7554 & 2.3056 & 2.6199 & 2.6666 & 2.7684 \\
\hline 806.5 & 0.7444 & 2.2674 & 2.7260 & 2.9487 & 3.1061 \\
\hline 1007.5 & 0.7269 & 2.2153 & 2.8218 & 3.0994 & 3.3273 \\
\hline 1204.2 & 0.7197 & 2.0631 & 2.8262 & 3.2517 & 3.5489 \\
\hline 1400.6 & 0.7074 & 1.9464 & 2.8682 & 3.3096 & 3.6907 \\
\hline 1601.4 & 0.6996 & 1.7877 & 2.8838 & 3.3773 & 3.8480 \\
\hline 1800.4 & 0.6882 & 1.6738 & 2.9376 & 3.3436 & 3.9162 \\
\hline
\end{tabular}


Table 13. Methane/Carbon Dioxide Adsorption on Dry Activated Carbon at $113^{\circ} \mathrm{F}$-continued

\begin{tabular}{|c|c|c|c|c|c|}
\hline \multirow[t]{2}{*}{$\begin{array}{l}\text { Pressure } \\
\text { (psia) }\end{array}$} & \multirow[t]{2}{*}{$\begin{array}{l}\text { Methane Gas } \\
\text { Mole Fraction }\end{array}$} & \multicolumn{2}{|c|}{$\begin{array}{l}\text { Methane Adsorption } \\
\text { (mmol/g AC) }\end{array}$} & \multicolumn{2}{|c|}{$\begin{array}{l}\text { Carbon Dioxide } \\
\text { Adsorption } \\
\text { (mmol/g AC) }\end{array}$} \\
\hline & & Gibbs & Absolute & Gibbs & Absolute \\
\hline \multicolumn{6}{|c|}{ Methane Feed Composition: $40.1 \%$} \\
\hline 98.3 & 0.5964 & 1.0588 & 1.0798 & 1.9070 & 1.9212 \\
\hline 209.0 & 0.5938 & 1.3512 & 1.4142 & 2.7123 & 2.7554 \\
\hline 398.6 & 0.6025 & 1.4356 & 1.5937 & 3.5672 & 3.6716 \\
\hline 606.2 & 0.5818 & 1.4032 & 1.6760 & 4.1068 & 4.3029 \\
\hline 804.0 & 0.5604 & 1.3304 & 1.7202 & 4.4255 & 4.7313 \\
\hline 1001.1 & 0.5479 & 1.1892 & 1.7096 & 4.6800 & 5.1095 \\
\hline 1202.8 & 0.5285 & 1.0770 & 1.7307 & 4.7692 & 5.3524 \\
\hline 1405.7 & 0.5134 & 0.9401 & 1.7391 & 4.8048 & 5.5621 \\
\hline 1596.6 & 0.4995 & 0.8204 & 1.7605 & 4.7543 & 5.6963 \\
\hline 1802.9 & 0.4862 & 0.6994 & 1.7984 & 4.6408 & 5.8023 \\
\hline \multicolumn{6}{|c|}{ Methane Feed Composition: $20.0 \%$} \\
\hline 98.9 & 0.3906 & 0.5581 & 0.5741 & 2.8761 & 2.9012 \\
\hline 195.3 & 0.3818 & 0.6574 & 0.6995 & 3.8653 & 3.9335 \\
\hline 398.9 & 0.3657 & 0.6479 & 0.7580 & 4.9912 & 5.1822 \\
\hline 611.2 & 0.3397 & 0.5800 & 0.7666 & 5.5878 & 5.950 \\
\hline 809.1 & 0.3230 & 0.4745 & 0.7411 & 5.9204 & 6.4790 \\
\hline 1007.9 & 0.3017 & 0.4000 & 0.7467 & 6.0182 & 6.8209 \\
\hline 1206.3 & 0.2856 & 0.2991 & 0.7350 & 5.9836 & 7.0740 \\
\hline 1401.6 & 0.2702 & 0.2037 & 0.7302 & 5.7622 & 7.1841 \\
\hline 1595.3 & 0.2563 & 0.1593 & 0.8032 & 5.5559 & 7.4241 \\
\hline 1800.3 & 0.2441 & 0.1057 & 0.8797 & 5.1616 & 7.5588 \\
\hline
\end{tabular}


Table 14. Universal Constants of PGR Equation of State

\begin{tabular}{|l|l|}
\hline Constants & Value \\
\hline$\tau$ & 0.74048 \\
\hline$U$ & -2.8969 \\
\hline$W$ & 2.6944 \\
\hline$Q_{1}$ & 10.5121 \\
\hline$Q_{2}$ & 1.0226 \\
\hline$Z_{M}$ & 0.47547 \\
\hline$\omega_{1}$ & 0.076354 \\
\hline$\omega_{2}$ & 2.0124 \\
\hline$\omega_{3}$ & -0.22322 \\
\hline$\omega_{4}$ & -0.70301 \\
\hline
\end{tabular}

Table 15. Pure Fluid Parameters for PGR Equation of State [15]

\begin{tabular}{|l|l|}
\hline Component & $\mathrm{T}^{*}(\mathrm{~K})$ \\
\hline Methane & 81.287 \\
\hline Nitrogen & 51.373 \\
\hline Carbon Dioxide & 111.31 \\
\hline
\end{tabular}


Table 16. Equations for the Local Attractive Parameter a(z)

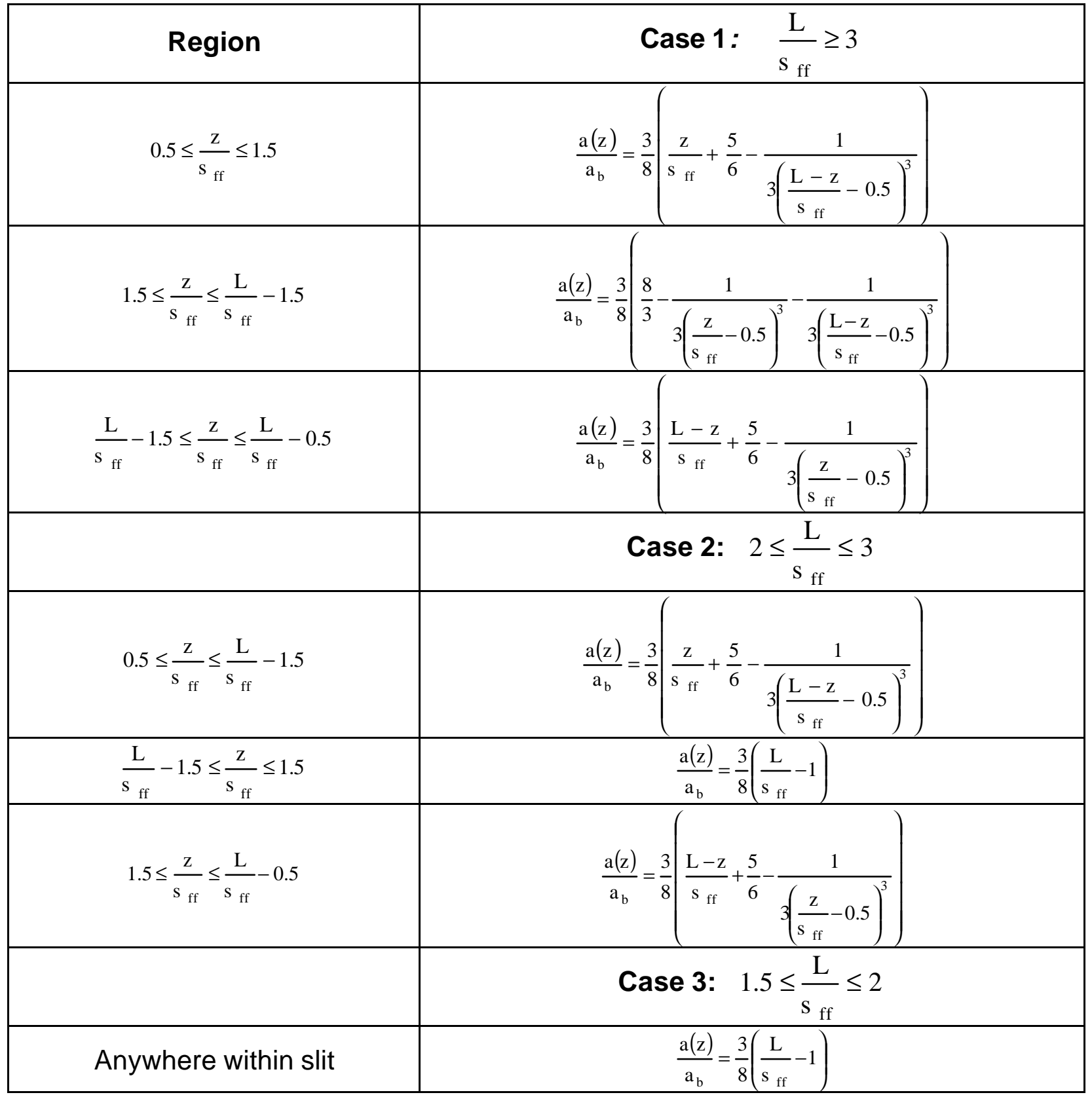

Table 17. SLD-PR Fluid Physical Parameters

\begin{tabular}{|l|c|c|c|c|}
\hline & $\begin{array}{c}\mathbf{T}_{\mathbf{c}} \\
\mathbf{K}\end{array}$ & $\begin{array}{c}\mathbf{P}_{\mathbf{c}} \\
\mathbf{M P a}\end{array}$ & $\begin{array}{c}\text { Fluid Diam. } \sigma_{\text {ff, }} \\
\mathbf{n m}\end{array}$ & $\begin{array}{c}\text { Acentric } \\
\text { Factor, } \omega\end{array}$ \\
\hline Nitrogen & 126.2 & 3.400 & 0.3798 & 0.038 \\
\hline Methane & 190.6 & 4.599 & 0.3758 & 0.012 \\
\hline CO $_{2}$ & 304.2 & 7.383 & 0.3941 & 0.224 \\
\hline Ethane & 305.3 & 4.872 & 0.4443 & 0.100 \\
\hline
\end{tabular}


Table 18. LRC Equation-of-State Representation of Pure Gas Adsorption ( $\eta=0.87$ )

\begin{tabular}{|c|c|c|c|c|c|}
\hline Component & $\begin{array}{c}\mathrm{L} \\
\text { (mmole/g coal) }\end{array}$ & $\begin{array}{c}\mathrm{Bx10}^{2} \\
\left(\mathrm{psia}^{-1}\right)\end{array}$ & $\begin{array}{c}\text { RMSE } \\
\text { (mmol/g coal) }\end{array}$ & \%AAD & NPTS \\
\hline \multicolumn{6}{|c|}{ Dry Activated Carbon at $113^{\circ} \mathrm{F}$} \\
\hline $\mathrm{CO}_{2}$ & 9.4592 & 1.4338 & 0.0872 & 1.22 & 33 \\
\hline $\mathrm{CH}_{4}$ & 6.0162 & 0.9674 & 0.0361 & 0.78 & 22 \\
\hline $\mathrm{N}_{2}$ & 5.0946 & 0.4439 & 0.0135 & 0.35 & 22 \\
\hline \multicolumn{6}{|c|}{ Wet Fruitland Coal at $115^{\circ} \mathrm{F}$} \\
\hline $\mathrm{CO}_{2}$ & 1.6170 & 0.7017 & 0.0421 & 3.67 & 20 \\
\hline $\mathrm{CH}_{4}$ & 1.1948 & 0.3642 & 0.0062 & 0.74 & 20 \\
\hline $\mathrm{N}_{2}$ & 1.0207 & 0.0936 & 0.0030 & 1.13 & 20 \\
\hline \multicolumn{6}{|c|}{ Wet Illinois- 6 Coal at $115^{\circ} \mathrm{F}$} \\
\hline $\mathrm{CO}_{2}$ & 1.6281 & 0.3471 & 0.0752 & 5.52 & 20 \\
\hline $\mathrm{CH}_{4}$ & 0.7188 & 0.2474 & 0.0058 & 1.54 & 20 \\
\hline $\mathrm{N}_{2}$ & 0.7496 & 0.0547 & 0.0032 & 3.10 & 20 \\
\hline \multicolumn{6}{|c|}{ Wet Lower Basin Fruitland Coal at $115^{\circ} \mathrm{F}$} \\
\hline $\mathrm{CO}_{2}$ & 0.6653 & 0.7985 & 0.0157 & 3.07 & 32 \\
\hline $\mathrm{CH}_{4}$ & 0.6178 & 0.2108 & 0.0087 & 2.71 & 16 \\
\hline $\mathrm{N}_{2}$ & 0.3947 & 0.0939 & 0.0047 & 3.63 & 17 \\
\hline
\end{tabular}


Table 19. LRC Equation-of-State Representation of Pure Gas Adsorption

\begin{tabular}{|c|c|c|c|c|c|c|}
\hline Comp. & $\begin{array}{c}\mathrm{L} \\
\text { (mmole/g coal) }\end{array}$ & $\begin{array}{l}{\mathrm{Bx} 10^{2}} \\
\left(\mathrm{psia}^{-1}\right)\end{array}$ & $\eta$ & $\begin{array}{c}\text { RMSE } \\
\text { (mmol/g coal) }\end{array}$ & \%AAD & NPTS \\
\hline \multicolumn{7}{|c|}{ Dry Activated Carbon at $113^{\circ} \mathrm{F}$} \\
\hline $\mathrm{CO}_{2}$ & 9.6877 & 1.6842 & 0.83 & 0.0797 & 1.07 & 33 \\
\hline $\mathrm{CH}_{4}$ & 6.2455 & 1.2696 & 0.80 & 0.0324 & 0.55 & 22 \\
\hline $\mathrm{N}_{2}$ & 5.1236 & 0.4513 & 0.87 & 0.0135 & 0.34 & 22 \\
\hline \multicolumn{7}{|c|}{ Wet Fruitland Coal at $115^{\circ} \mathrm{F}$} \\
\hline $\mathrm{CO}_{2}$ & 1.8942 & 0.8809 & 0.78 & 0.0349 & 3.32 & 20 \\
\hline $\mathrm{CH}_{4}$ & 1.2443 & 0.3896 & 0.85 & 0.0047 & 0.65 & 20 \\
\hline $\mathrm{N}_{2}$ & 0.9979 & 0.0945 & 0.87 & 0.0032 & 1.13 & 20 \\
\hline \multicolumn{7}{|c|}{ Wet Illinois-6 Coal at $115^{\circ} \mathrm{F}$} \\
\hline $\mathrm{CO}_{2}$ & 3.8241 & 0.5065 & 0.60 & 0.0459 & 2.66 & 20 \\
\hline $\mathrm{CH}_{4}$ & 0.9291 & 0.2549 & 0.86 & 0.0057 & 1.52 & 20 \\
\hline $\mathrm{N}_{2}$ & 0.6589 & 0.0546 & 0.89 & 0.0031 & 3.08 & 20 \\
\hline \multicolumn{7}{|c|}{ Wet Lower Basin Fruitland Coal at $115^{\circ} \mathrm{F}$} \\
\hline $\mathrm{CO}_{2}$ & 0.5794 & 0.2796 & 1.13 & 0.0119 & 2.26 & 32 \\
\hline $\mathrm{CH}_{4}$ & 1.1173 & 0.4126 & 0.64 & 0.0054 & 1.37 & 16 \\
\hline $\mathrm{N}_{2}$ & 0.5366 & 0.0909 & 0.81 & 0.0041 & 3.24 & 17 \\
\hline
\end{tabular}


Table 20. ZGR Equation-of-State Representation of Pure Gas Adsorption

\begin{tabular}{|c|c|c|c|c|c|c|}
\hline Component & $\alpha$ & $\beta$ & $-\ln k$ & $\begin{array}{c}\text { RMSE } \\
\text { (mmol/g coal) }\end{array}$ & \%AAD & NPTS \\
\hline \multicolumn{7}{|c|}{ Dry Activated Carbon at $113^{\circ} \mathrm{F}$} \\
\hline $\mathrm{CO}_{2}$ & 5726 & 0.0539 & -2.08 & 0.0801 & 1.07 & 33 \\
\hline $\mathrm{CH}_{4}$ & 9902 & 0.0907 & -1.20 & 0.0402 & 0.70 & 22 \\
\hline $\mathrm{N}_{2}$ & 13580 & 0.1142 & 0.02 & 0.0144 & 0.38 & 22 \\
\hline \multicolumn{7}{|c|}{ Wet Fruitland Coal at $115^{\circ} \mathrm{F}$} \\
\hline $\mathrm{CO}_{2}$ & 992 & 0.0936 & 0.85 & 0.0338 & 3.15 & 20 \\
\hline $\mathrm{CH}_{4}$ & 50181 & 0.4335 & 1.70 & 0.0052 & 0.74 & 20 \\
\hline $\mathrm{N}_{2}$ & 125240 & 0.8912 & 3.46 & 0.0032 & 1.86 & 20 \\
\hline \multicolumn{7}{|c|}{ Wet Illinois- 6 Coal at $115^{\circ} \mathrm{F}$} \\
\hline $\mathrm{CO}_{2}$ & 10783 & 0.1219 & 1.79 & 0.0881 & 5.42 & 20 \\
\hline $\mathrm{CH}_{4}$ & 100360 & 0.8000 & 2.69 & 0.0060 & 1.65 & 20 \\
\hline $\mathrm{N}_{2}$ & 313530 & 2.0045 & 4.42 & 0.0046 & 3.78 & 20 \\
\hline \multicolumn{7}{|c|}{ Wet Lower Basin Fruitland Coal at $115^{\circ} \mathrm{F}$} \\
\hline $\mathrm{CO}_{2}$ & 127970 & 0.9113 & 1.65 & 0.0119 & 2.27 & 32 \\
\hline $\mathrm{CH}_{4}$ & 20022 & 0.3404 & 3.14 & 0.0043 & 1.62 & 16 \\
\hline $\mathrm{N}_{2}$ & 79183 & 0.7287 & 4.69 & 0.0035 & 2.89 & 17 \\
\hline
\end{tabular}


Table 21. PGR Equation-of-State Representation of Pure Gas Adsorption

\begin{tabular}{|c|c|c|c|c|c|c|}
\hline Component & $\mathbf{L}^{*}$ & C & $-\ln k$ & $\begin{array}{c}\text { RMSE } \\
\text { (mmol/g coal) }\end{array}$ & \%AAD & NPTS \\
\hline \multicolumn{7}{|c|}{ Dry Activated Carbon at $113^{\circ} \mathrm{F}$} \\
\hline $\mathrm{CO}_{2}$ & 0.0949 & 0.1638 & 0.001 & 0.2194 & 2.68 & 33 \\
\hline $\mathrm{CH}_{4}$ & 0.1164 & 0.3259 & 0.732 & 0.0855 & 1.66 & 22 \\
\hline $\mathrm{N}_{2}$ & 0.0690 & 1.0710 & 1.601 & 0.0177 & 0.46 & 22 \\
\hline \multicolumn{7}{|c|}{ Wet Fruitland Coal at $115^{\circ} \mathrm{F}$} \\
\hline $\mathrm{CO}_{2}$ & 0.5216 & 0.3202 & 2.359 & 0.0311 & 3.01 & 20 \\
\hline $\mathrm{CH}_{4}$ & 0.4212 & 0.8672 & 3.290 & 0.0051 & 0.78 & 20 \\
\hline $\mathrm{N}_{2}$ & 0.3934 & 0.9346 & 4.977 & 0.0042 & 2.14 & 20 \\
\hline \multicolumn{7}{|c|}{ Wet Illinois-6 Coal at $115^{\circ} \mathrm{F}$} \\
\hline $\mathrm{CO}_{2}$ & 0.3381 & 1.6200 & 2.802 & 0.0172 & 1.47 & 20 \\
\hline $\mathrm{CH}_{4}$ & 0.7949 & 0.7076 & 4.273 & 0.0059 & 1.93 & 20 \\
\hline $\mathrm{N}_{2}$ & 1.0470 & 0.5197 & 5.811 & 0.0038 & 3.87 & 20 \\
\hline \multicolumn{7}{|c|}{ Wet Lower Basin Fruitland Coal at $115^{\circ} \mathrm{F}$} \\
\hline $\mathrm{CO}_{2}$ & 1.5860 & 0.1113 & 3.362 & 0.0268 & 4.90 & 32 \\
\hline $\mathrm{CH}_{4}$ & 0.8515 & $1.0000^{*}$ & 4.419 & 0.0080 & 2.43 & 16 \\
\hline $\mathrm{N}_{2}$ & 0.9657 & 0.7626 & 6.066 & 0.0043 & 3.46 & 17 \\
\hline
\end{tabular}

* Reached the regression limit 
Table 22. ZGR Equation-of-State Representation of Pure Gas Gibbs Adsorption

\begin{tabular}{|c|c|c|c|c|c|c|c|}
\hline Comp. & $\alpha$ & $\beta$ & $\begin{array}{c}\rho_{\mathrm{a}} \\
(\mathrm{g} / \mathrm{cc})\end{array}$ & $-\ln \mathbf{k}$ & $\begin{array}{c}\text { RMSE } \\
\text { (mmol/g coal) }\end{array}$ & \%AAD & NPTS \\
\hline \multicolumn{8}{|c|}{ Dry Activated Carbon at $113^{\circ} \mathrm{F}$} \\
\hline $\mathrm{CO}_{2}$ & 4041 & 0.0460 & 0.982 & -2.20 & 0.0776 & 1.27 & 50 \\
\hline $\mathrm{CH}_{4}$ & 8017 & 0.0805 & 0.346 & -1.23 & 0.0220 & 0.45 & 22 \\
\hline $\mathrm{N}_{2}$ & 13870 & 0.1152 & 0.839 & 0.03 & 0.0135 & 0.37 & 22 \\
\hline \multicolumn{8}{|c|}{ Wet Illinois- 6 Coal at $115^{\circ} \mathrm{F}$} \\
\hline $\mathrm{CO}_{2}$ & 9020 & 0.1386 & 1.694 & 1.62 & 0.0126 & 1.46 & 20 \\
\hline $\mathrm{CH}_{4}$ & 116910 & 0.9136 & 0.567 & 2.66 & 0.0048 & 1.50 & 20 \\
\hline $\mathrm{N}_{2}$ & 305350 & 1.959 & 0.808 & 4.42 & 0.0031 & 3.32 & 20 \\
\hline
\end{tabular}


Table 23. SLD Model of Carbon Dioxide on Activated Carbon at $113^{\circ} \mathrm{F}$

\begin{tabular}{|c|c|c|c|c|}
\hline \multirow{2}{*}{$\begin{array}{c}\text { SLD Model } \\
\text { Parameters }\end{array}$} & \multicolumn{4}{|c|}{ SLD Model Options } \\
\cline { 2 - 5 } & Original & Length & Covolume & Low Pressure \\
\hline & 48.8 & 85.9 & 81.8 & 79.0 \\
\hline $\mathrm{e}_{\mathrm{fs}} / \mathrm{k}(\mathrm{K})$ & 1744 & 676 & 1094 & 747 \\
\hline $\mathrm{SA}\left(\mathrm{m}^{2}\right)$ & 0.60 & 1.17 & 1.16 & 0.99 \\
\hline $\mathrm{L}(\mathrm{nm})$ & 0 & -24.0 & 0 & 0 \\
\hline $\mathrm{L}_{\mathrm{s}}\left(\mathrm{cm}^{3} / \mathrm{mol}\right)$ & 1.00 & 1.00 & 1.54 & 1.00 \\
\hline $\mathrm{b}_{\text {mod }} / \mathrm{b}_{\text {original }}$ & \multicolumn{5}{|c|}{} \\
\hline \multicolumn{5}{|l|}{} \\
\hline $\mathrm{NPTS}$ & 52 & 52 & 52 & 25 \\
\hline$\%$ AAD & 14.9 & 3.8 & 2.2 & 1.3 \\
\hline
\end{tabular}

Table 24. SLD Model of Ethane on Activated Carbon at $113^{\circ} \mathrm{F}$

\begin{tabular}{|c|c|c|c|c|}
\hline \multirow{2}{*}{$\begin{array}{c}\text { SLD Model } \\
\text { Parameters }\end{array}$} & \multicolumn{4}{|c|}{ SLD Model Options } \\
\cline { 2 - 5 } & Original & Length & Covolume & Low Pressure \\
\hline & \multicolumn{5}{|c|}{} \\
\hline $\mathrm{e}_{\mathrm{fs}} / \mathrm{k}(\mathrm{K})$ & 180.0 & 104 & 179.6 & 180.0 \\
\hline $\mathrm{SA}\left(\mathrm{m}^{2}\right)$ & 999 & 606 & 648 & 393 \\
\hline $\mathrm{L}(\mathrm{nm})$ & 0.69 & 1.24 & 1.56 & 1.49 \\
\hline $\mathrm{L}_{\mathrm{s}}\left(\mathrm{cm}^{3} / \mathrm{mol}\right)$ & 0 & -34.4 & 0 & 0 \\
\hline $\mathrm{b}_{\text {mod }} / \mathrm{b}_{\text {original }}$ & 1.00 & 1.00 & 1.59 & 1.00 \\
\hline & \multicolumn{5}{|l}{} \\
\hline $\mathrm{NPTS}$ & 21 & 21 & 21 & 7 \\
\hline$\% \mathrm{AAD}$ & 29.7 & 6.6 & 5.6 & 2.1 \\
\hline
\end{tabular}


Table 25. SLD Model of Methane on Activated Carbon at $113^{\circ} \mathrm{F}$

\begin{tabular}{|c|c|c|c|}
\hline \multirow{2}{*}{$\begin{array}{c}\text { SLD Model } \\
\text { Parameters }\end{array}$} & \multicolumn{3}{|c|}{ SLD Model Options } \\
\cline { 2 - 4 } & Original & Length & Covolume \\
\hline & \multicolumn{3}{|c|}{} \\
\hline $\mathrm{e}_{\mathrm{fs}} / \mathrm{k}(\mathrm{K})$ & 75.1 & 80.4 & 76.5 \\
\hline $\mathrm{SA}\left(\mathrm{m}^{2}\right)$ & 565 & 521 & 702 \\
\hline $\mathrm{L}(\mathrm{nm})$ & 0.92 & 1.01 & 1.04 \\
\hline $\mathrm{L}_{\mathrm{s}}\left(\mathrm{cm}^{3} / \mathrm{mol}\right)$ & 0 & -8.5 & 0 \\
\hline $\mathrm{b}_{\text {mod }} / \mathrm{b}_{\text {original }}$ & 1.0 & 1.0 & 1.34 \\
\hline $\mathrm{NPTS}$ & & & 22 \\
\hline$\% \mathrm{AAD}$ & 22 & 22 & 0.54 \\
\hline
\end{tabular}

Table 26. SLD Model of Nitrogen on Activated Carbon at $113^{\circ} \mathrm{F}$

\begin{tabular}{|c|c|c|c|}
\hline \multirow{2}{*}{$\begin{array}{c}\text { SLD Model } \\
\text { Parameters }\end{array}$} & \multicolumn{3}{|c|}{ SLD Model Options } \\
\cline { 2 - 4 } & None & Length & Covolume \\
\hline & 57.5 & 61.2 & 56.4 \\
\hline $\mathrm{e}_{\mathrm{fs}} / \mathrm{k}(\mathrm{K})$ & 459 & 424 & 606 \\
\hline $\mathrm{SA}\left(\mathrm{m}^{2}\right)$ & 0.89 & 0.99 & 1.11 \\
\hline $\mathrm{L}\left(\mathrm{nm}^{3}\right)$ & 0 & -13.0 & 0 \\
\hline $\mathrm{L}_{\mathrm{s}}\left(\mathrm{cm}^{3} / \mathrm{mol}\right)$ & 1.00 & 1.00 & 1.48 \\
\hline $\mathrm{b}_{\text {mod }} / \mathrm{b}_{\text {original }}$ & & & 22 \\
\hline $\mathrm{NPTS}$ & 22 & 22 & 0.33 \\
\hline$\% \mathrm{AAD}$ & 0.48 & 0.33 & \\
\hline & & & \\
\hline
\end{tabular}


Table 27. Regression Results for the Slit Form of the SLD Adsorption Model Using a Modified Covolume

\begin{tabular}{|c|c|c|c|}
\hline \multirow[t]{2}{*}{ Model Parameters } & \multicolumn{3}{|c|}{ Pure Gas Adsorbed } \\
\hline & Nitrogen & Methane & $\mathrm{CO}_{2}$ \\
\hline \multicolumn{4}{|l|}{ Activated Carbon } \\
\hline $\mathrm{e}_{\mathrm{fs}} / \mathrm{k}(\mathrm{K})$ & 52 & 71 & 85 \\
\hline $\mathrm{SA}\left(\mathrm{m}^{2}\right)$ & 733 & 877 & 1154 \\
\hline $\mathrm{L}(\mathrm{nm})$ & 1.11 & 1.11 & 1.11 \\
\hline$b_{\text {mod }} / b_{\text {original }}$ & 1.63 & 1.56 & 1.63 \\
\hline NPTS & 22 & 22 & 52 \\
\hline $\mathrm{AAD}(\%)$ & 0.9 & 1.6 & 2.3 \\
\hline \multicolumn{4}{|l|}{ Wet Fruitland Coal } \\
\hline $\mathrm{e}_{\mathrm{fs}} / \mathrm{k}(\mathrm{K})$ & 33 & 53 & 59 \\
\hline $\mathrm{SA}\left(\mathrm{m}^{2}\right)$ & 59 & 87 & 120 \\
\hline $\mathrm{L}(\mathrm{nm})$ & 1.12 & 1.12 & 1.12 \\
\hline$b_{\text {mod }} / b_{\text {original }}$ & 0.97 & 1.00 & 1.13 \\
\hline NPTS & 63 & 40 & 43 \\
\hline AAD (\%) & 9.5 & 1.1 & 8.5 \\
\hline \multicolumn{4}{|l|}{ Wet Illinois-6 Coal } \\
\hline $\mathrm{e}_{\mathrm{fs}} / \mathrm{k}(\mathrm{K})$ & 28 & 47 & 63 \\
\hline $\mathrm{SA}\left(\mathrm{m}^{2}\right)$ & 35 & 47 & 64 \\
\hline$L(n m)$ & 1.13 & 1.13 & 1.13 \\
\hline$b_{\text {mod }} / b_{\text {original }}$ & 0.76 & 0.77 & 0.85 \\
\hline NPTS & 20 & 20 & 20 \\
\hline AAD (\%) & 3.5 & 4.4 & 3.9 \\
\hline \multicolumn{4}{|l|}{ LB Fruitland Coal } \\
\hline $\mathrm{e}_{\mathrm{fs}} / \mathrm{k}(\mathrm{K})$ & 28 & 43 & 55 \\
\hline $\mathrm{SA}\left(\mathrm{m}^{2}\right)$ & 34 & 30 & 32 \\
\hline $\mathrm{L}(\mathrm{nm})$ & 0.87 & 0.87 & 0.87 \\
\hline $\mathrm{b}_{\text {mod }} / \mathrm{b}_{\text {original }}$ & 0.71 & 0.68 & 0.52 \\
\hline NPTS & 17 & 16 & 18 \\
\hline AAD (\%) & 5.5 & 3.6 & 4.1 \\
\hline
\end{tabular}


Table 28. ZGR Equation of State Representation of Binary Mixtures on Illinois-6 coal at $115^{\circ} \mathrm{F}$

\begin{tabular}{|c|c|c|c|c|c|c|}
\hline Mixture & \multicolumn{3}{|c|}{$\% A A D$} & \multicolumn{3}{|c|}{$\begin{array}{c}\text { RMSE } \\
\text { (mmole/g coal) }\end{array}$} \\
\hline \multicolumn{7}{|c|}{$C_{i j}=D_{i j}=0$} \\
\hline & $\omega_{1}$ & $\omega_{2}$ & Total & $\omega_{1}$ & $\omega_{2}$ & Total \\
\hline $\mathrm{CH}_{4} / \mathrm{N}_{2}$ & 20.04 & 32.14 & 7.48 & 0.0208 & 0.0116 & 0.0131 \\
\hline $\mathrm{CH}_{4} / \mathrm{CO}_{2}$ & 27.55 & 16.08 & 8.00 & 0.0341 & 0.0684 & 0.0510 \\
\hline $\mathrm{N}_{2} / \mathrm{CO}_{2}$ & 79.82 & 9.50 & 6.27 & 0.0465 & 0.0551 & 0.0321 \\
\hline \multicolumn{7}{|c|}{ Regressed $C_{i j}\left(D_{i j}=0\right)$} \\
\hline & $\omega_{1}$ & $\omega_{2}$ & Total & $\omega_{1}$ & $\omega_{2}$ & Total \\
\hline $\mathrm{CH}_{4} / \mathrm{N}_{2}$ & 17.58 & 18.30 & 4.80 & 0.0239 & 0.0058 & 0.0107 \\
\hline $\mathrm{CH}_{4} / \mathrm{CO}_{2}$ & 24.11 & 13.17 & 7.98 & 0.0373 & 0.0661 & 0.0499 \\
\hline $\mathrm{N}_{2} / \mathrm{CO}_{2}$ & 18.30 & 8.91 & 4.67 & 0.0093 & 0.0521 & 0.0310 \\
\hline \multicolumn{7}{|c|}{ Regressed $\mathrm{D}_{\mathrm{ij}}\left(\mathrm{C}_{\mathrm{ij}}=\mathbf{0}\right)$} \\
\hline & $\omega_{1}$ & $\omega_{2}$ & Total & $\omega_{1}$ & $\omega_{2}$ & Total \\
\hline $\mathrm{CH}_{4} / \mathrm{N}_{2}$ & 17.61 & 18.22 & 4.75 & 0.0241 & 0.0058 & 0.0110 \\
\hline $\mathrm{CH}_{4} / \mathrm{CO}_{2}$ & 15.62 & 11.59 & 7.54 & 0.0300 & 0.0624 & 0.0490 \\
\hline $\mathrm{N}_{2} / \mathrm{CO}_{2}$ & 53.57 & 10.08 & 5.15 & 0.0221 & 0.0554 & 0.0297 \\
\hline \multicolumn{7}{|c|}{ Regressed $C_{i j}$ and $D_{i j}$} \\
\hline & $\omega_{1}$ & $\omega_{2}$ & Total & $\omega_{1}$ & $\omega_{2}$ & Total \\
\hline $\mathrm{CH}_{4} / \mathrm{N}_{2}$ & 17.63 & 14.79 & 4.71 & 0.0241 & 0.0055 & 0.0115 \\
\hline $\mathrm{CH}_{4} / \mathrm{CO}_{2}$ & 10.78 & 7.56 & 3.54 & 0.0159 & 0.0378 & 0.0242 \\
\hline $\mathrm{N}_{2} / \mathrm{CO}_{2}$ & 13.98 & 5.76 & 2.87 & 0.0051 & 0.0383 & 0.0224 \\
\hline
\end{tabular}


Table 29. LRC Representation of Binary Mixtures on Illinois- 6 coal at $115^{\circ} \mathrm{F}$

\begin{tabular}{|c|c|c|c|c|c|c|}
\hline Mixture & \multicolumn{3}{|c|}{$\% A A D$} & \multicolumn{3}{|c|}{$\begin{array}{c}\text { RMSE } \\
\text { (mmole/g coal) } \\
\end{array}$} \\
\hline \multicolumn{7}{|c|}{ Parameters from Binary Data Regression } \\
\hline & $\omega_{1}$ & $\omega_{2}$ & Total & $\omega_{1}$ & $\omega_{2}$ & Total \\
\hline $\mathrm{CH}_{4} / \mathrm{N}_{2}$ & 7.35 & 14.80 & 6.17 & 0.0165 & 0.0054 & 0.0167 \\
\hline $\mathrm{CH}_{4} / \mathrm{CO}_{2}$ & 13.80 & 6.28 & 3.40 & 0.0183 & 0.0311 & 0.0205 \\
\hline $\mathrm{N}_{2} / \mathrm{CO}_{2}$ & 35.88 & 7.44 & 5.25 & 0.0235 & 0.0286 & 0.0187 \\
\hline \multicolumn{7}{|c|}{ Parameters from Pure Data Regression } \\
\hline & $\omega_{1}$ & $\omega_{2}$ & Total & $\omega_{1}$ & $\omega_{2}$ & Total \\
\hline $\mathrm{CH}_{4} / \mathrm{N}_{2}$ & 29.07 & 18.00 & 18.53 & 0.0334 & 0.0069 & 0.0375 \\
\hline $\mathrm{CH}_{4} / \mathrm{CO}_{2}$ & 48.24 & 12.94 & 3.82 & 0.0499 & 0.0452 & 0.0282 \\
\hline $\mathrm{N}_{2} / \mathrm{CO}_{2}$ & 53.32 & 13.29 & 11.15 & 0.0143 & 0.0716 & 0.0702 \\
\hline
\end{tabular}


Figure 1. Schematic Diagram of Experimental Apparatus

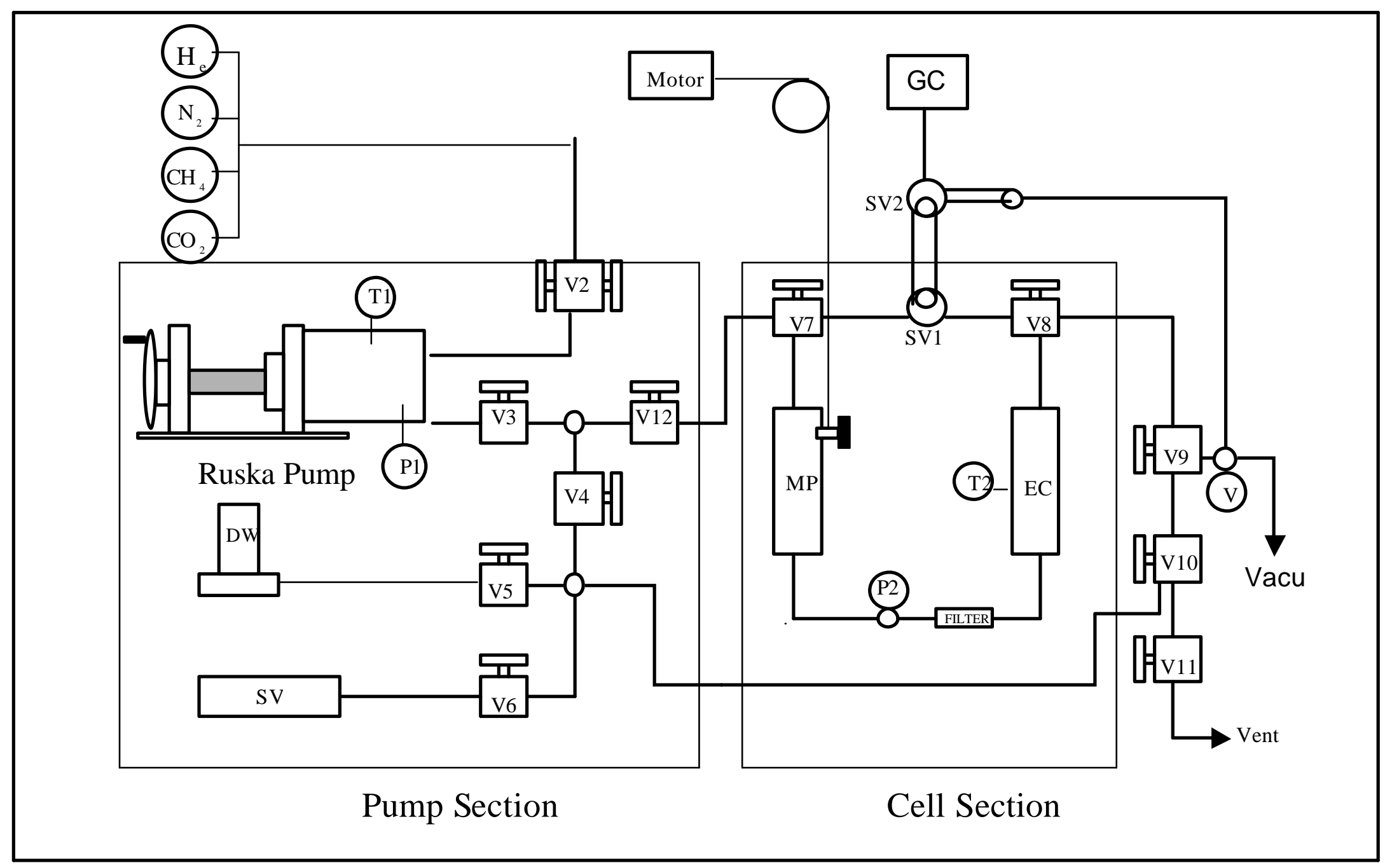


Figure 2. Gibbs Adsorption of Methane on Wet Lower Basin Fruitland Coal at $115^{\circ} \mathrm{F}$

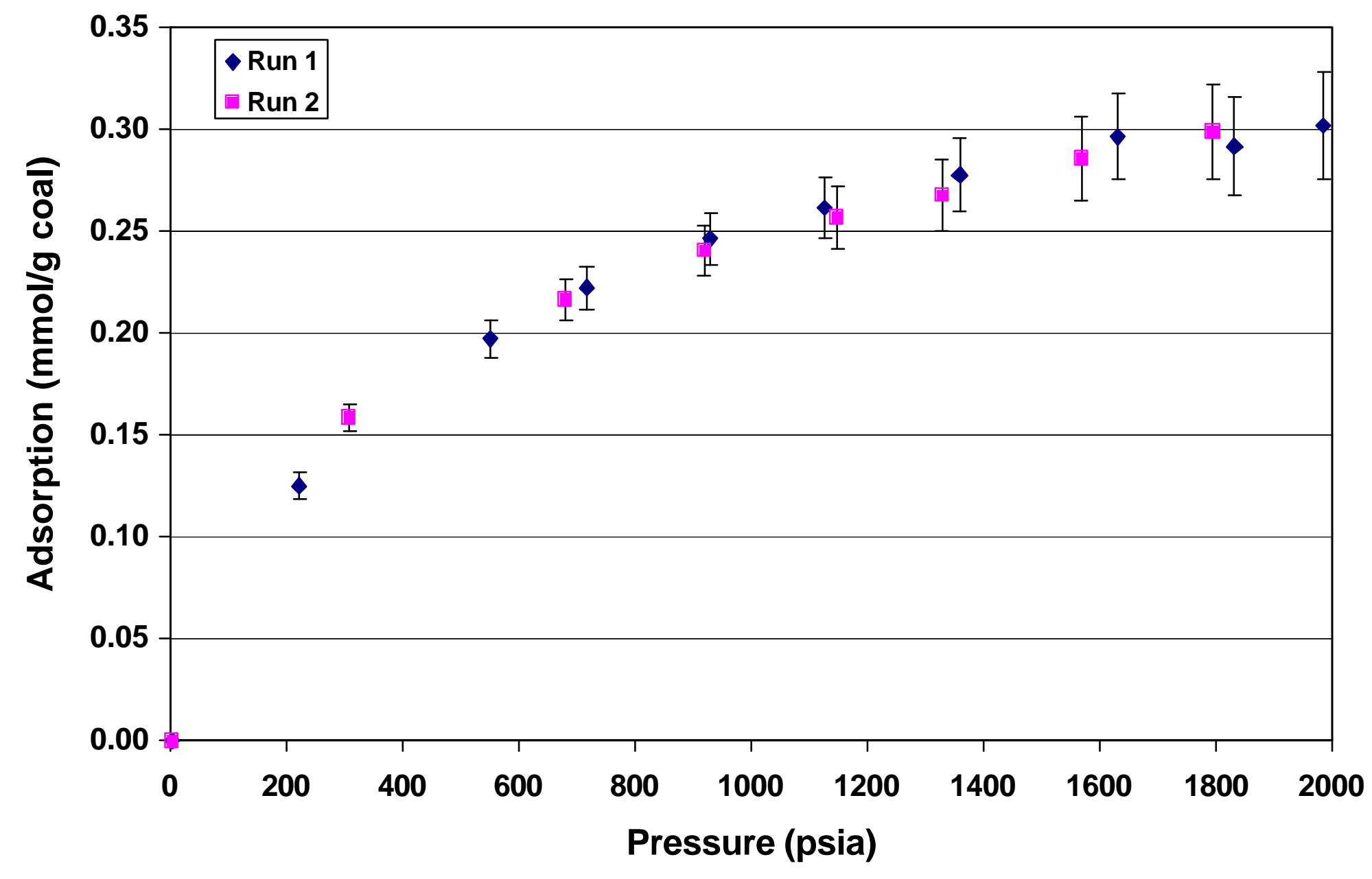


Figure 3. Absolute Adsorption of Methane on Wet Lower Basin Fruitland Coal at $115^{\circ} \mathrm{F}$

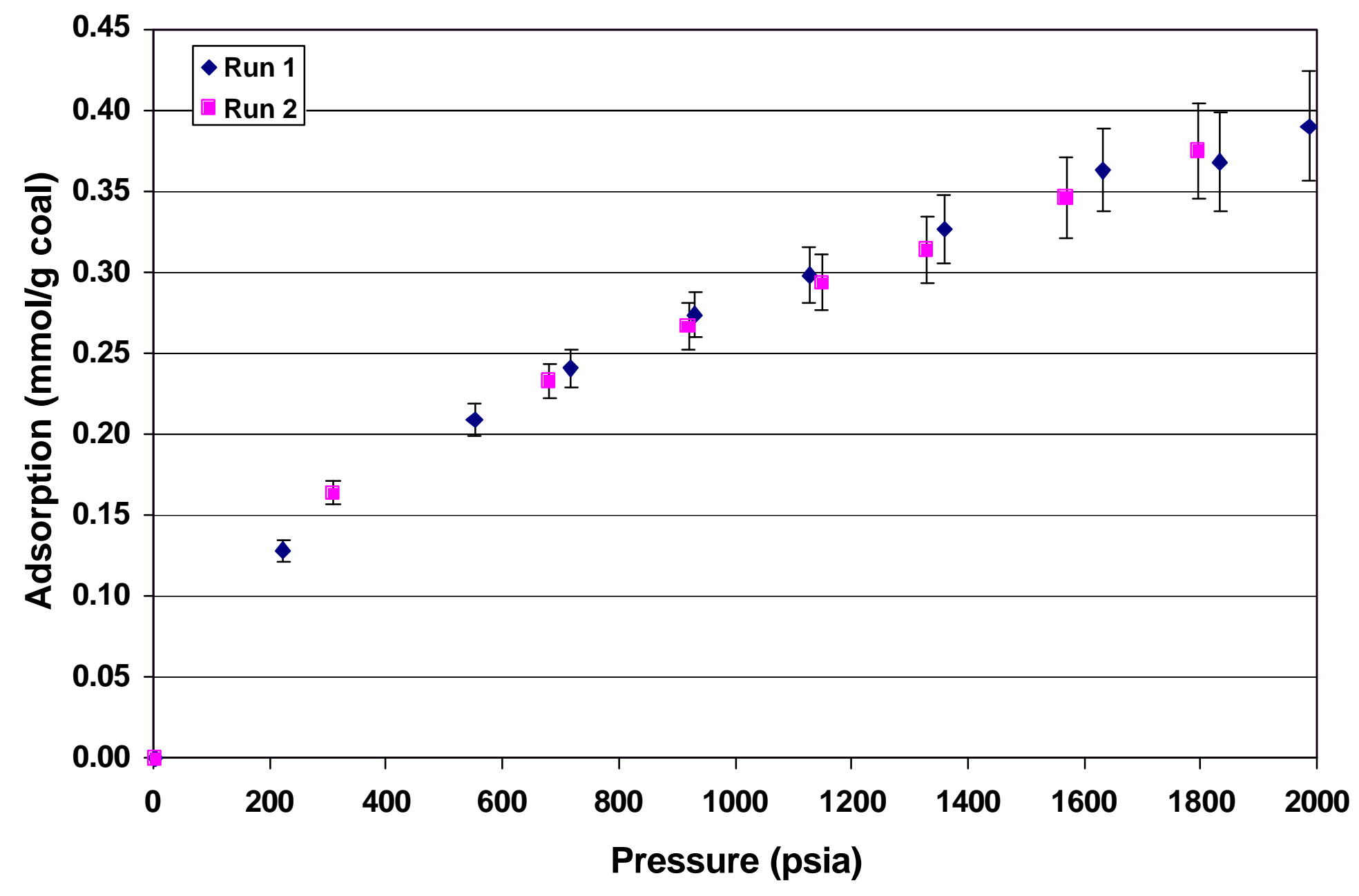


Figure 4. Gibbs Adsorption of Nitrogen on Wet Lower Basin Fruitland Coal at $115^{\circ} \mathrm{F}$

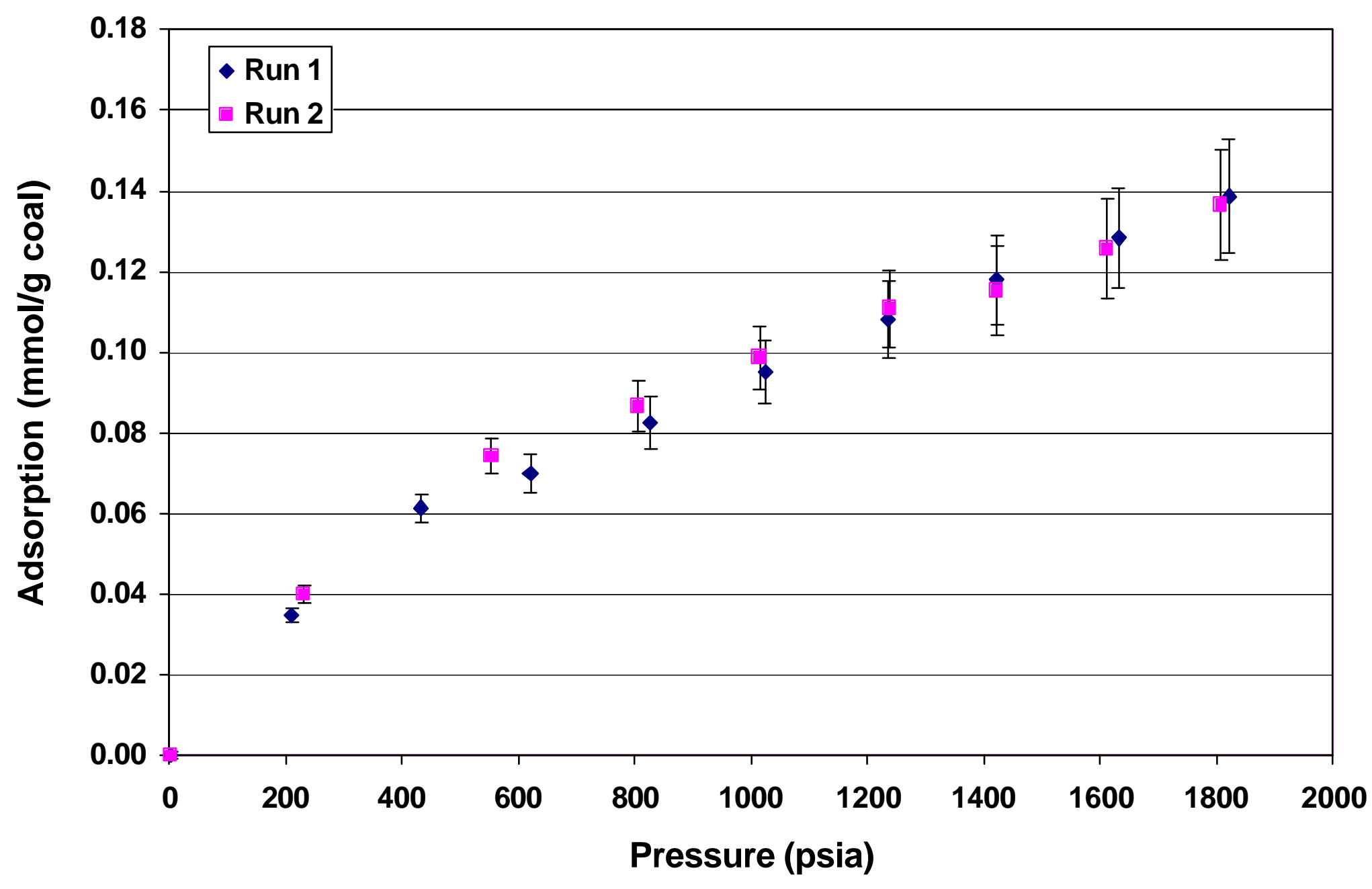


Figure 5. Absolute Adsorption of Nitrogen on Wet Lower Basin Fruitland Coal at $115^{\circ} \mathrm{F}$

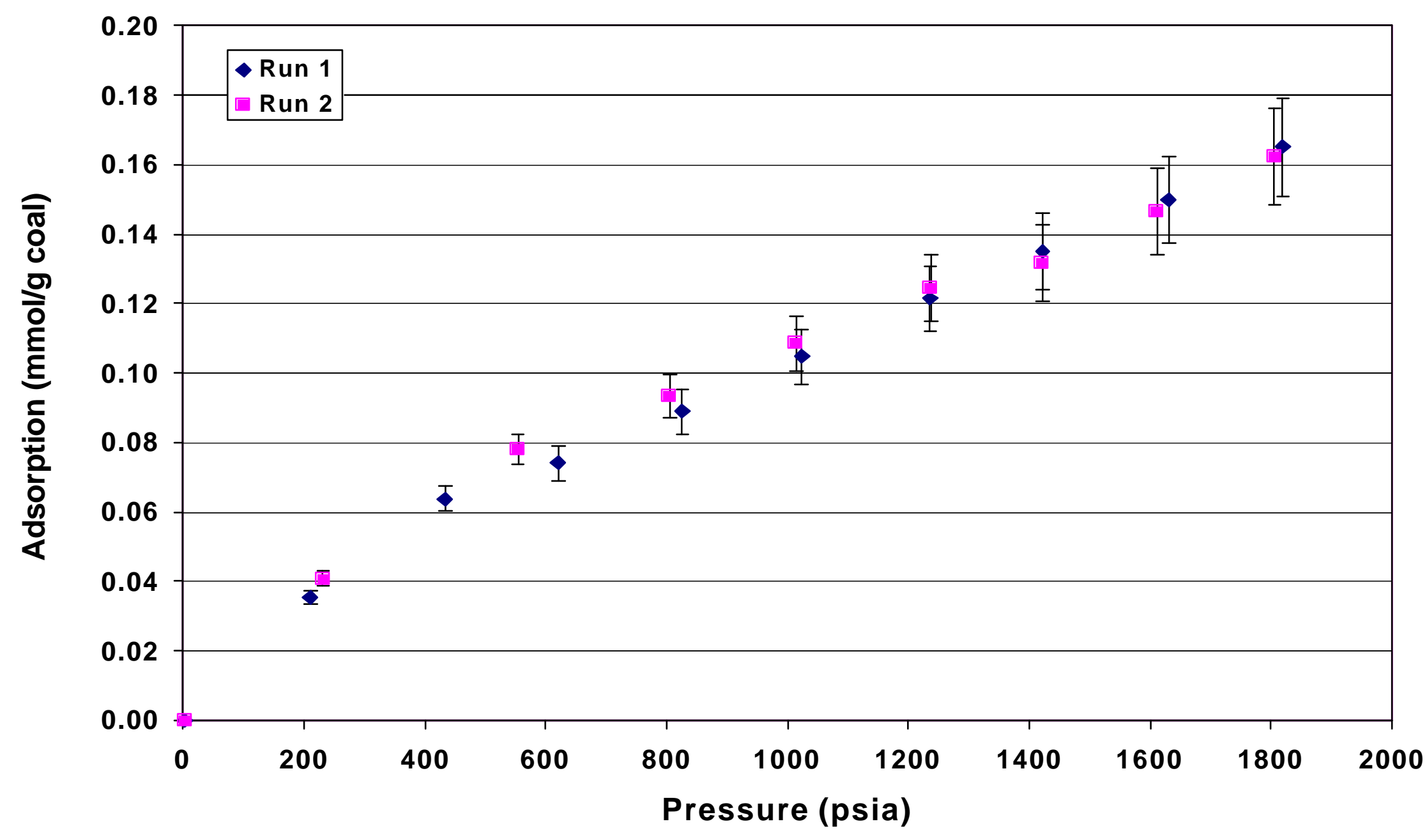


Figure 6. Gibbs Adsorption of Carbon Dioxide on Wet Lower Basin Fruitland Coal at $115^{\circ} \mathrm{F}$ (Wagner $Z$ Factors)

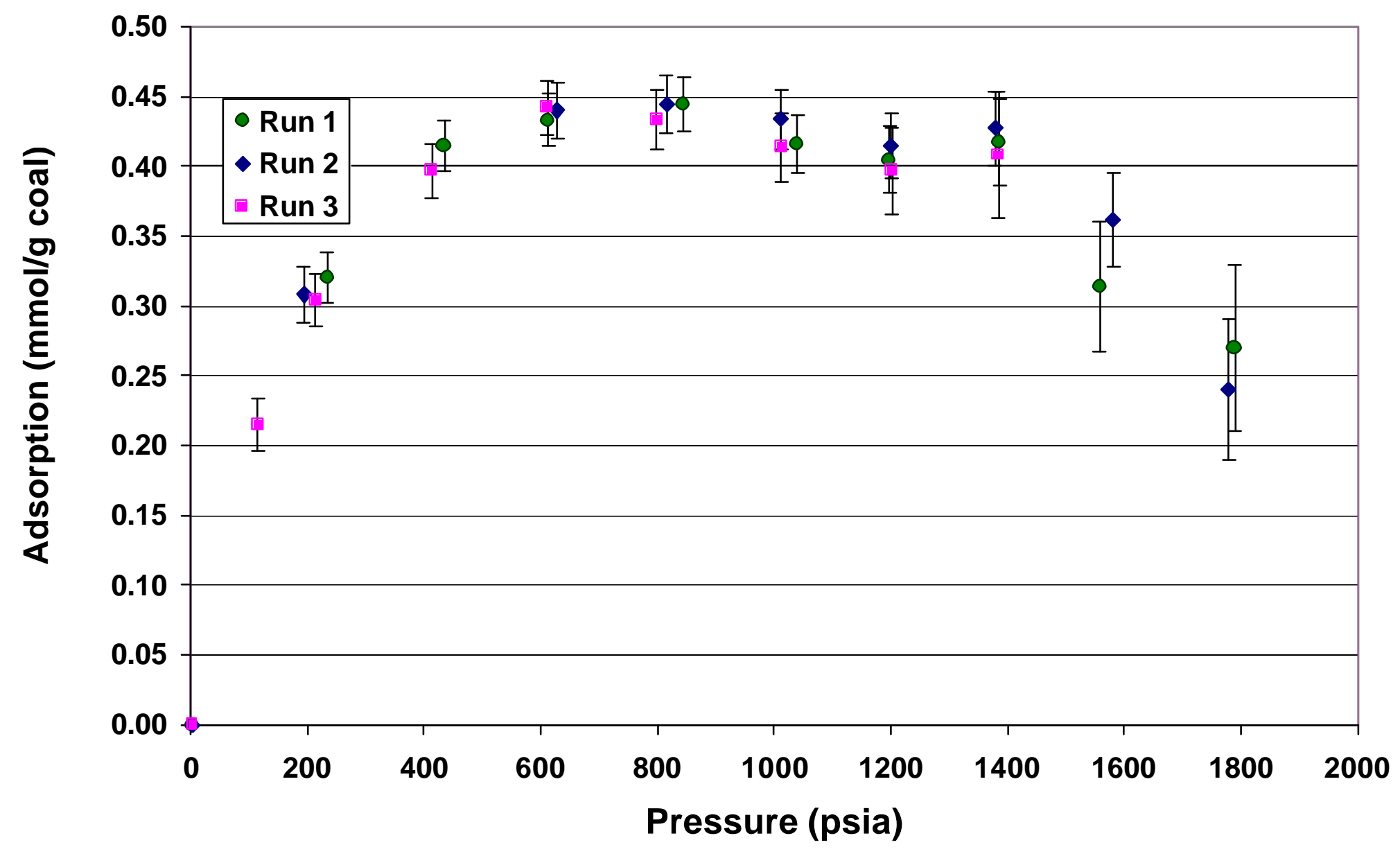


Figure 7. Gibbs Adsorption of Carbon Dioxide on Wet Lower Basin Fruitland Coal at $115^{\circ} \mathrm{F}$ (IUPAC Z Factors)

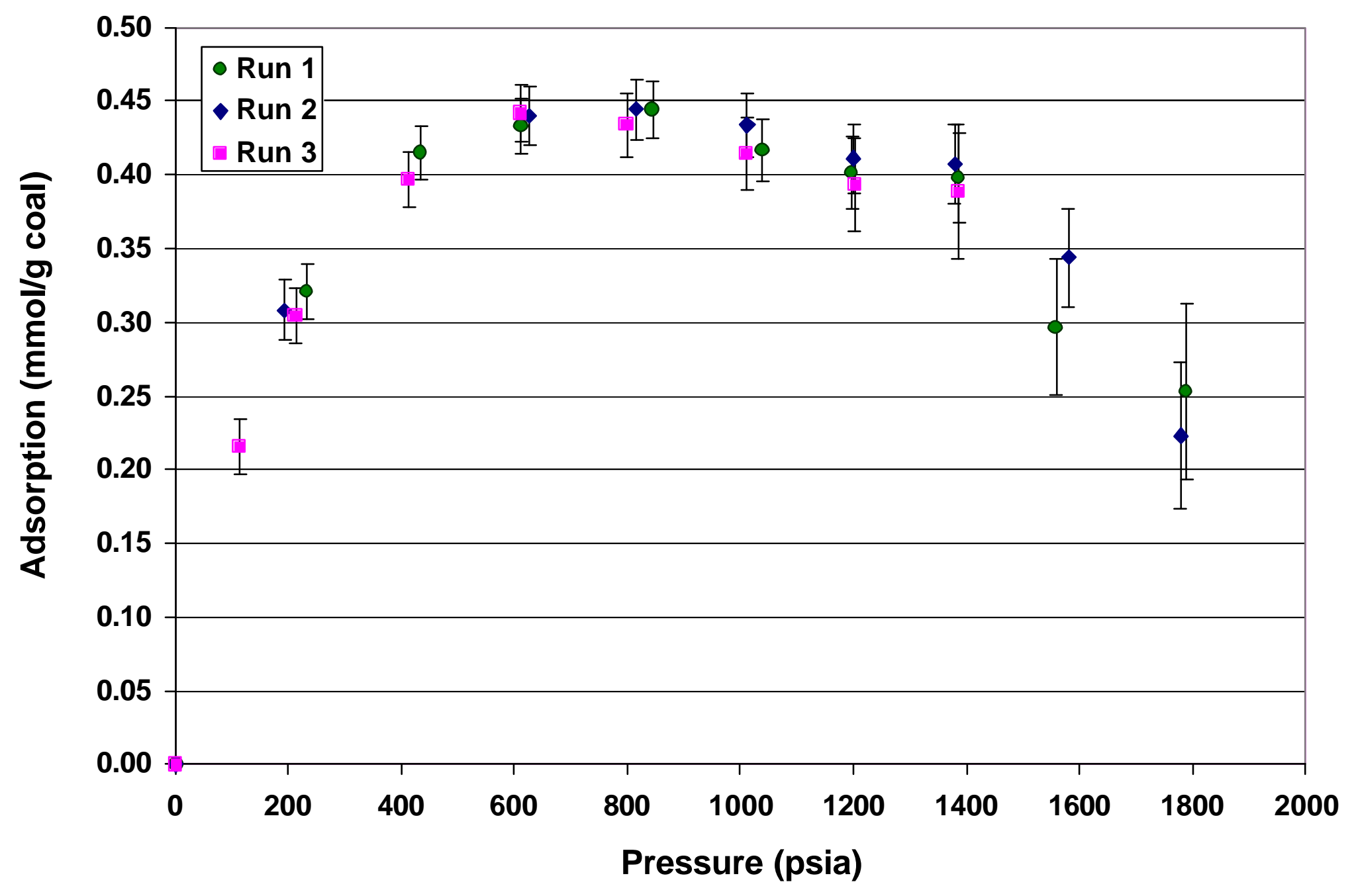


Figure 8. Gibbs Adsorption of Carbon Dioxide on Wet Lower Basin Fruitland Coal at $115^{\circ} \mathrm{F}$ (IUPAC Z Factors)

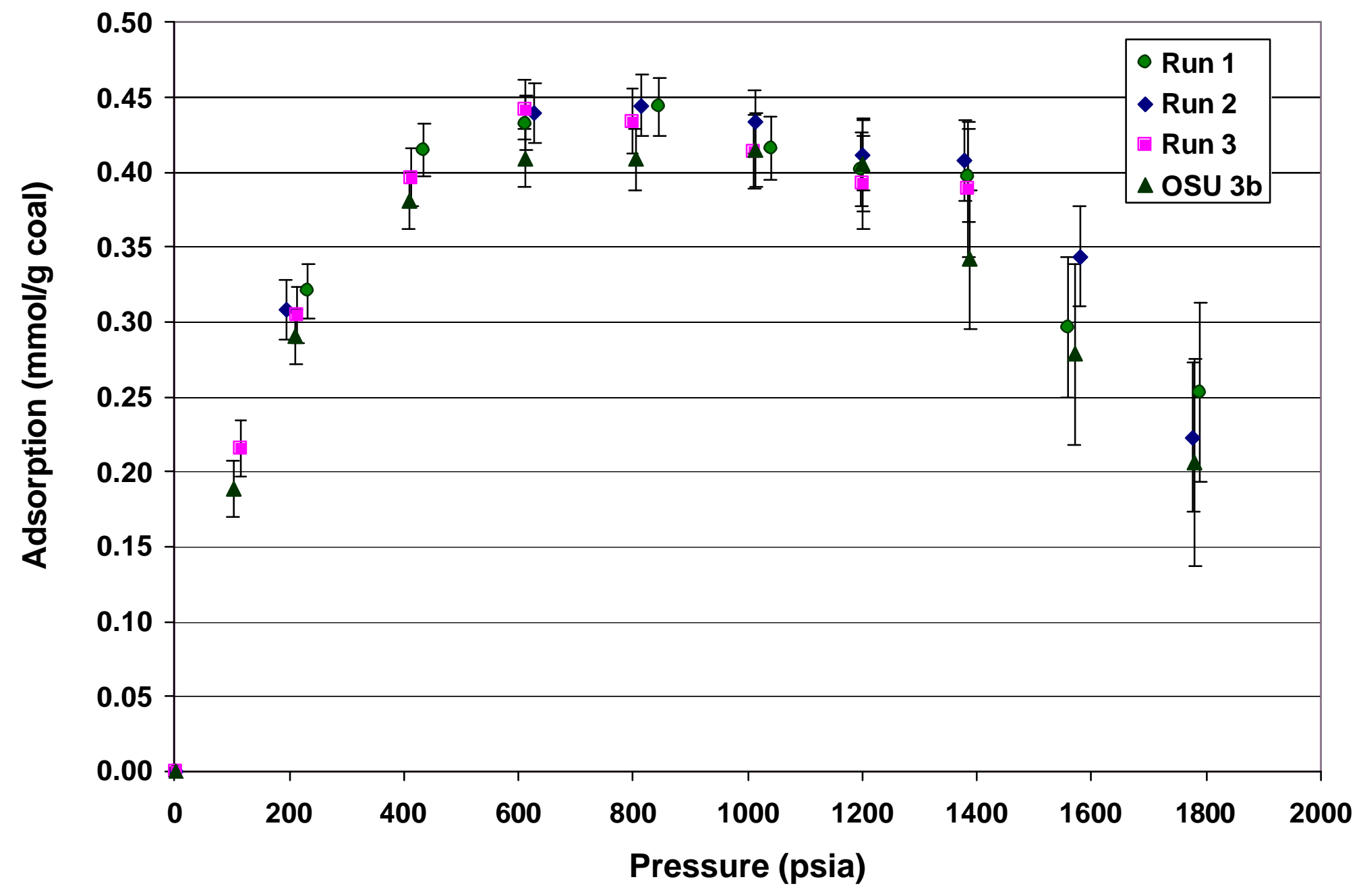


Figure 9. Gibbs Adsorption of Carbon Dioxide on Two Different Samples of Wet Lower Basin Fruitland Coal at $115^{\circ} \mathrm{F}$ (IUPAC Z Factors)

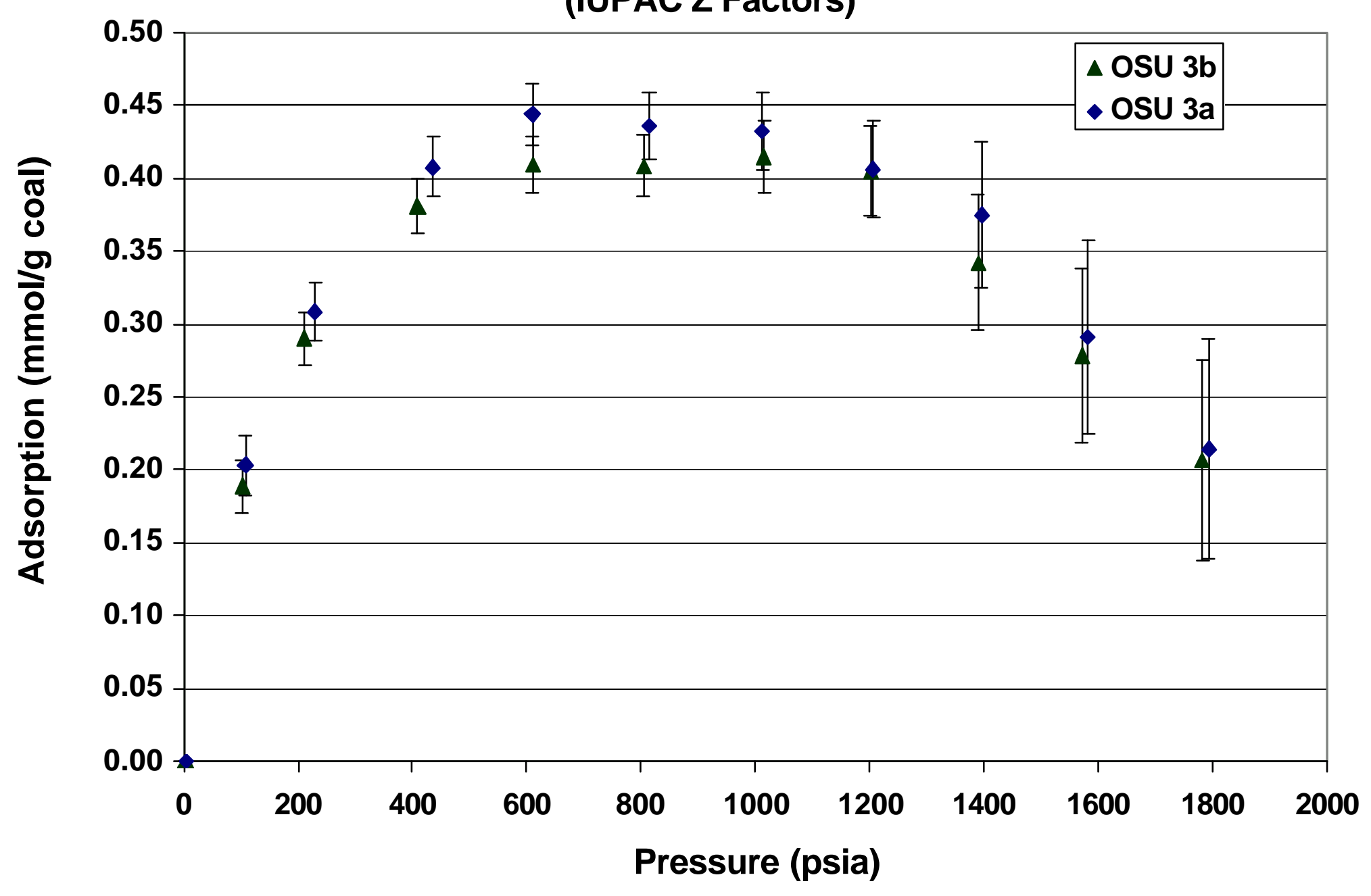


Figure 10. Pure Gas Gibbs Adsorption on Activated Carbon at $130^{\circ} \mathrm{F}$

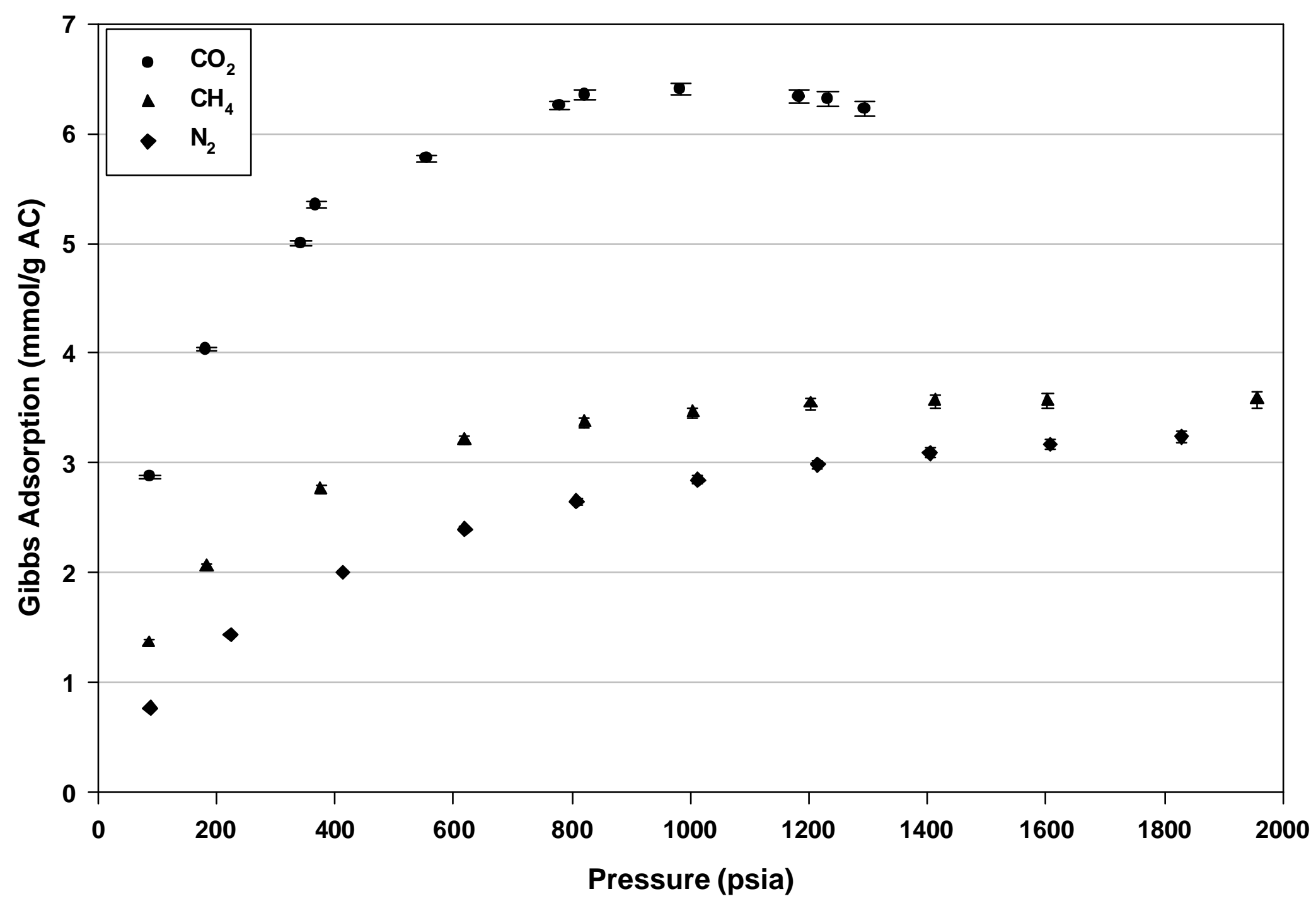


Figure 11. Absolute Adsorption of Methane/Nitrogen

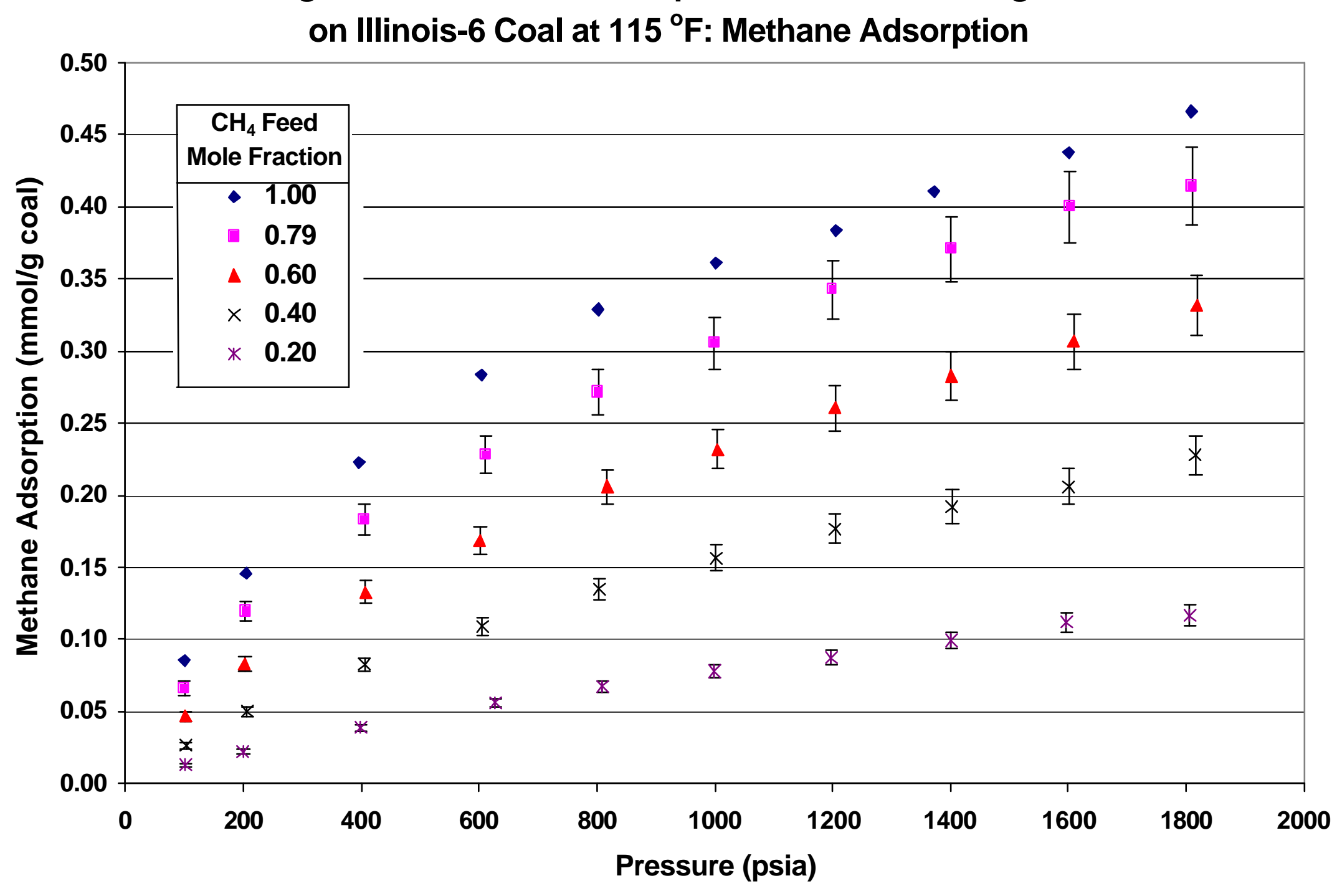


Figure 12. Absolute Adsorption of Methane/Nitrogen on Illinois- 6 Coal at $115^{\circ} \mathrm{F}$ : Nitrogen Adsorption

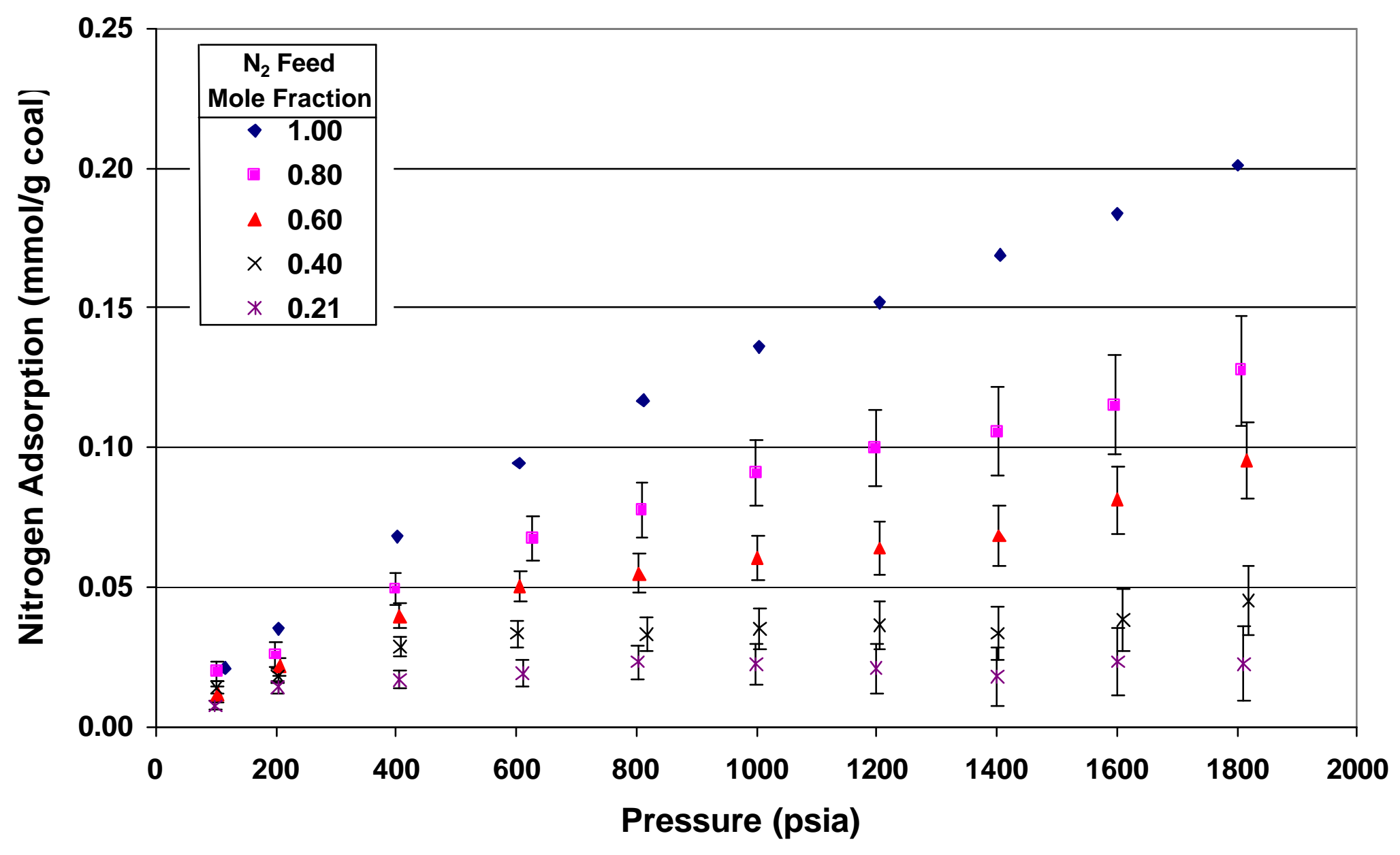


Figure 13. Absolute Adsorption of Methane/Nitrogen on Illinois-6 Coal at $115^{\circ} \mathrm{F}$ : Total Adsorption

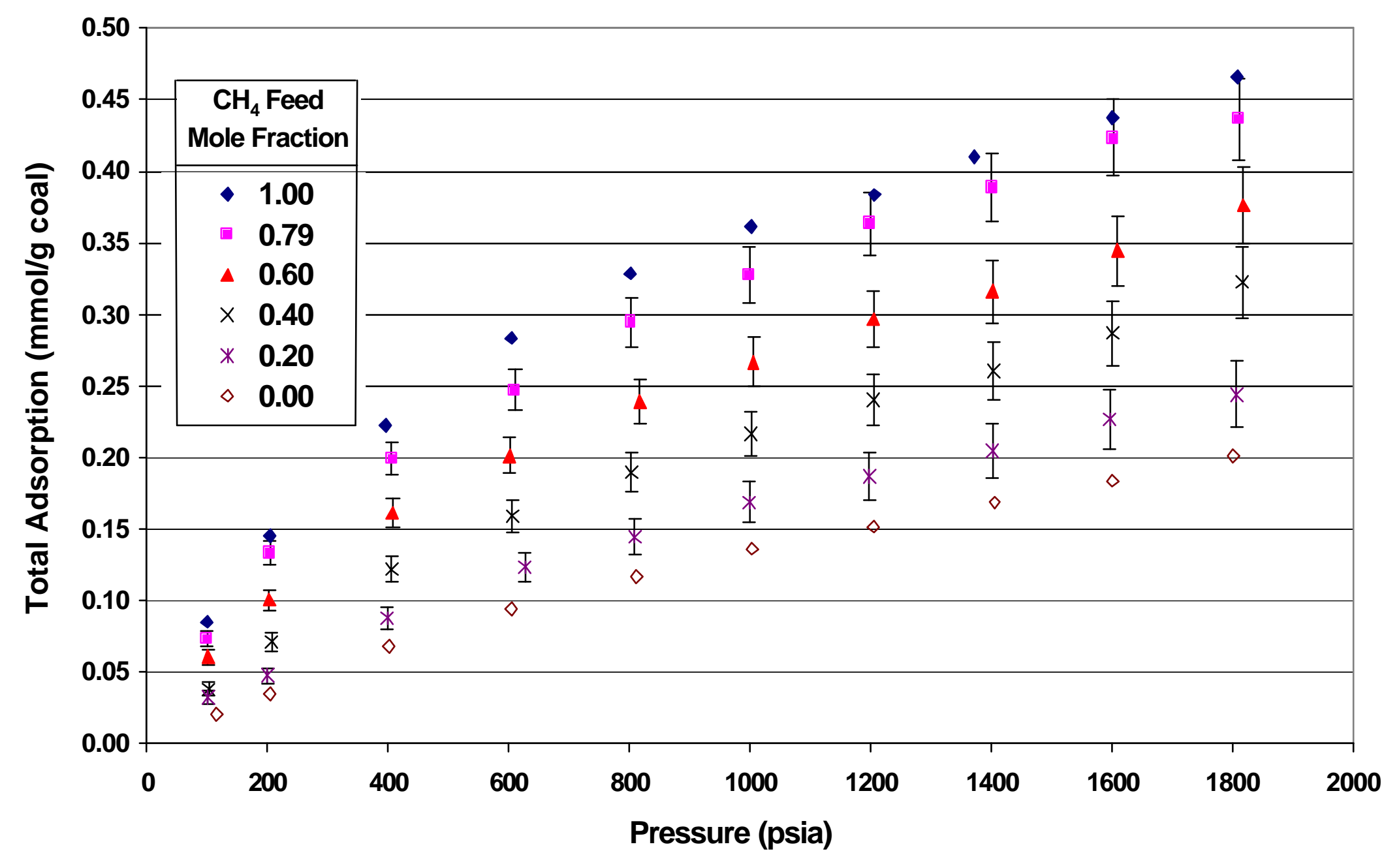


Figure 14. Absolute Adsorption of Methane/Carbon Dioxide on Illinois-6 Coal at $115^{\circ} \mathrm{F}$ : Methane Adsorption

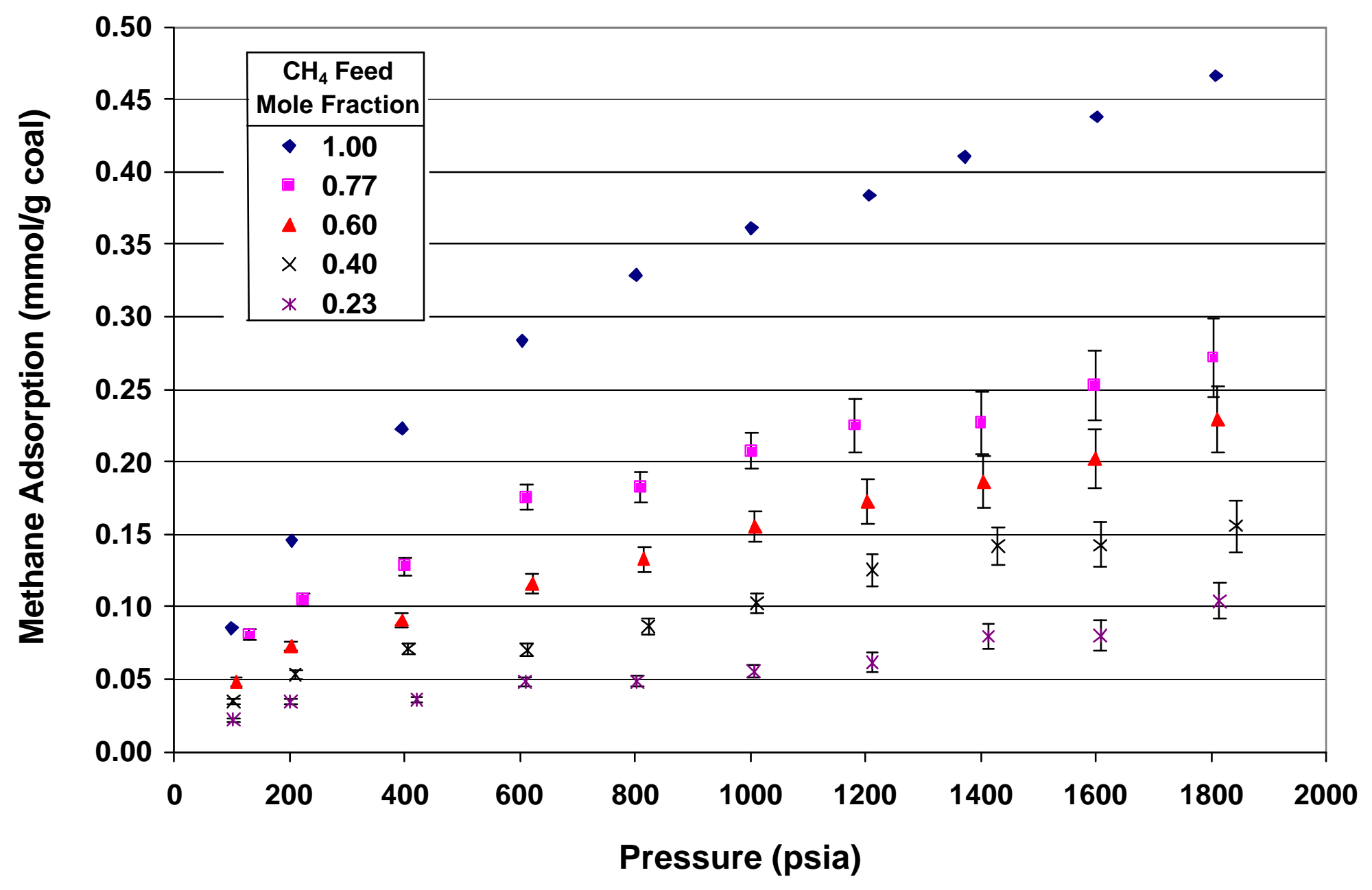


Figure 15. Absolute Adsorption of Methane/Carbon Dioxide on Illinois- 6 Coal at $115^{\circ} \mathrm{F}$ : Carbon Dioxide Adsorption

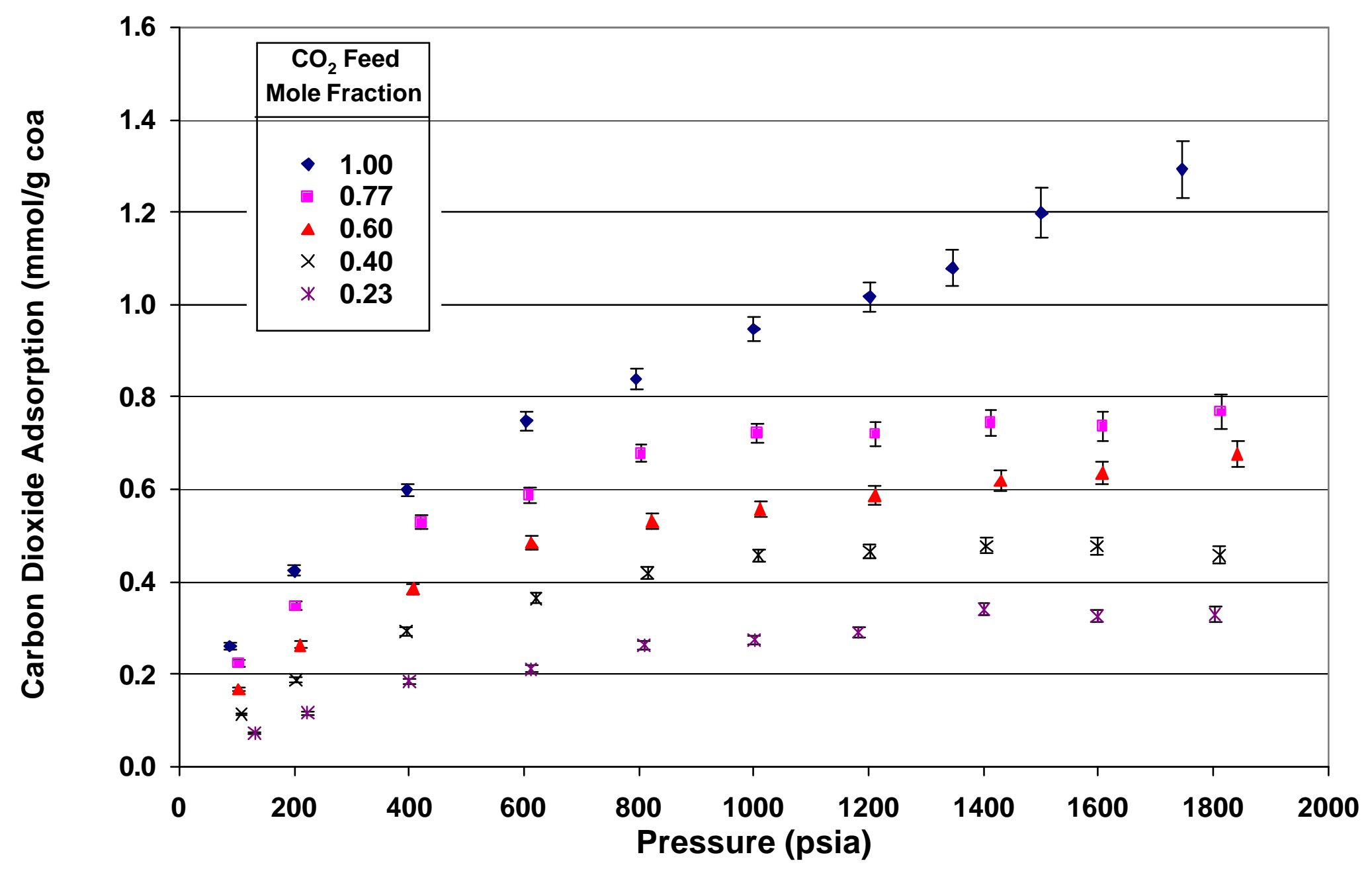


Figure 16. Absolute Adsorption of Methane/Carbon Dioxide on Illinois- 6 Coal at $115^{\circ} \mathrm{F}$ : Total Adsorption

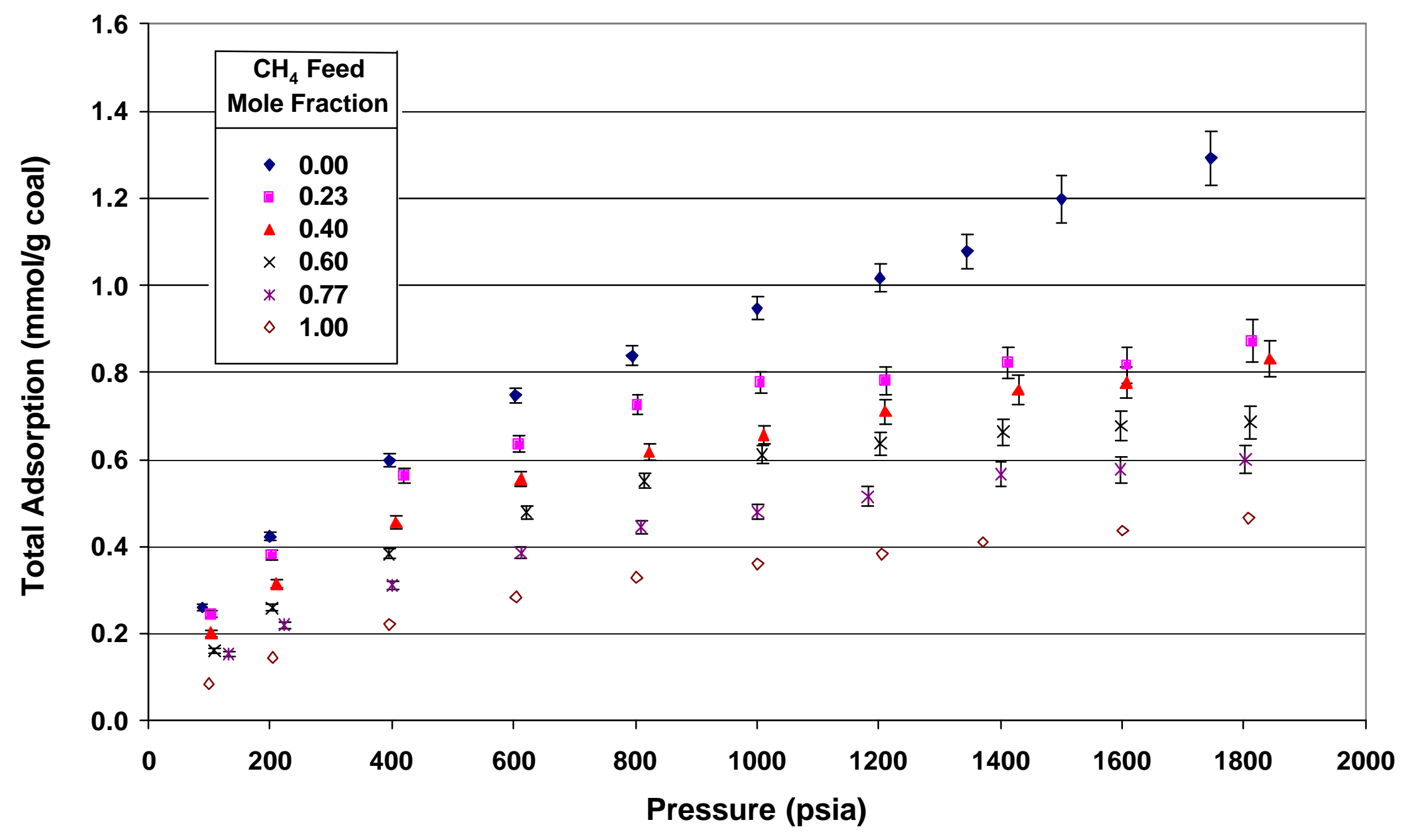


Figure 17. Absolute Adsorption of Nitrogen/Carbon Dioxide on Illinois-6 Coal at $115^{\circ} \mathrm{F}$ : Carbon Dioxide Adsorption

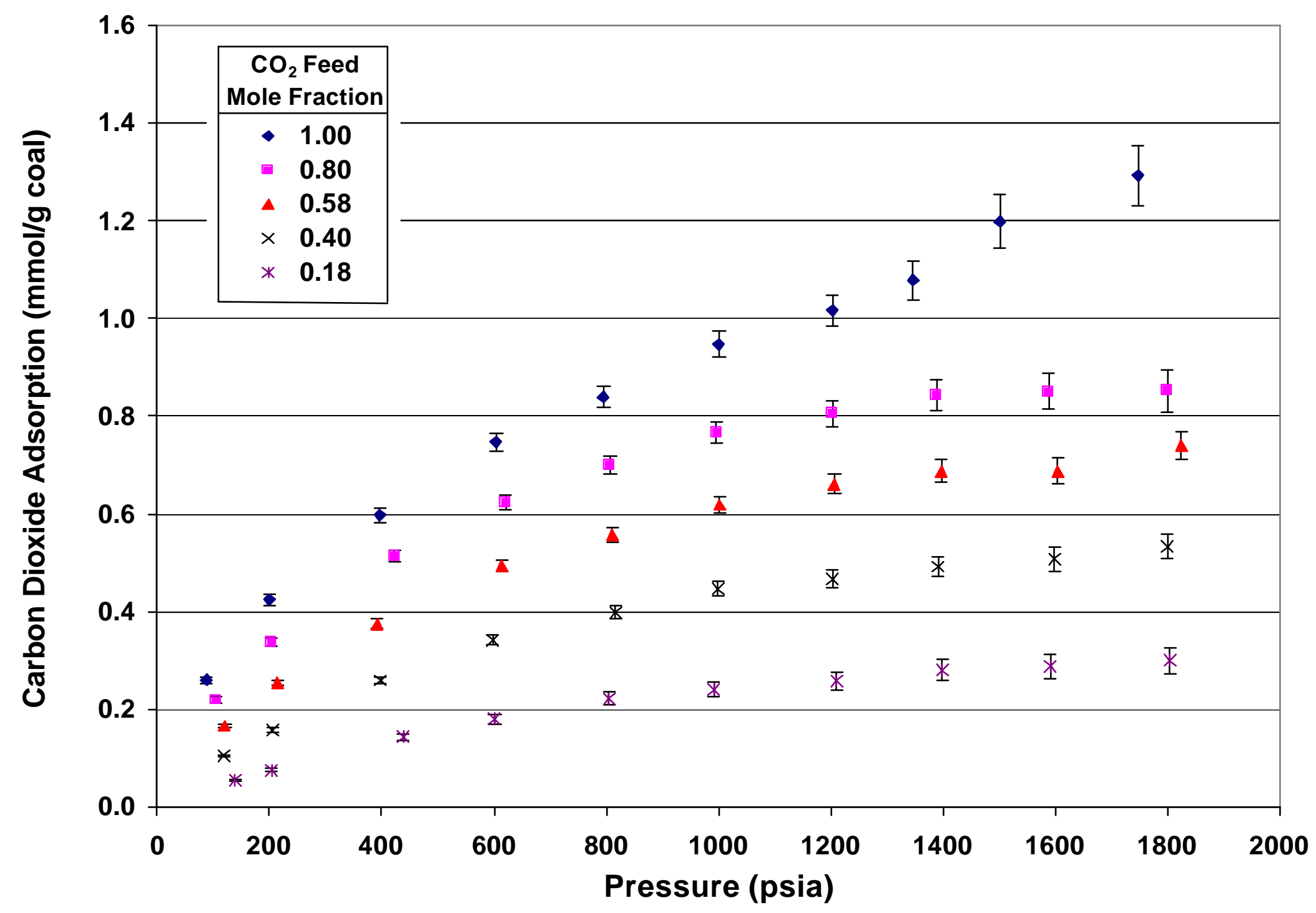


Figure 18. Absolute Adsorption of Nitrogen/Carbon Dioxide on Illinois-6 Coal at $115^{\circ} \mathrm{F}$ : Nitrogen Adsorption

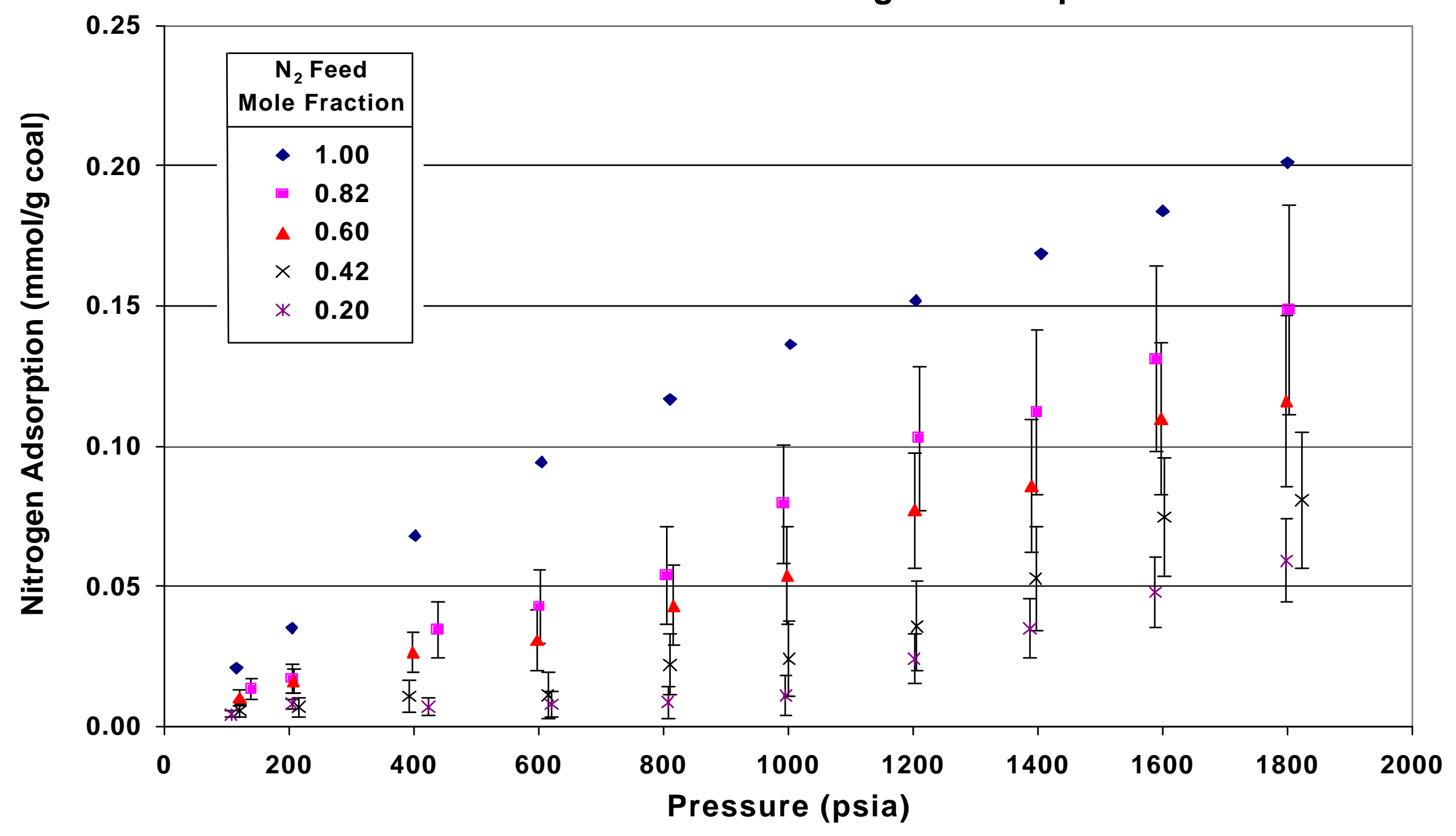


Figure 19. Absolute Adsorption of Nitrogen/Carbon Dioxide on Illinois- 6 Coal at $115^{\circ} \mathrm{F}$ : Total Adsorption

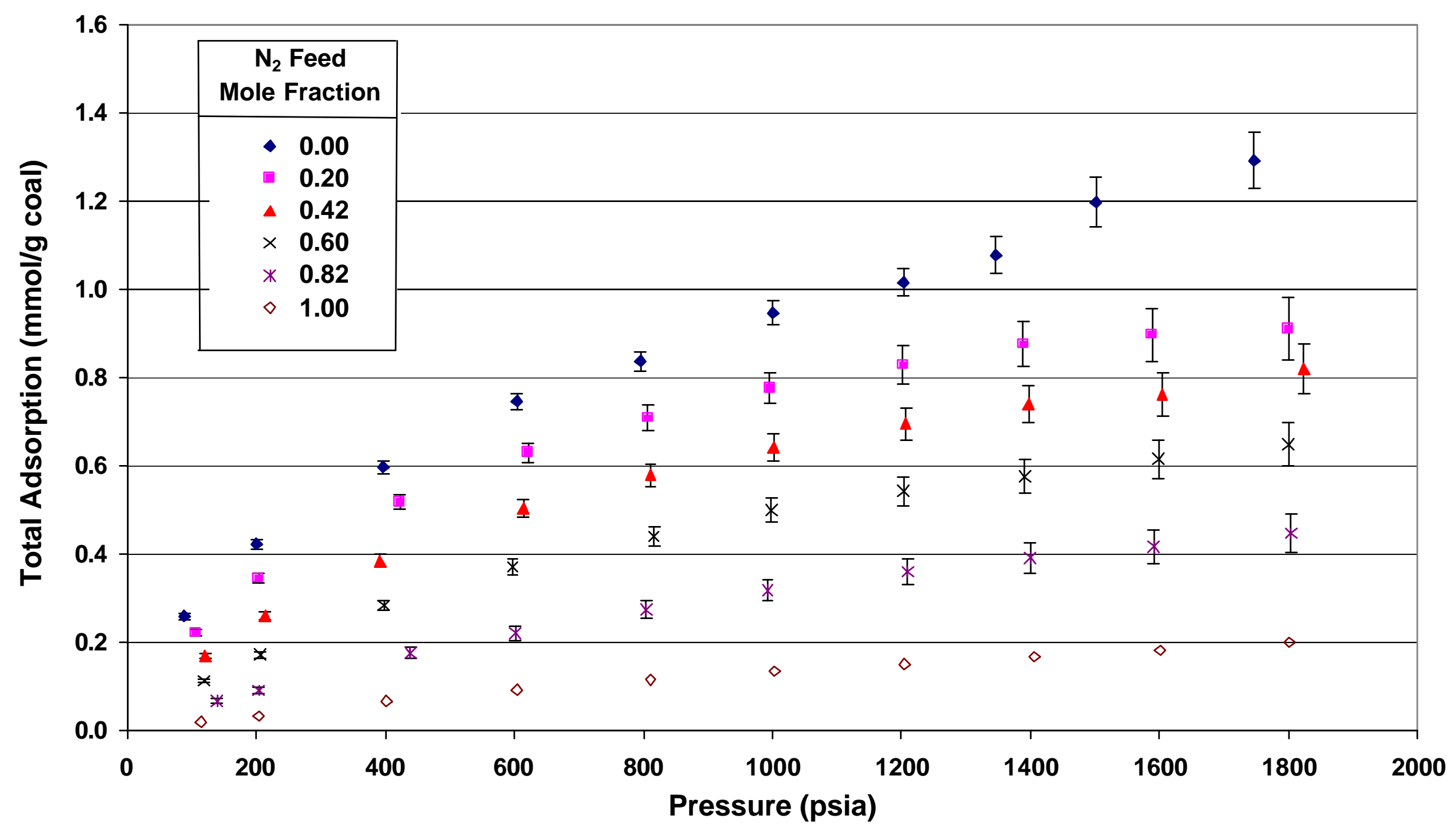


Figure 20. Gibbs Adsorption of Methane/Nitrogen on Activated Carbon at $113^{\circ} \mathrm{F}$ : Total Adsorption

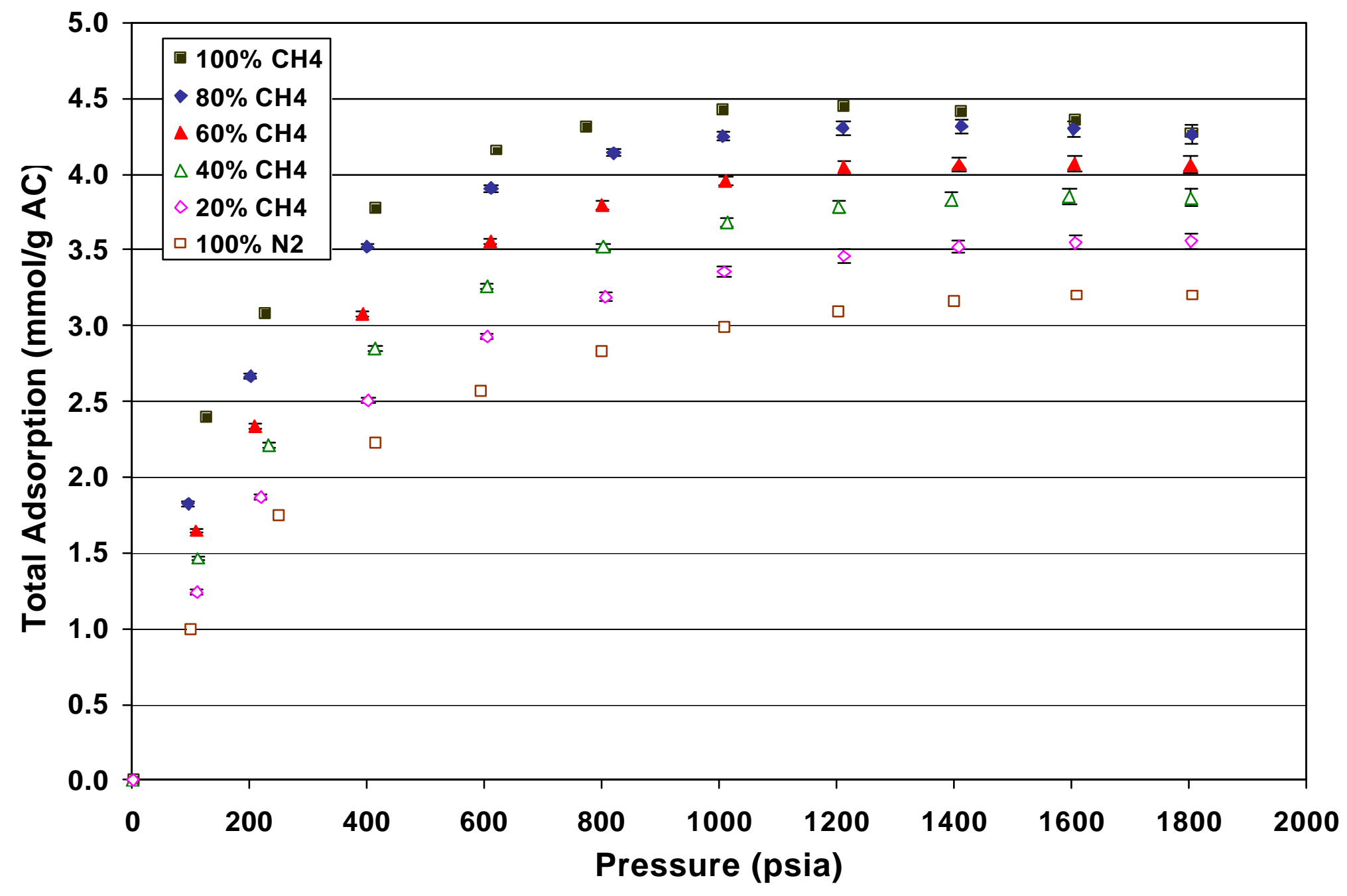


Figure 21. Gibbs Adsorption of Methane/Nitrogen on Activated Carbon at $113^{\circ} \mathrm{F}$ : Methane Adsorption

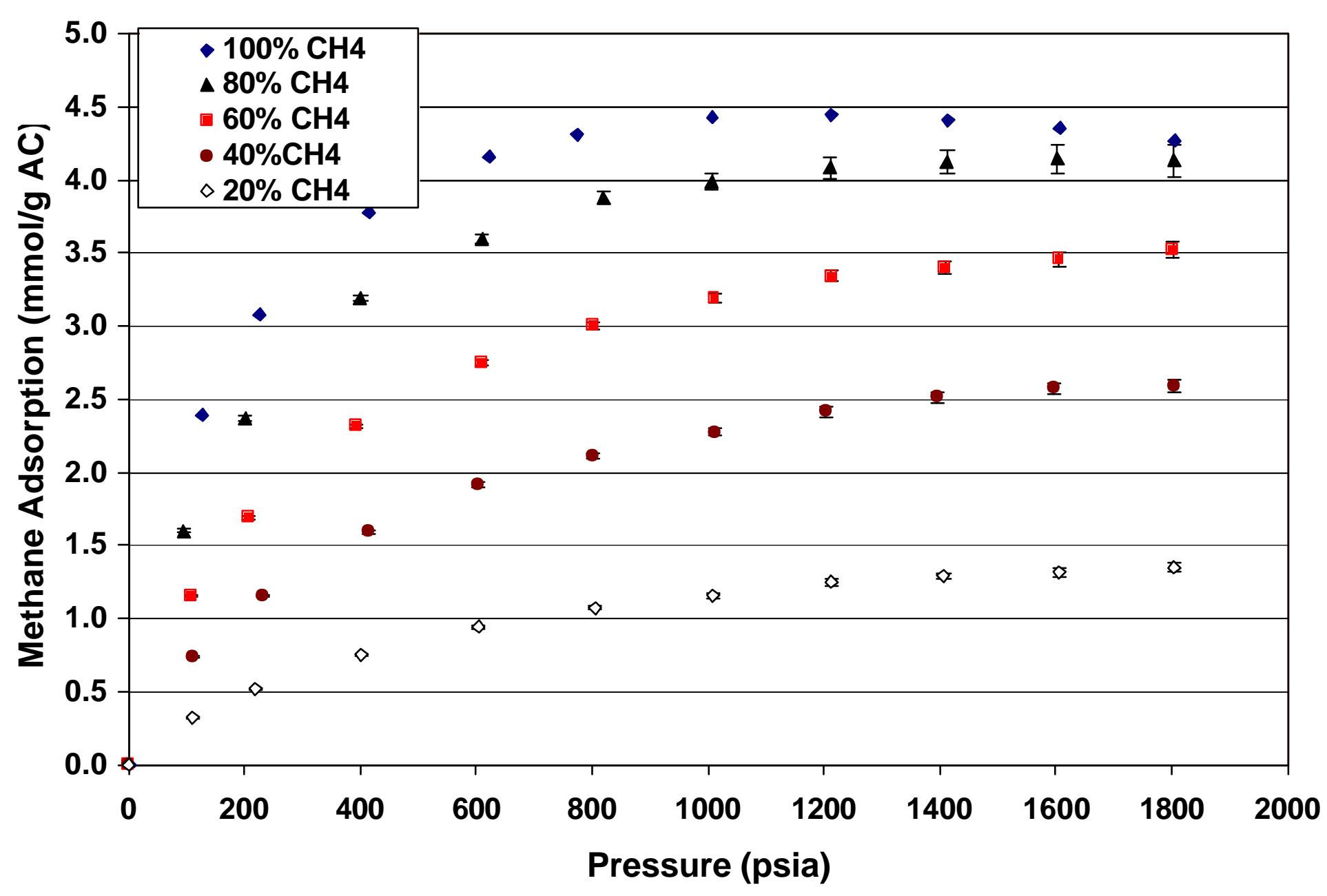


Figure 22. Gibbs Adsorption of Methane/Nitrogen on Activated Carbon at $113^{\circ} \mathrm{F}$ : Nitrogen Adsorption

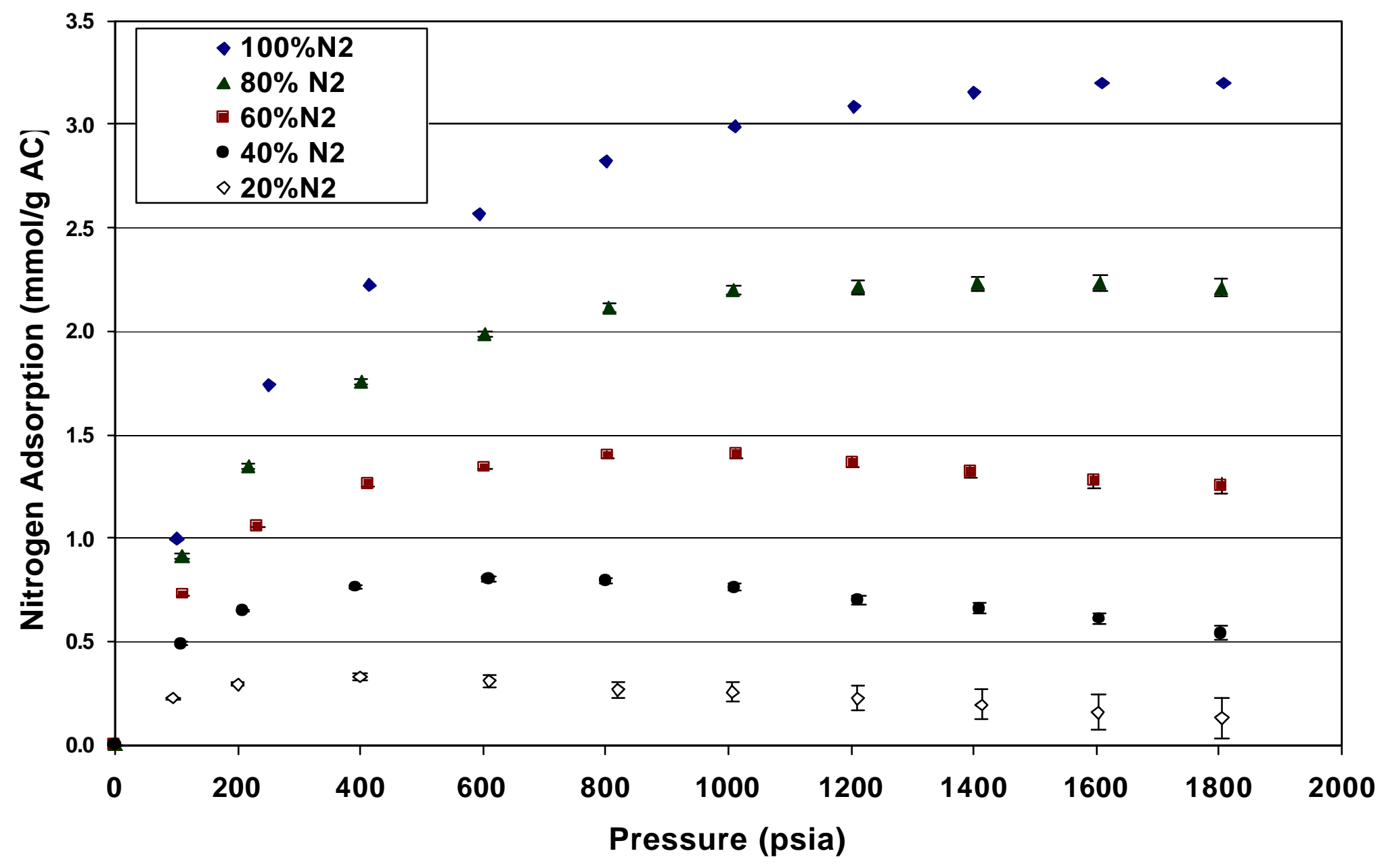


Figure 23. Absolute Adsorption of Methane/Nitrogen on Activated Carbon at $113^{\circ} \mathrm{F}$ : Total Adsorption

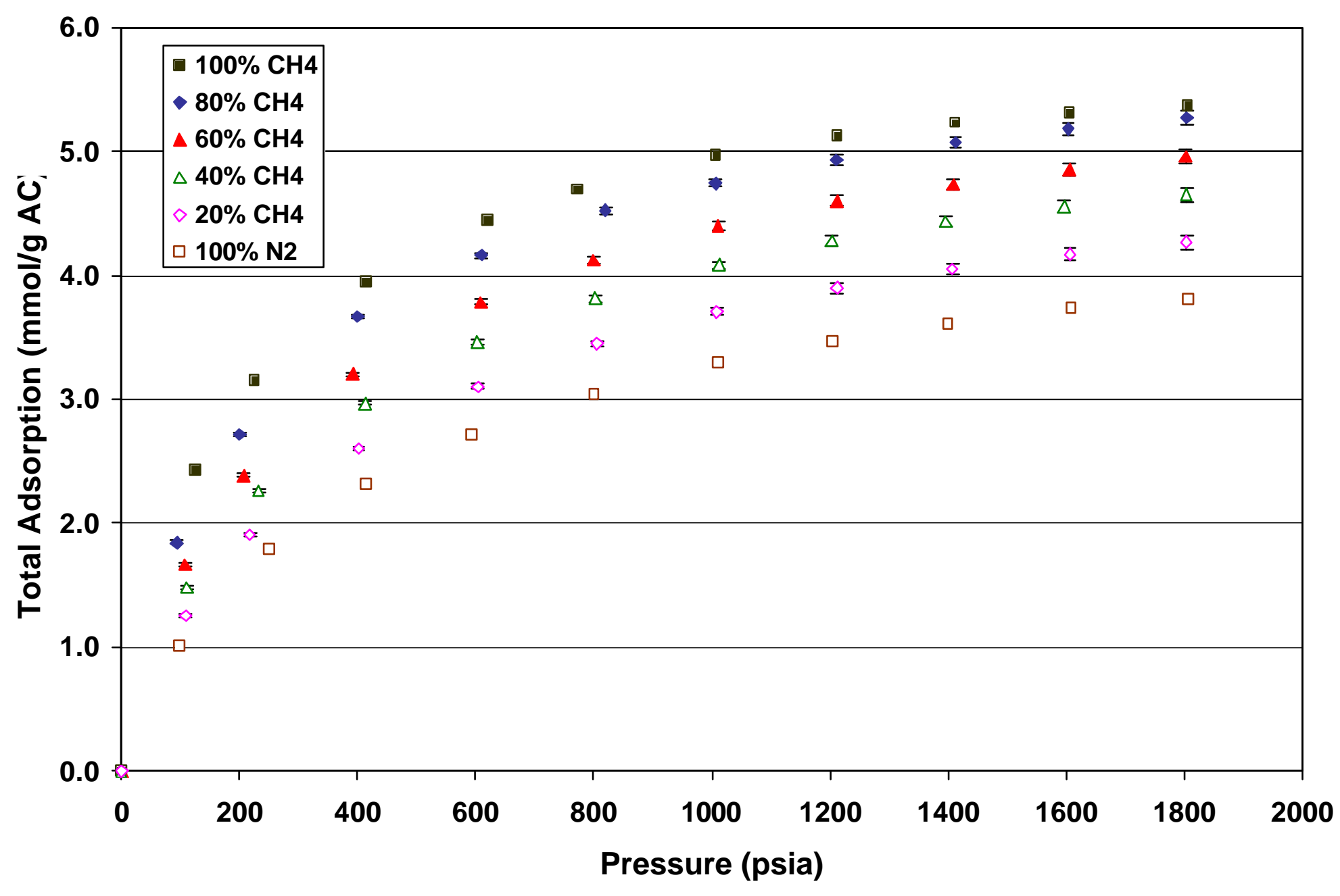


Figure 24. Absolute Adsorption of Methane/Nitrogen on Activated Carbon at $113^{\circ} \mathrm{F}$ : Methane Adsorption

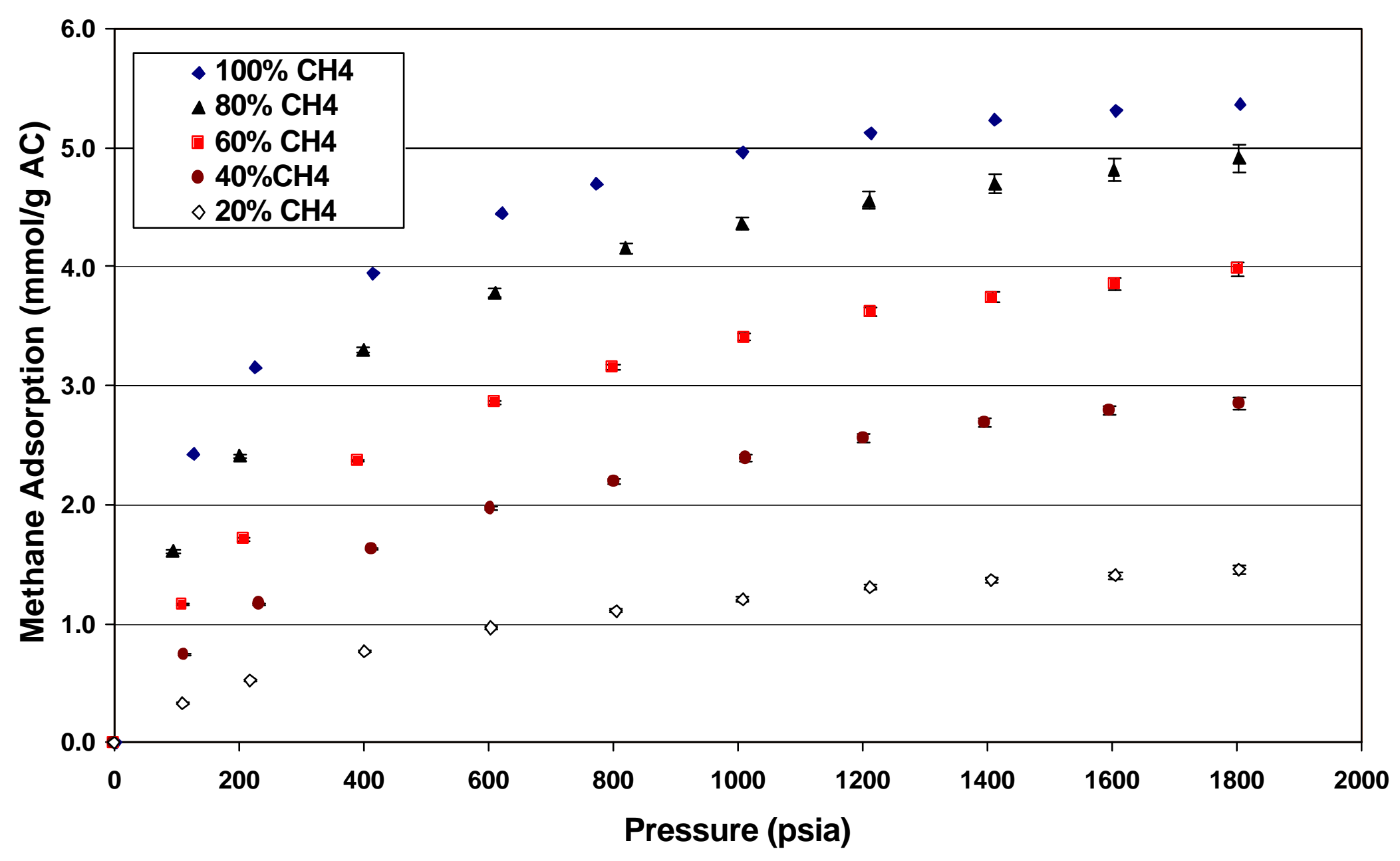


Figure 25. Absolute Adsorption of Methane/Nitrogen on Activated Carbon at $113^{\circ} \mathrm{F}$ : Nitrogen Adsorption

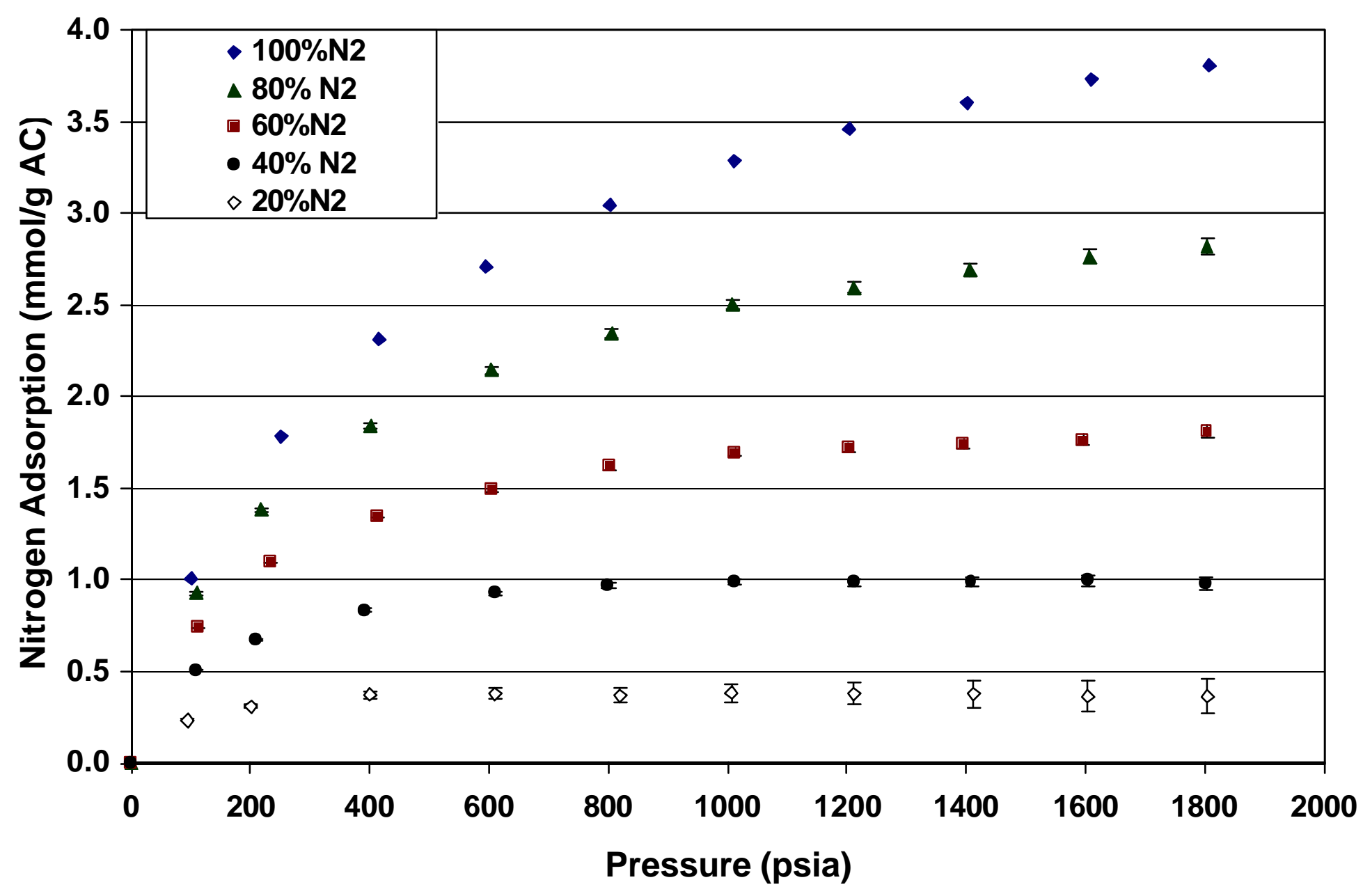


Figure 26. Gibbs Adsorption of Methane/Carbon Dioxide on Activated Carbon at $113^{\circ} \mathrm{F}$ : Total Adsorption

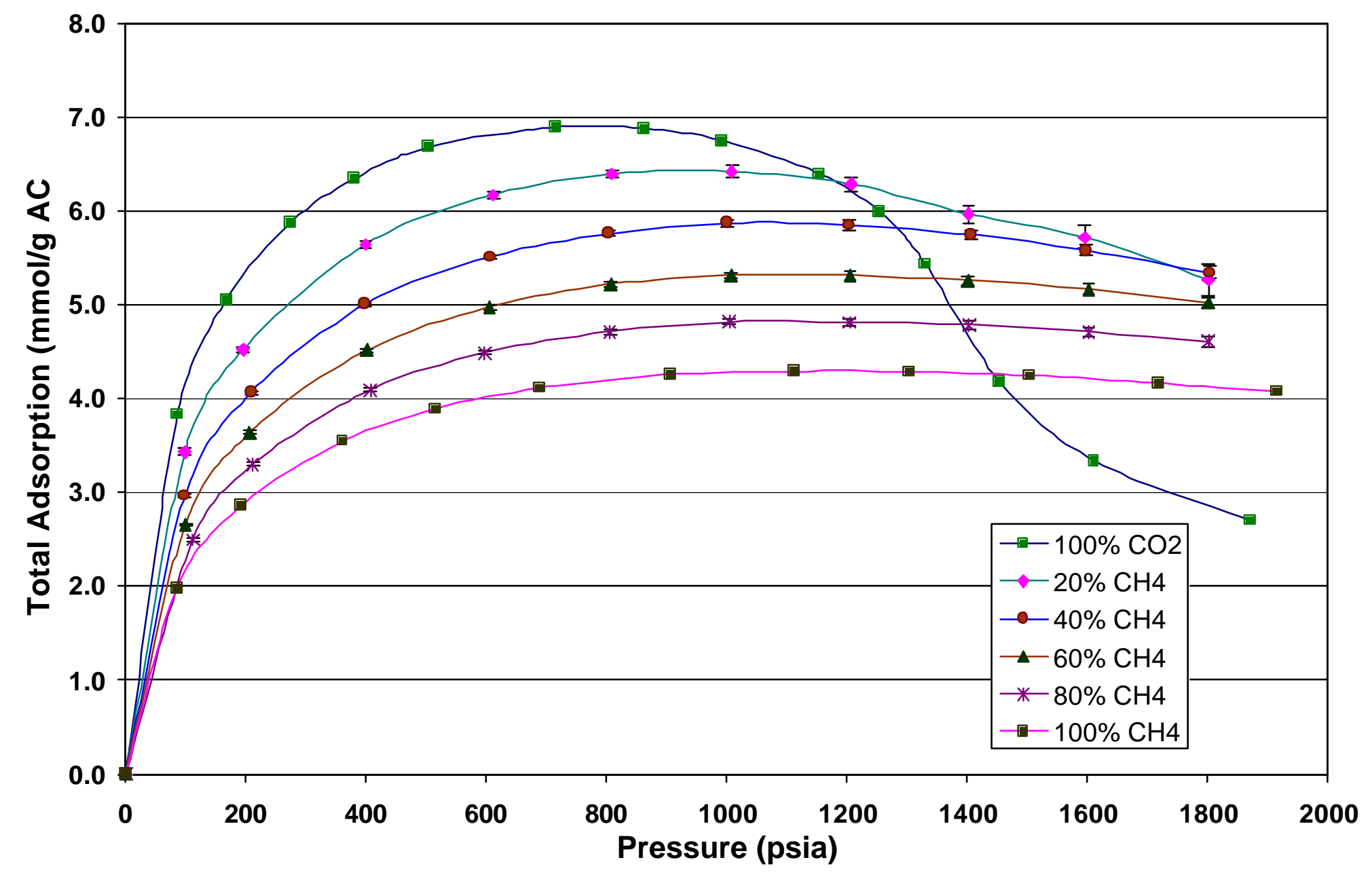


Figure 27. Gibbs Adsorption of Methane/Carbon Dioxide on Activated Carbon at $113^{\circ} \mathrm{F}$ : Methane Adsorption

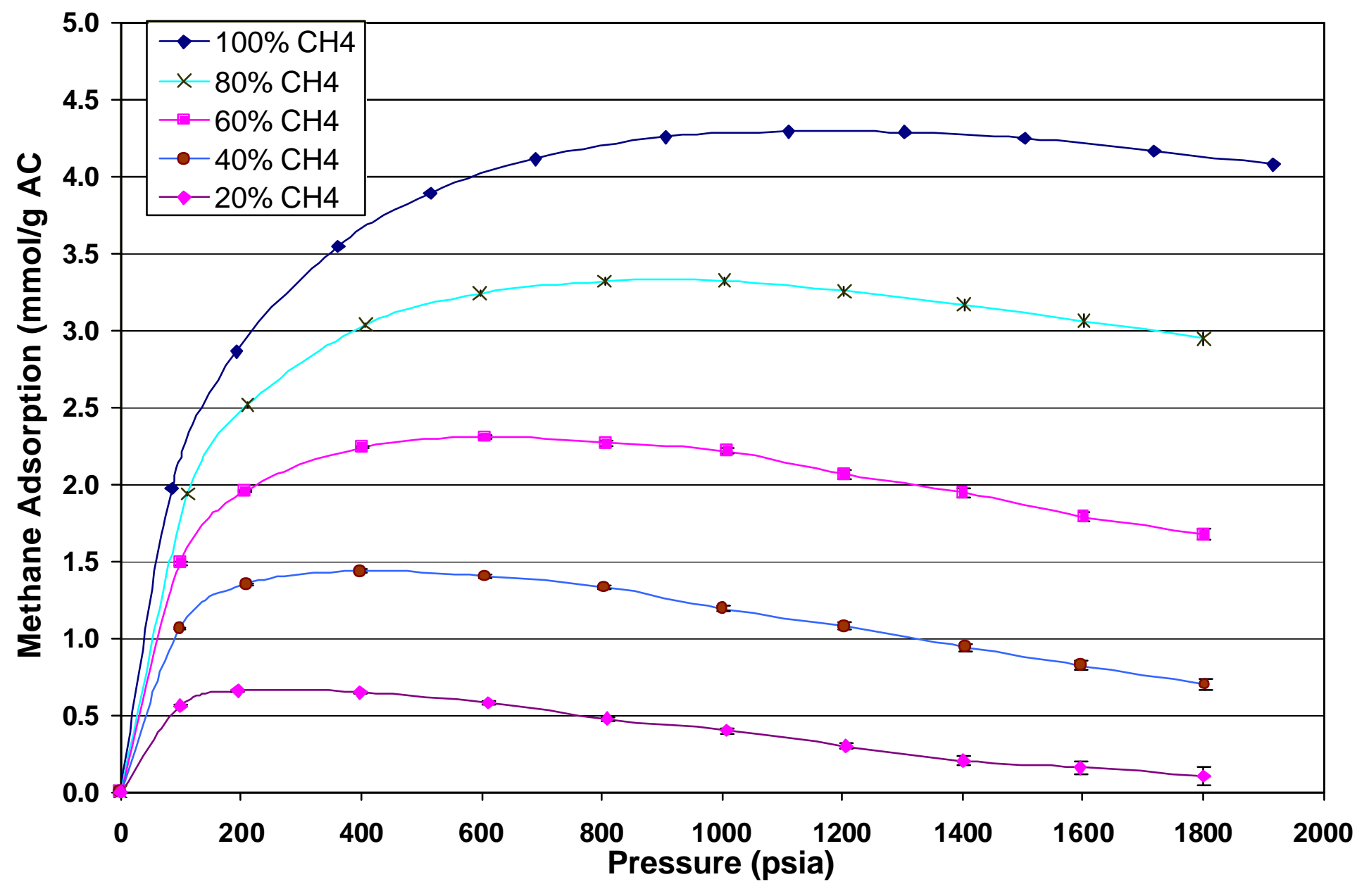


Figure 28. Gibbs Adsorption of Methane/Carbon Dioxide on Activated Carbon at $113^{\circ} \mathrm{F}$ : Carbon Dioxide Adsorption

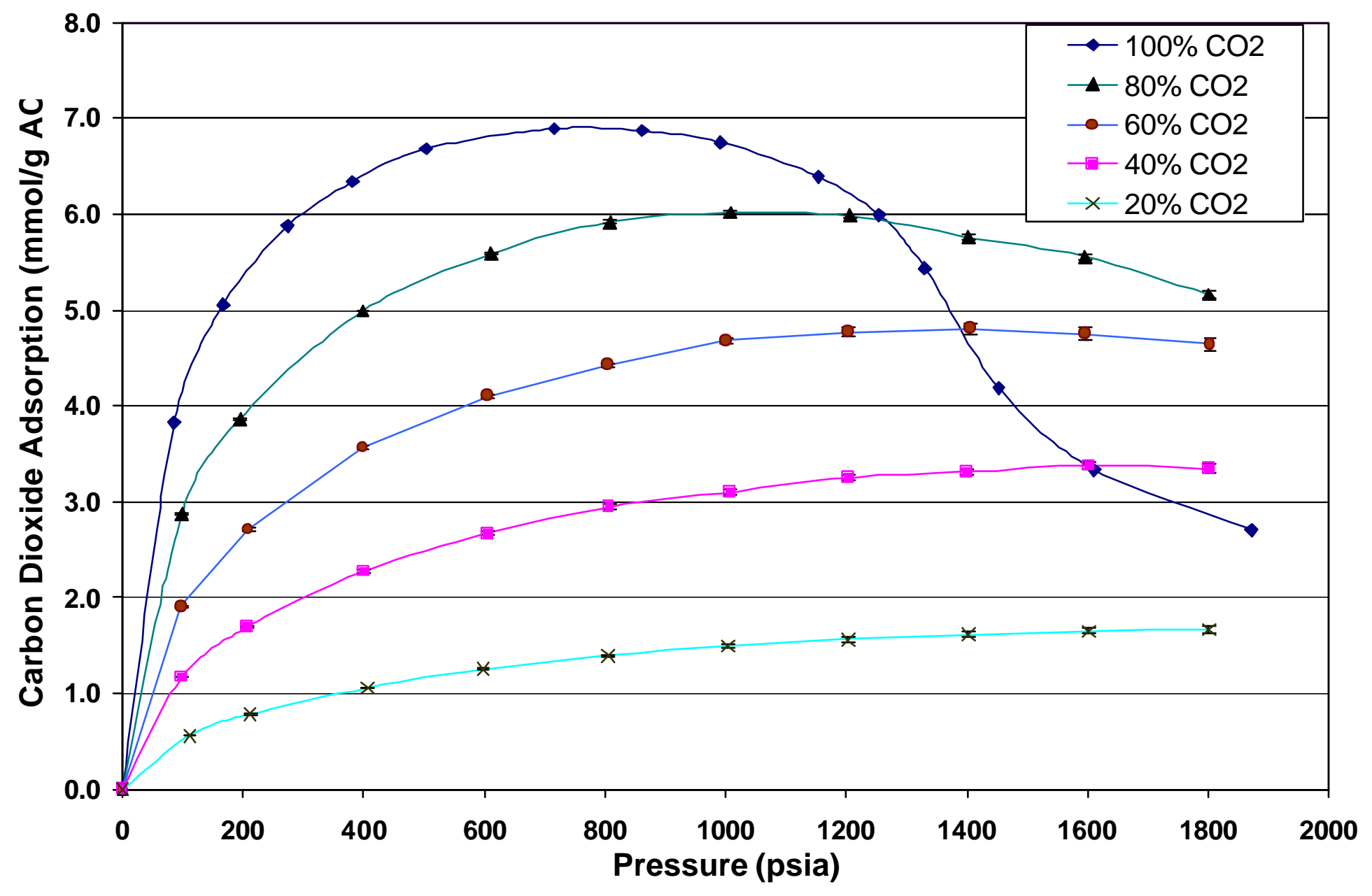


Figure 29. Absolute Adsorption of Methane/Carbon Dioxide on Activated Carbon at $113^{\circ} \mathrm{F}$ : Total Adsorption

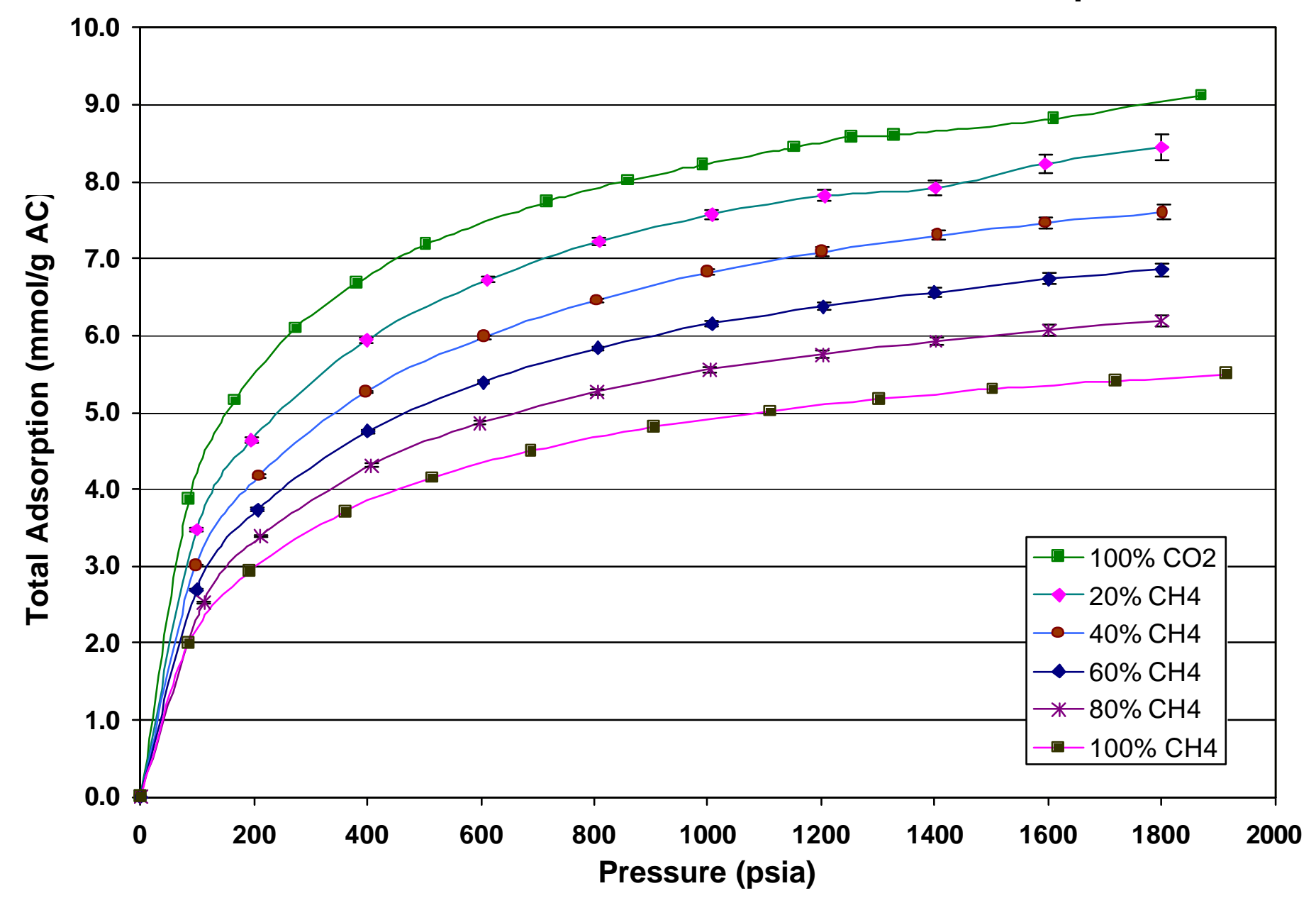


Figure 30. Absolute Adsorption of Methane/Carbon Dioxide on Activated Carbon at $113^{\circ} \mathrm{F}$ : Methane Adsorption

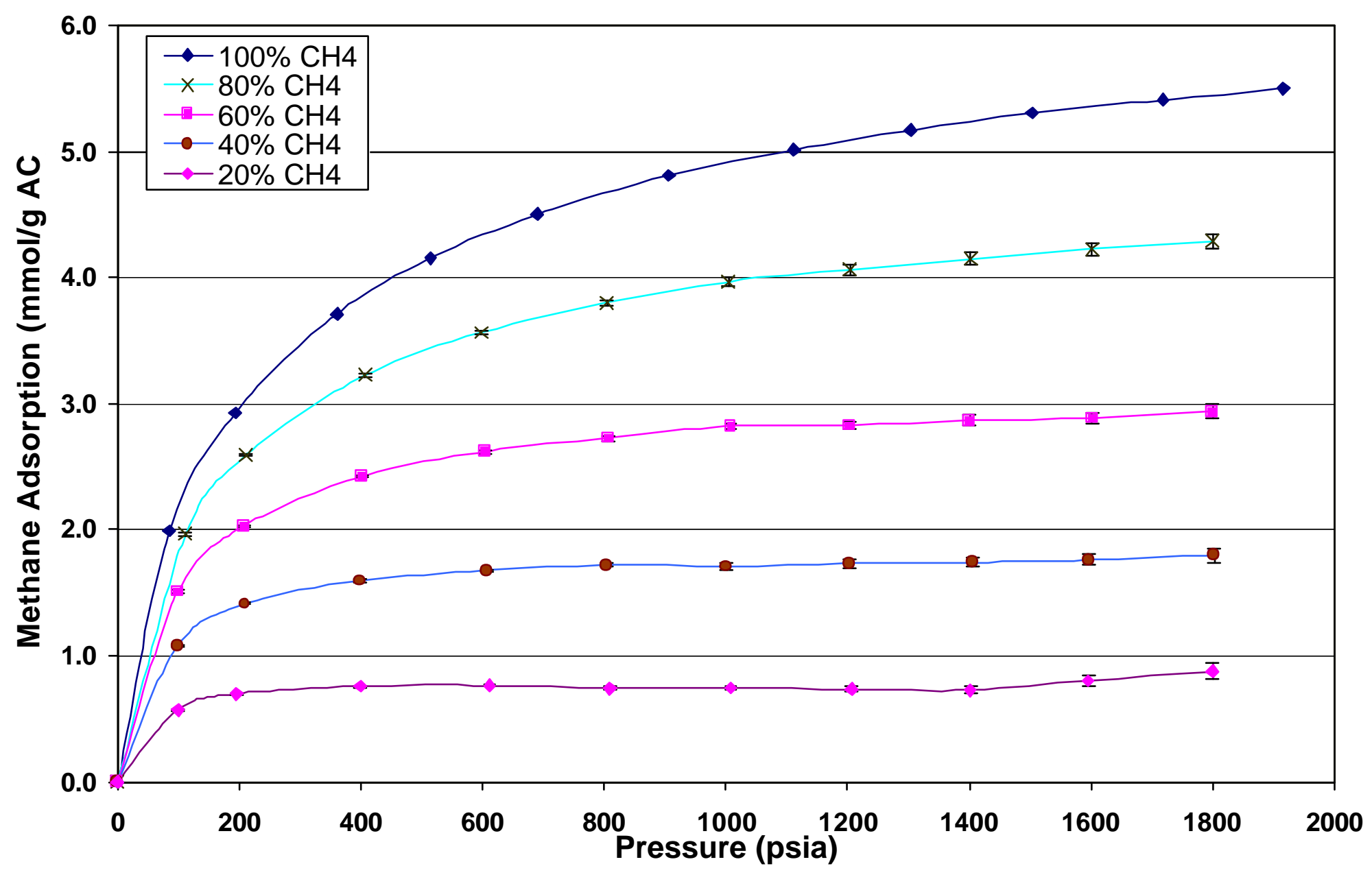


Figure 31. Absolute Adsorption of Methane/Carbon Dioxide on Activated Carbon at $113^{\circ} \mathrm{F}$ : Carbon Dioxide Adsorption

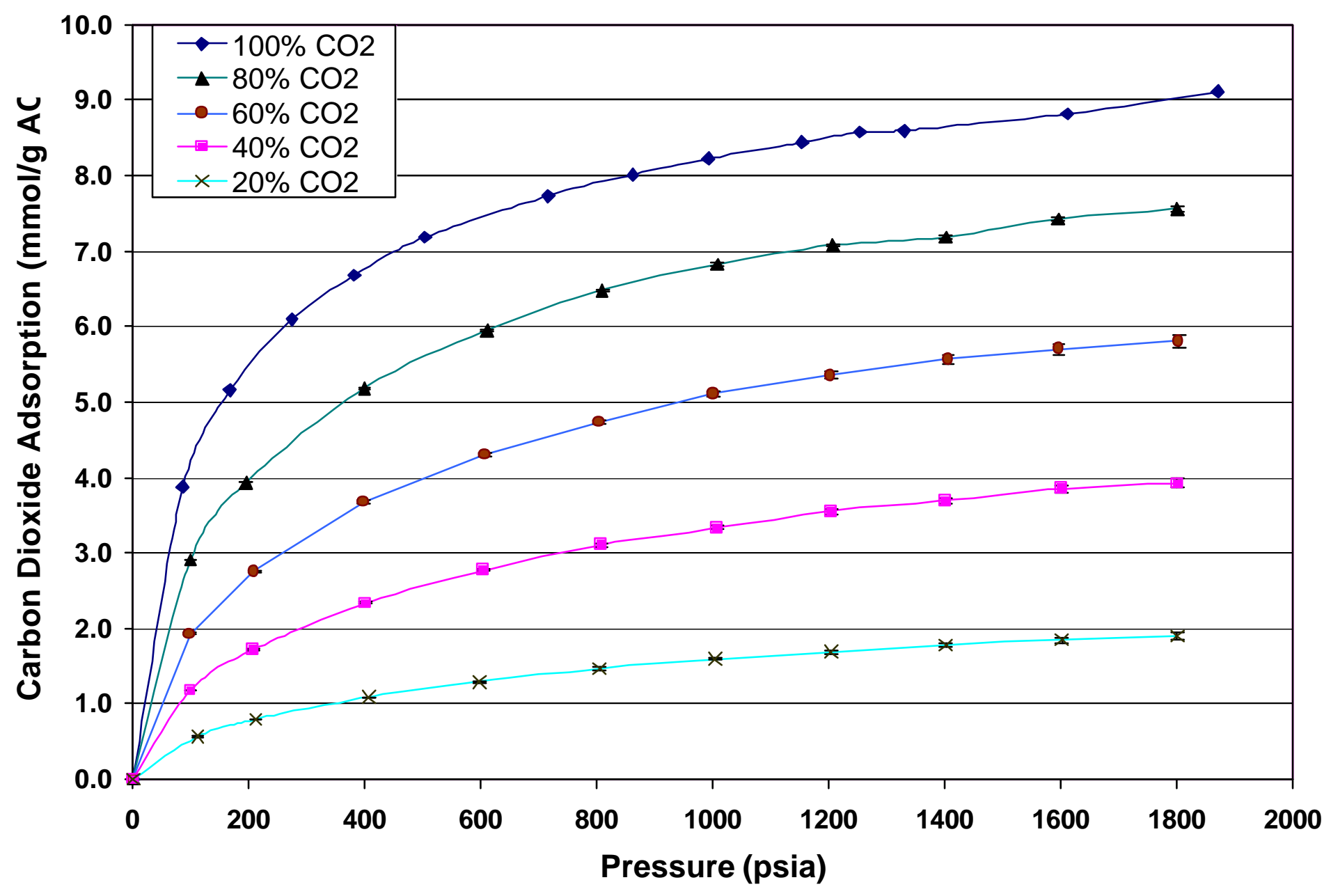


Figure 32. ZGR Representation of Pure Gas Absolute Adsorption on Dry Activated Carbon at $113{ }^{\circ} \mathrm{F}$

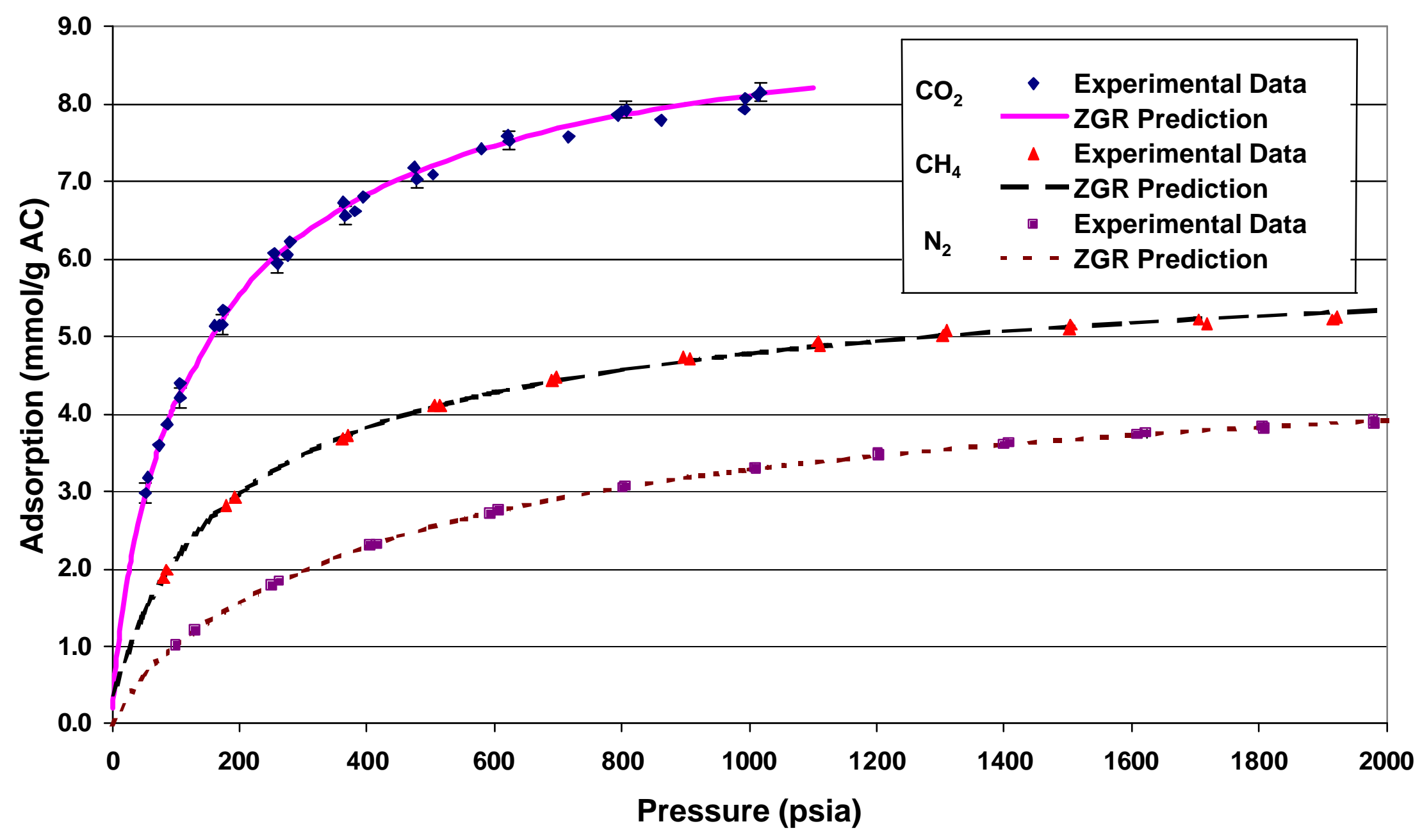


Figure 33. ZGR Representation of Pure Gas Absolute Adsorption on Wet Fruitland Coal at $115^{\circ} \mathrm{F}$

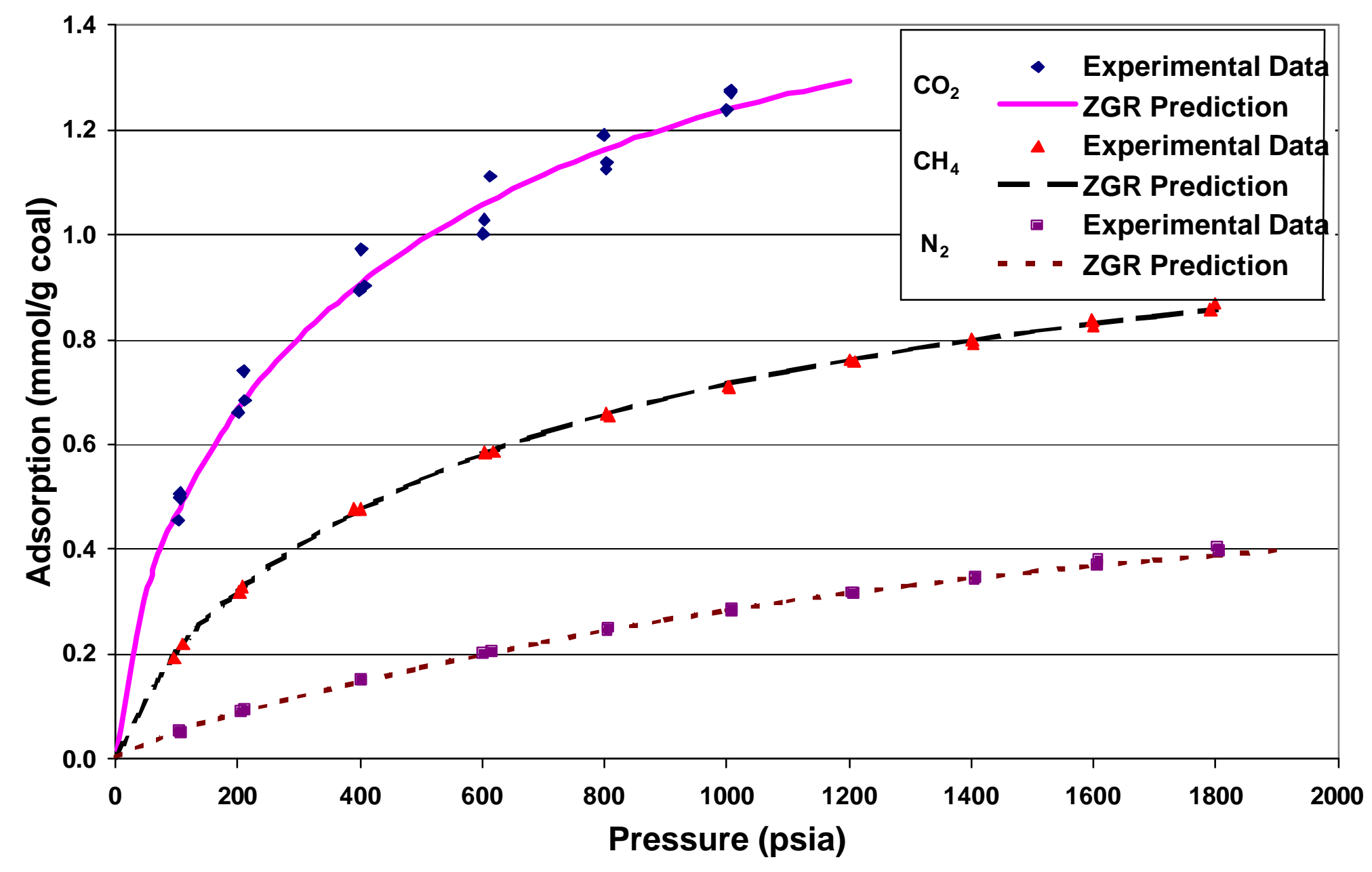


Figure 34. ZGR Representation of Pure Gas Absolute Adsorption on Wet Illinois- 6 Coal at $115^{\circ} \mathrm{F}$

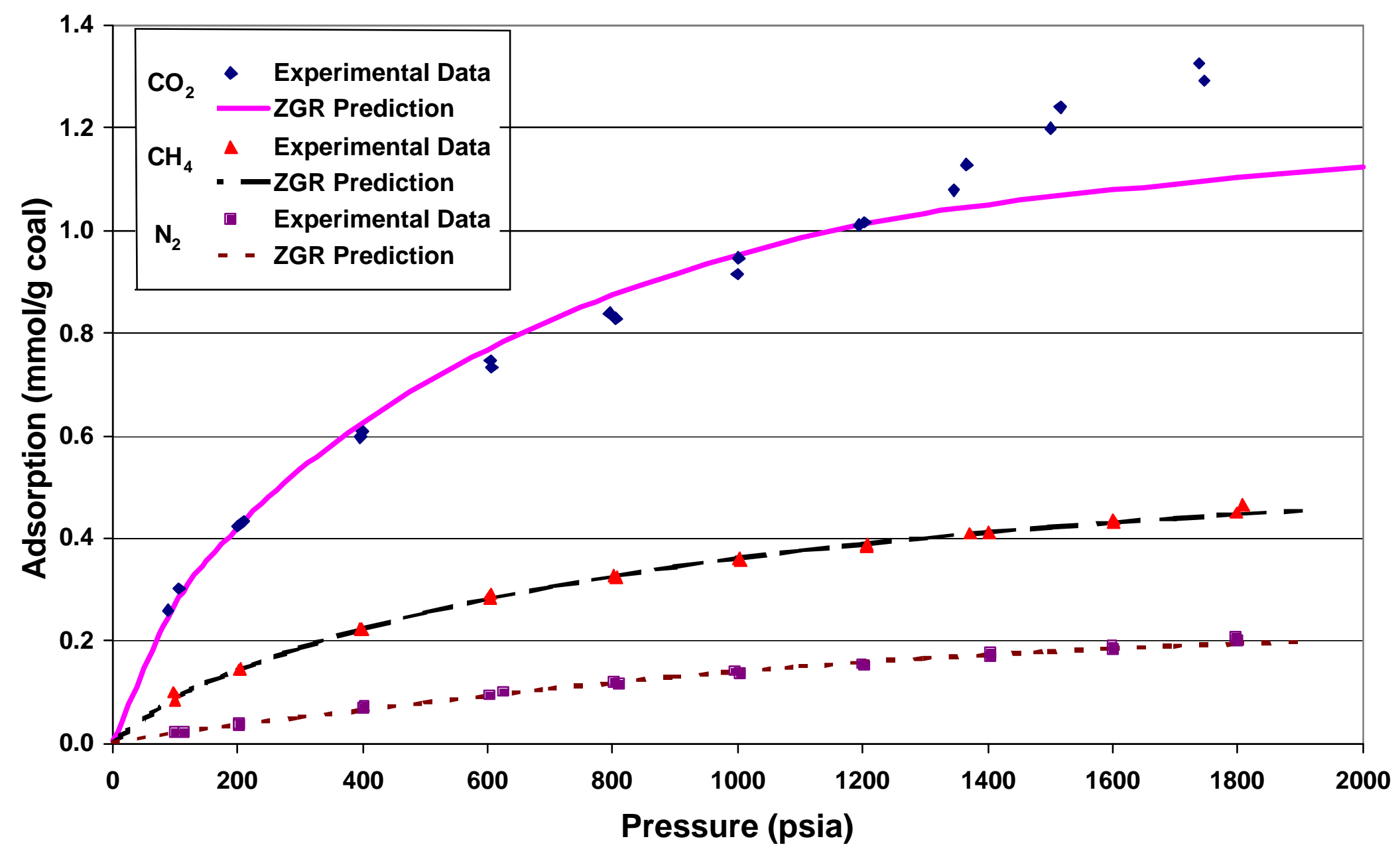


Figure 35. ZGR Representation of Pure Gas Absolute Adsorption on Wet Lower Basin Fruitland Coal at $115^{\circ} \mathrm{F}$

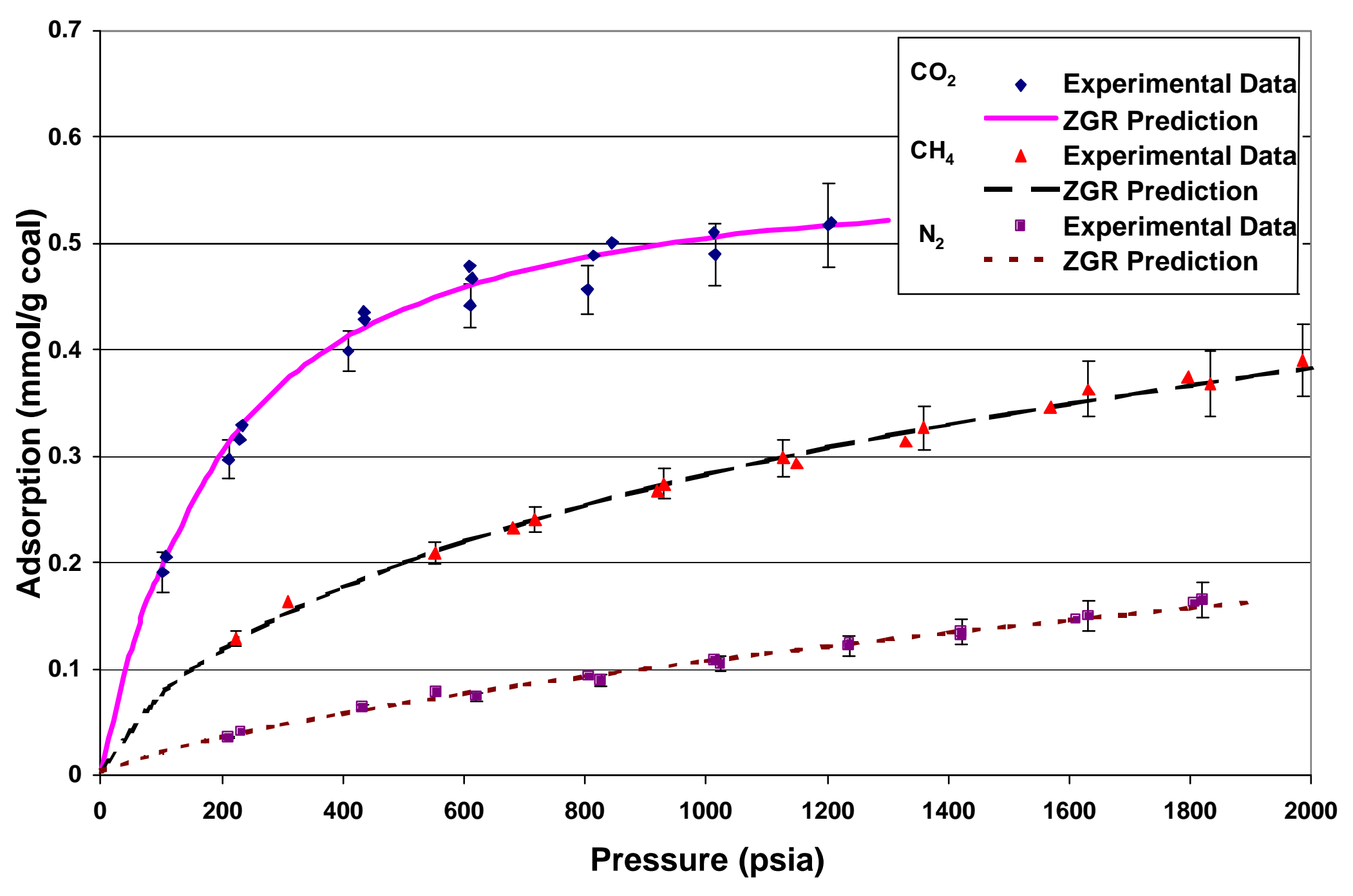


Figure 36. Pure Gas Gibbs Adsorption on Activated Carbon at $113^{\circ} \mathrm{F}$

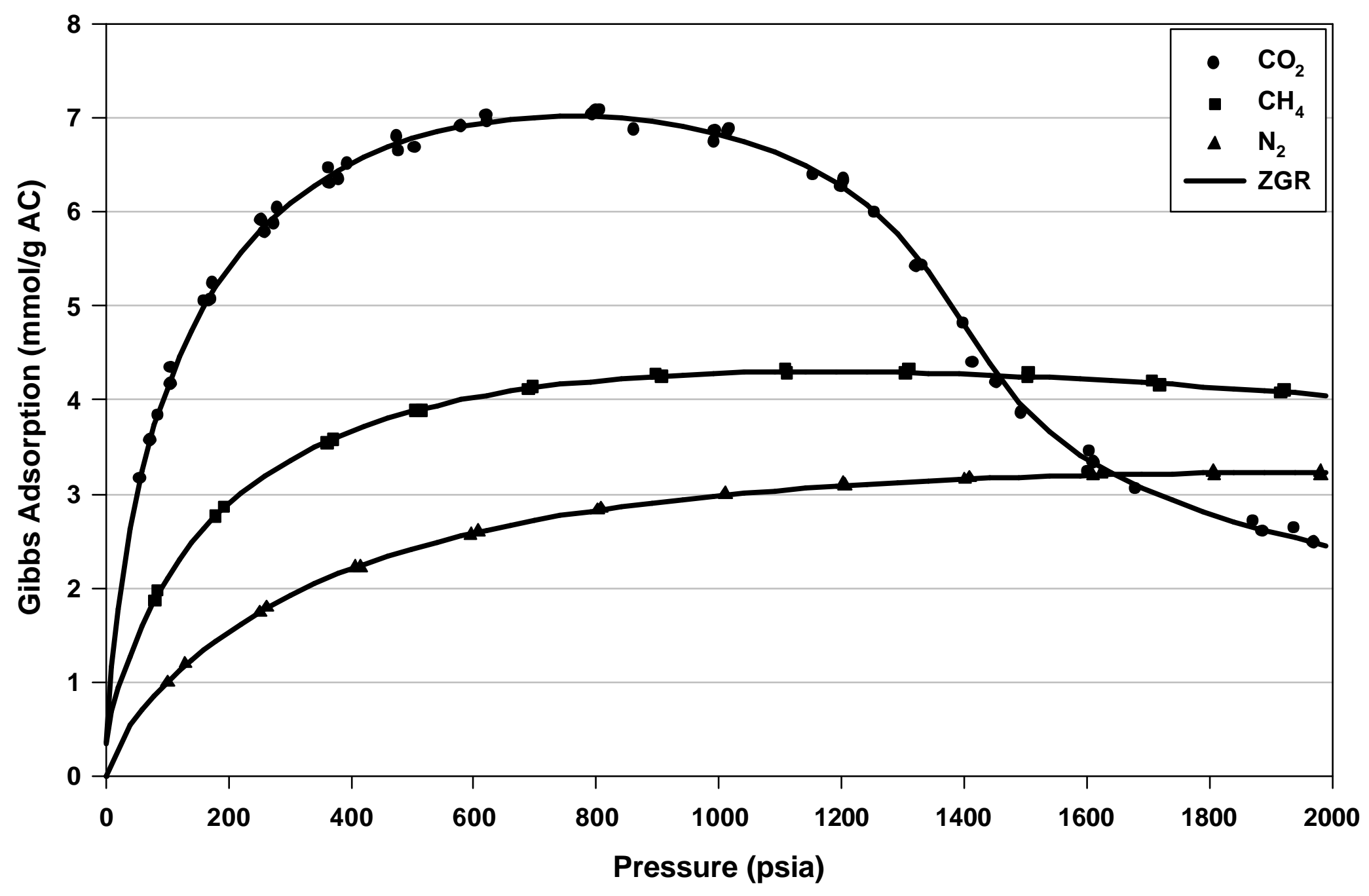


Figure 37. Pure Gas Absolute Adsorption on Activated Carbon at $113^{\circ} \mathrm{F}$

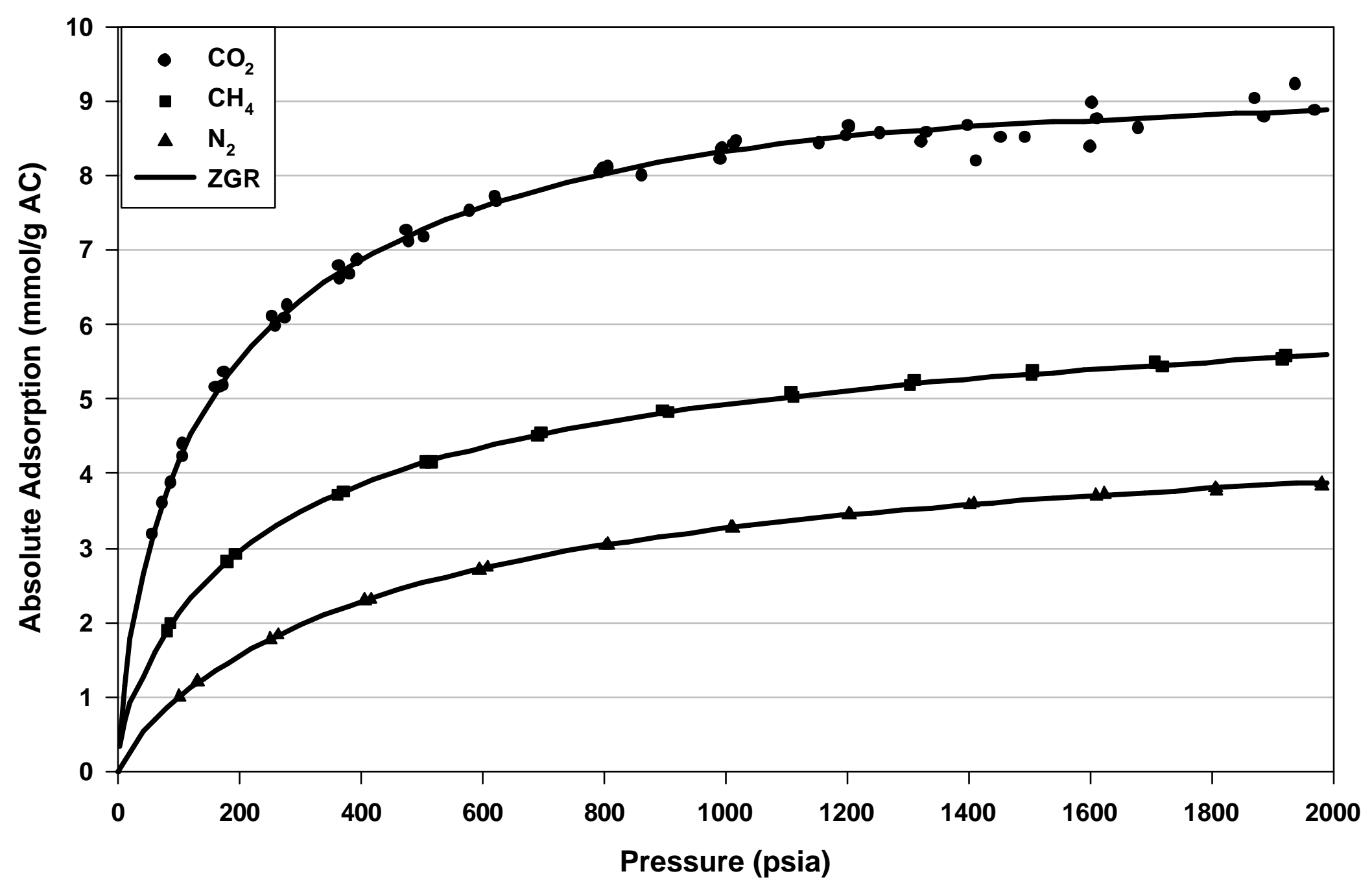


Figure 38. Pure Gas Gibbs Adsorption on Illinois-6 Coal at $115^{\circ} \mathrm{F}$

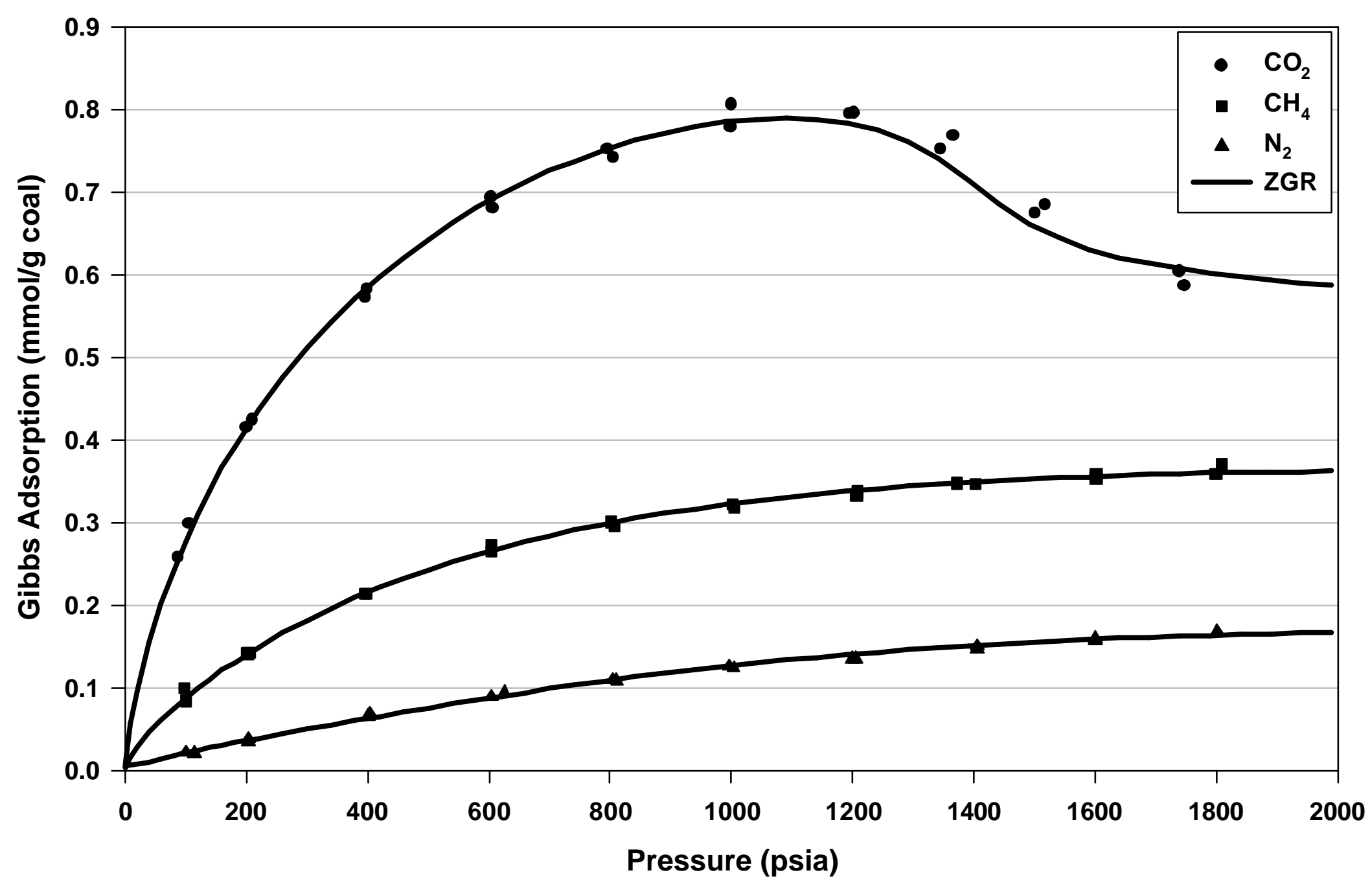


Figure 39. Pure Gas Absolute Adsorption on Illinois-6 Coal at $115^{\circ} \mathrm{F}$

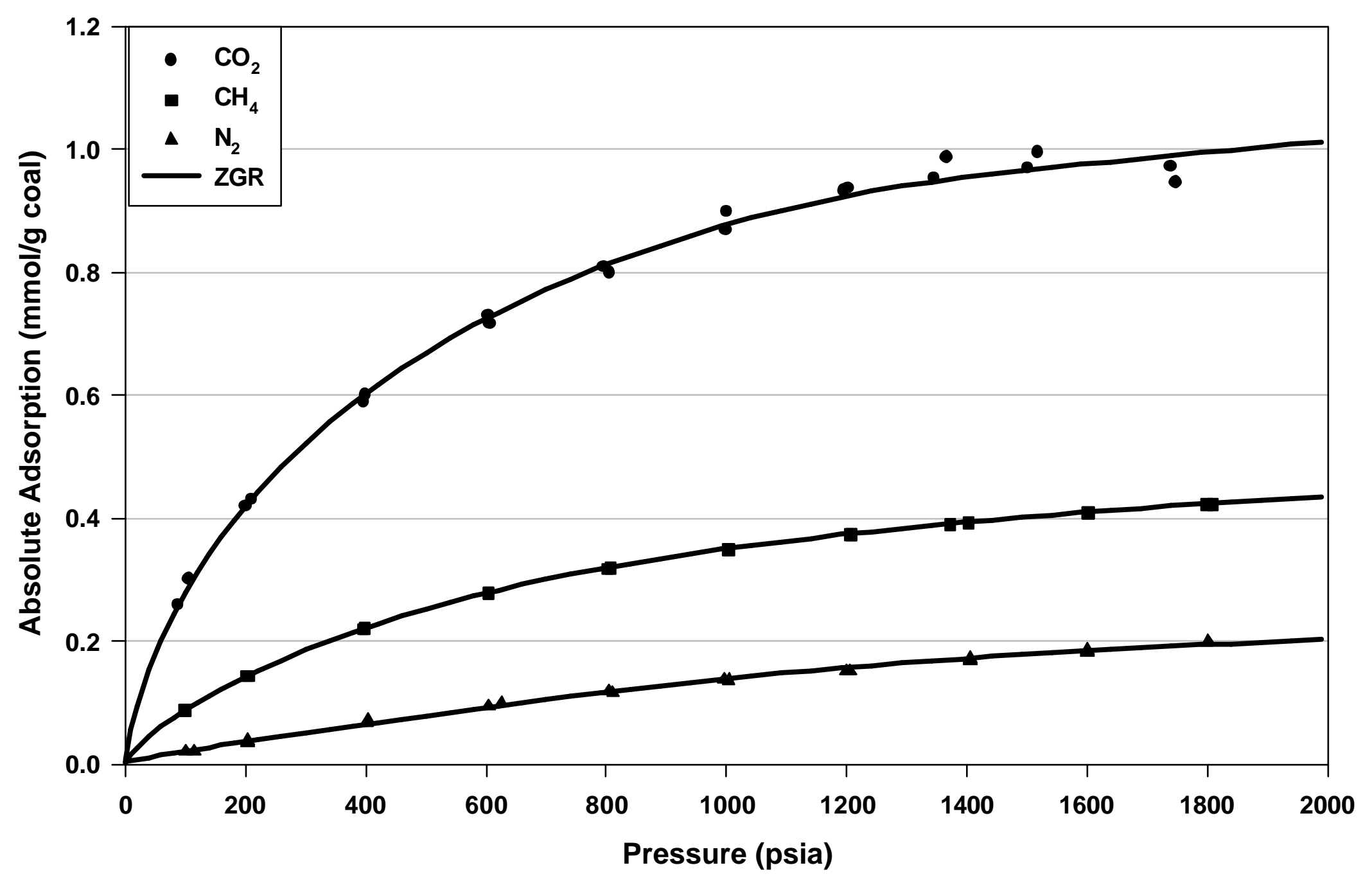


Figure 40. Depiction of Slit SLD Model

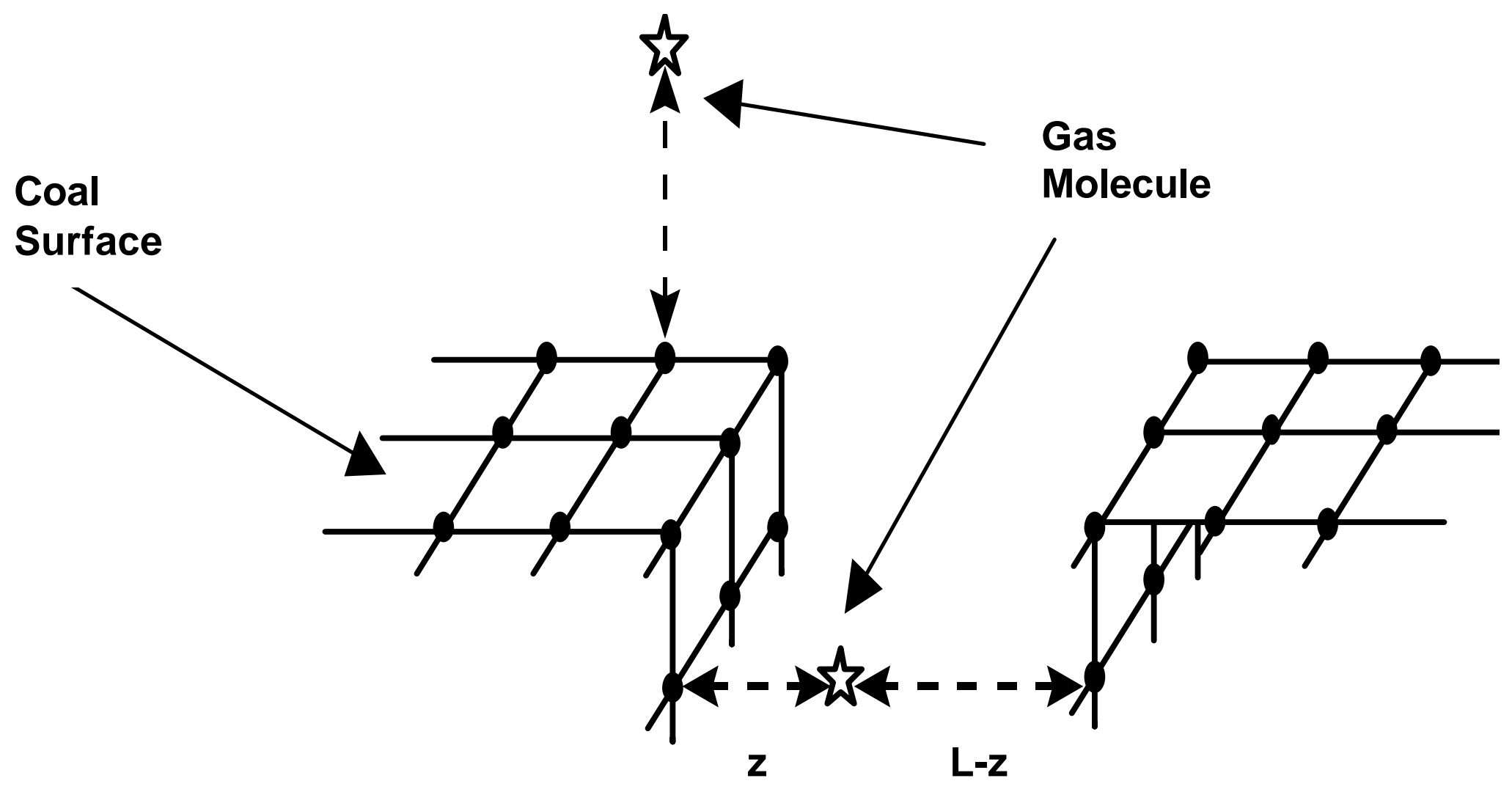


Figure 41. Volumetric Strain of Coal Matrix upon Adsorption and Desorption of Methane (Data: Harpalani et al. 1989)

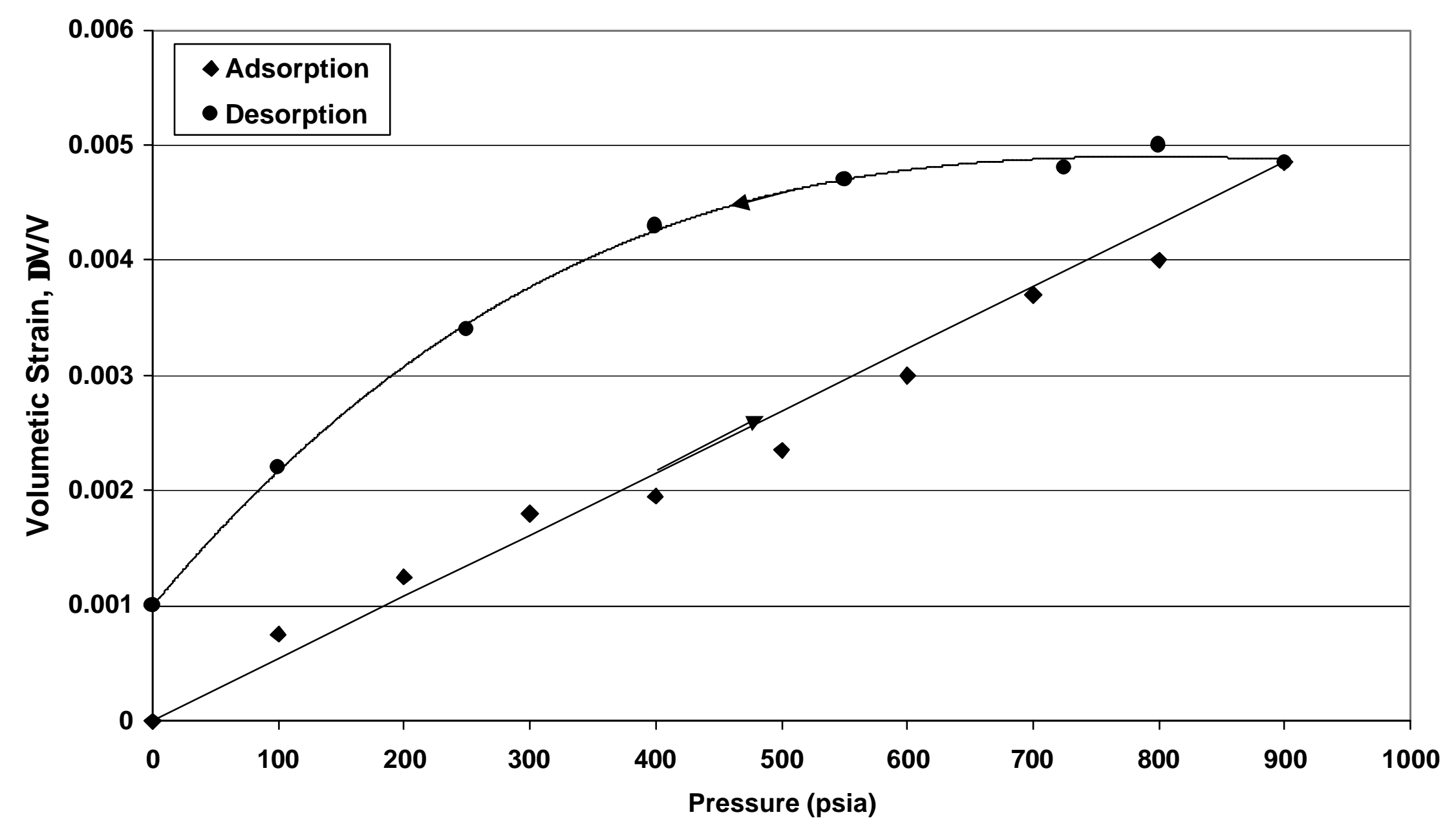


Figure 42. Effect of Coal Permeability on the Adsorption and Desorption of Methane (Data: Harpalani et al. 1989)

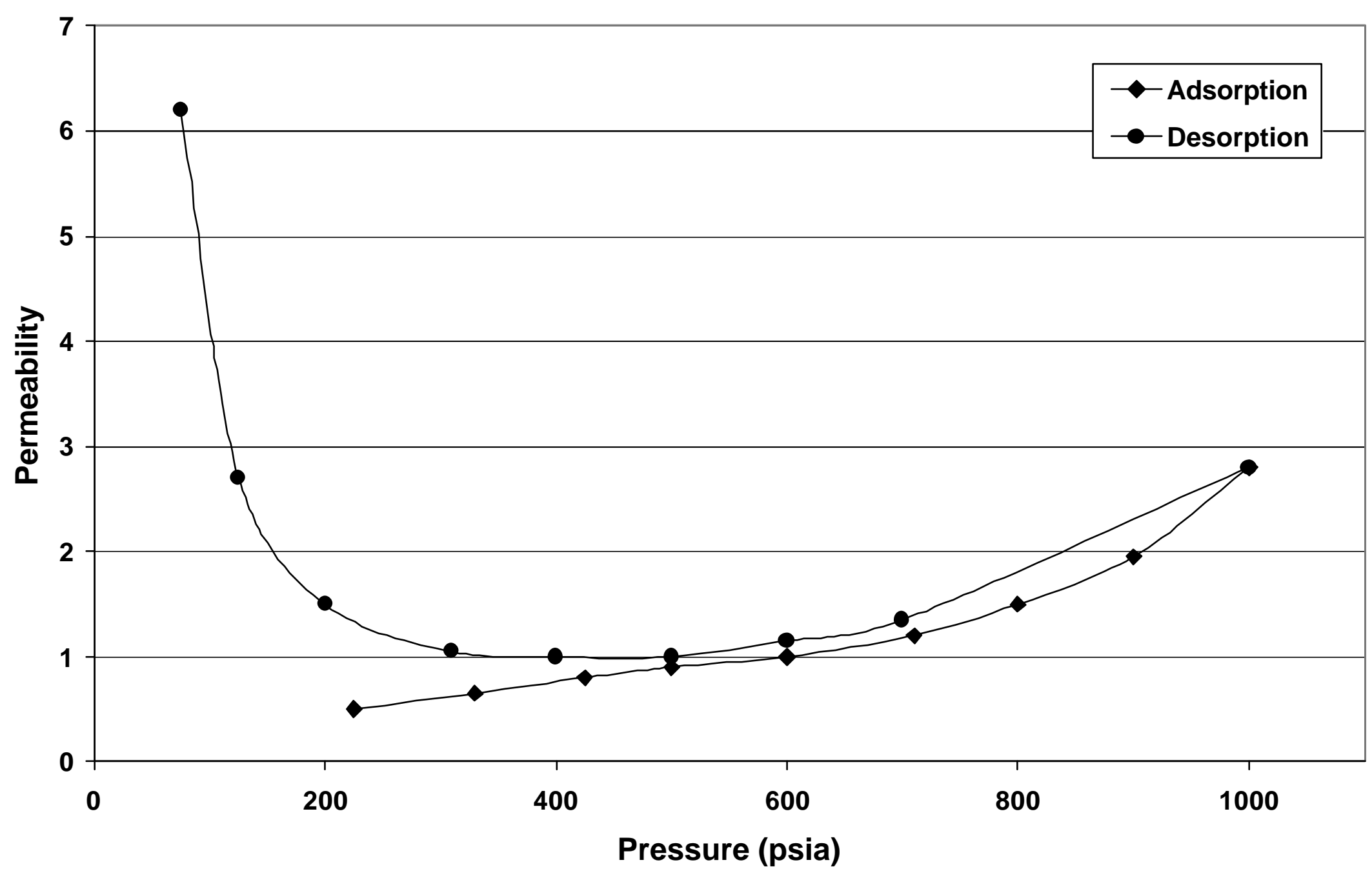


Figure 43. Estimation of Adsorption Phase Volume and Density

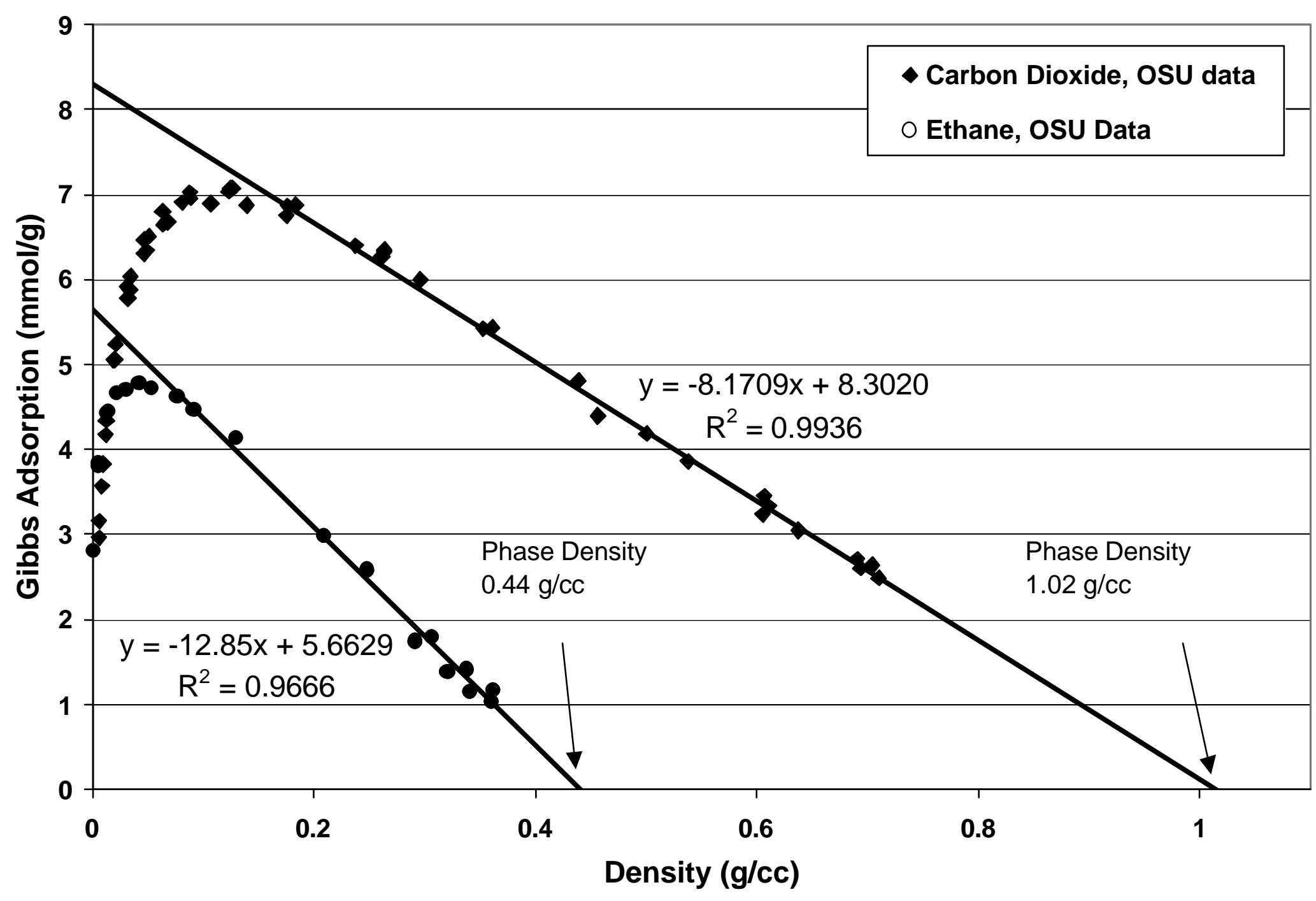


Figure 44. Effect of Swelling on Isotherm Shape

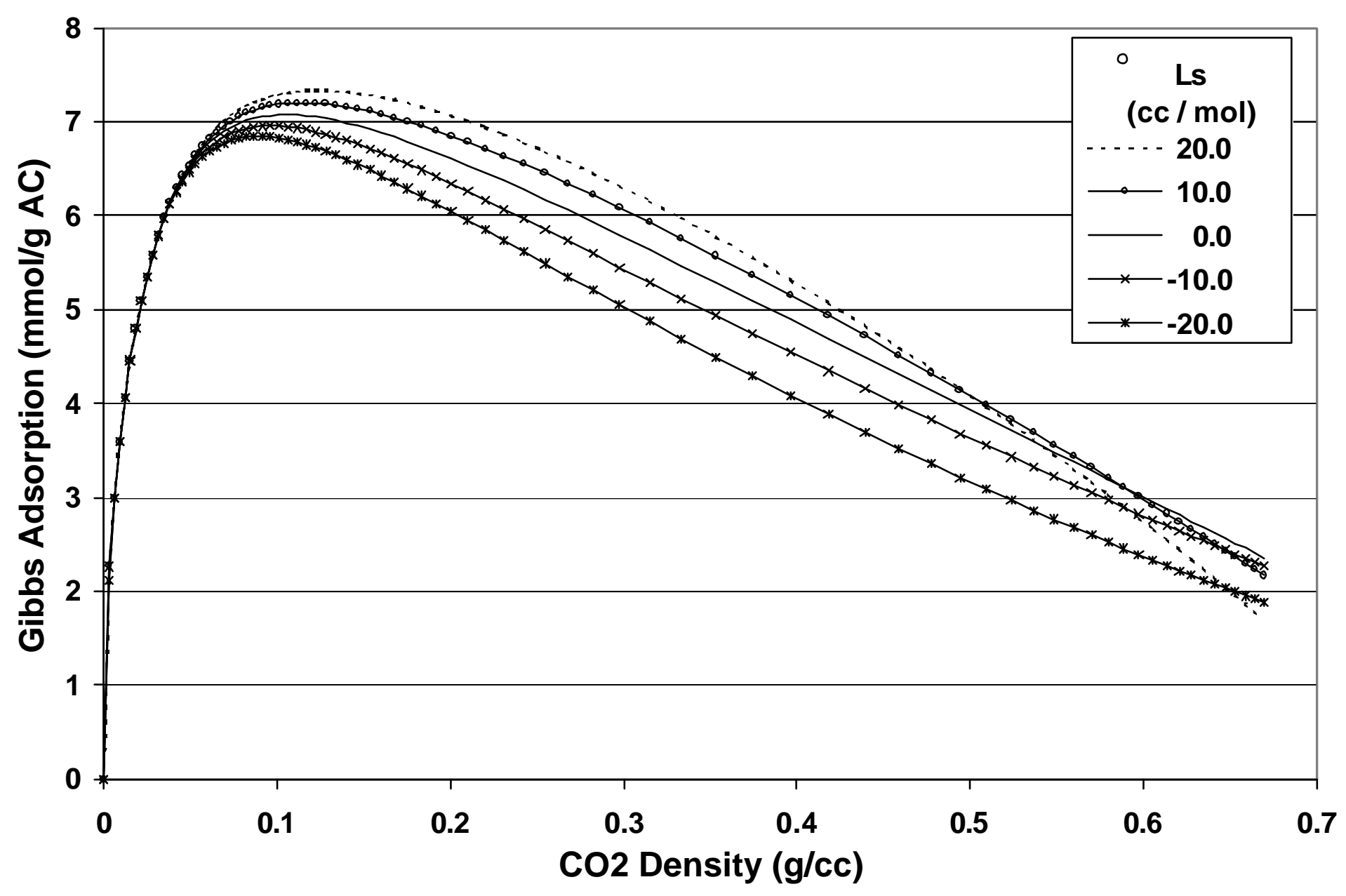


Figure 45. PR SLD model of $\mathrm{CO}_{2}$ Gibbs Excess Adsorption on Activated Carbon at $113^{\circ} \mathrm{F}$

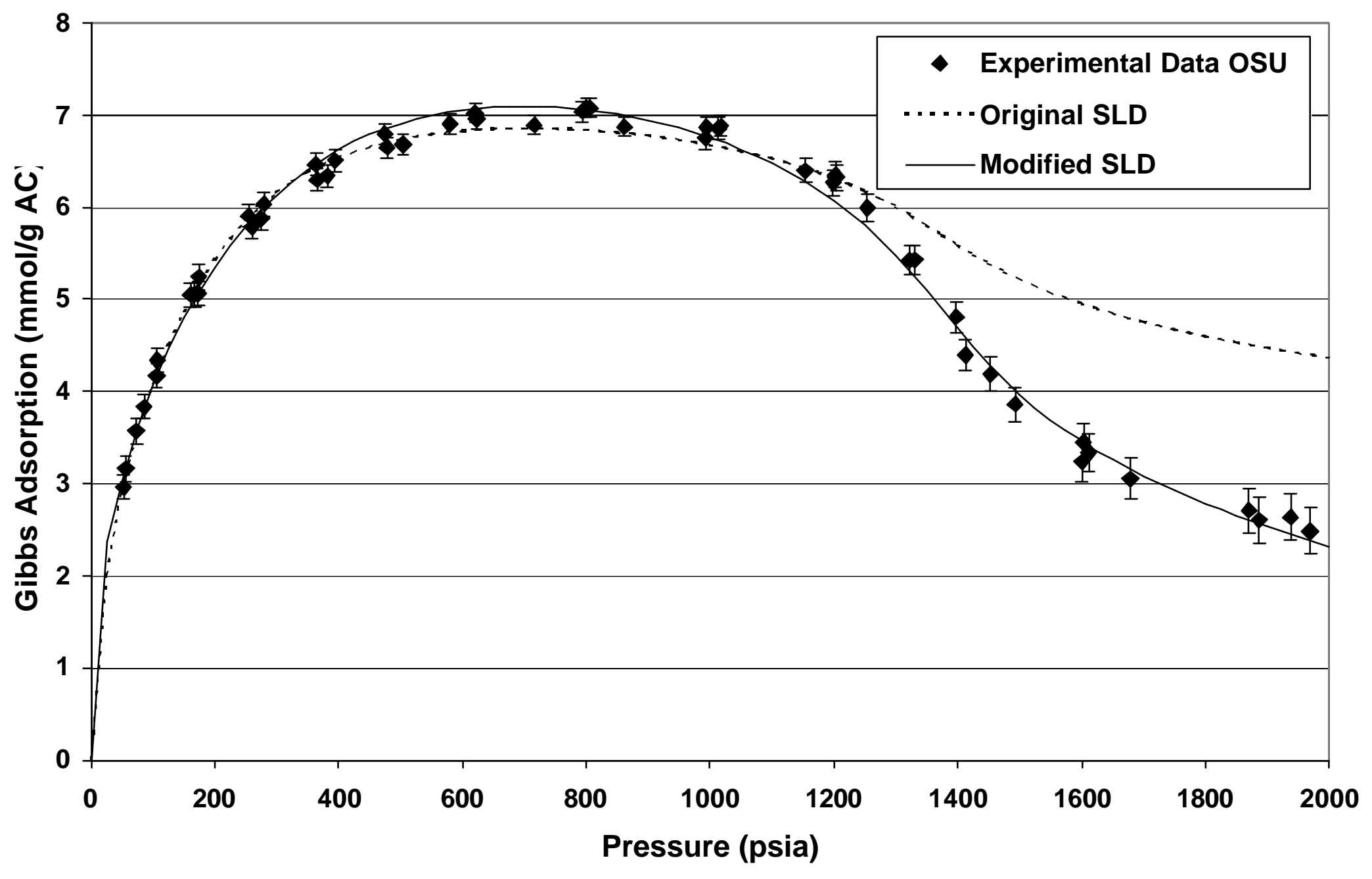


Figure 46. Effect of PR Covolume on Local Density for $\mathrm{CO}_{2}$ on Activated Carbon at $113^{\circ} \mathrm{F}$ and 100 psia

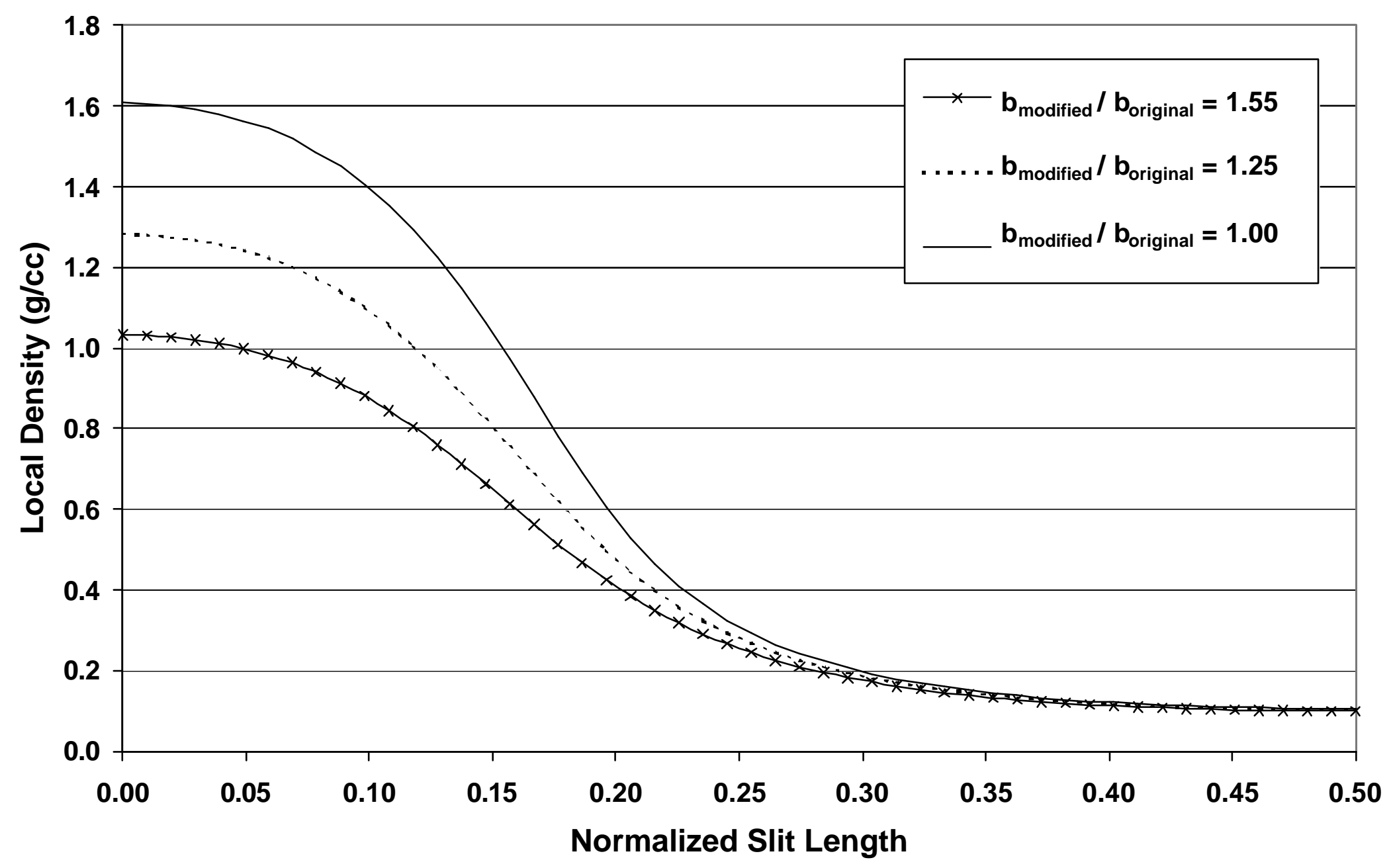


Figure 47. Correlation of $e_{\mathrm{fs}}$ with Modified PR Covolume

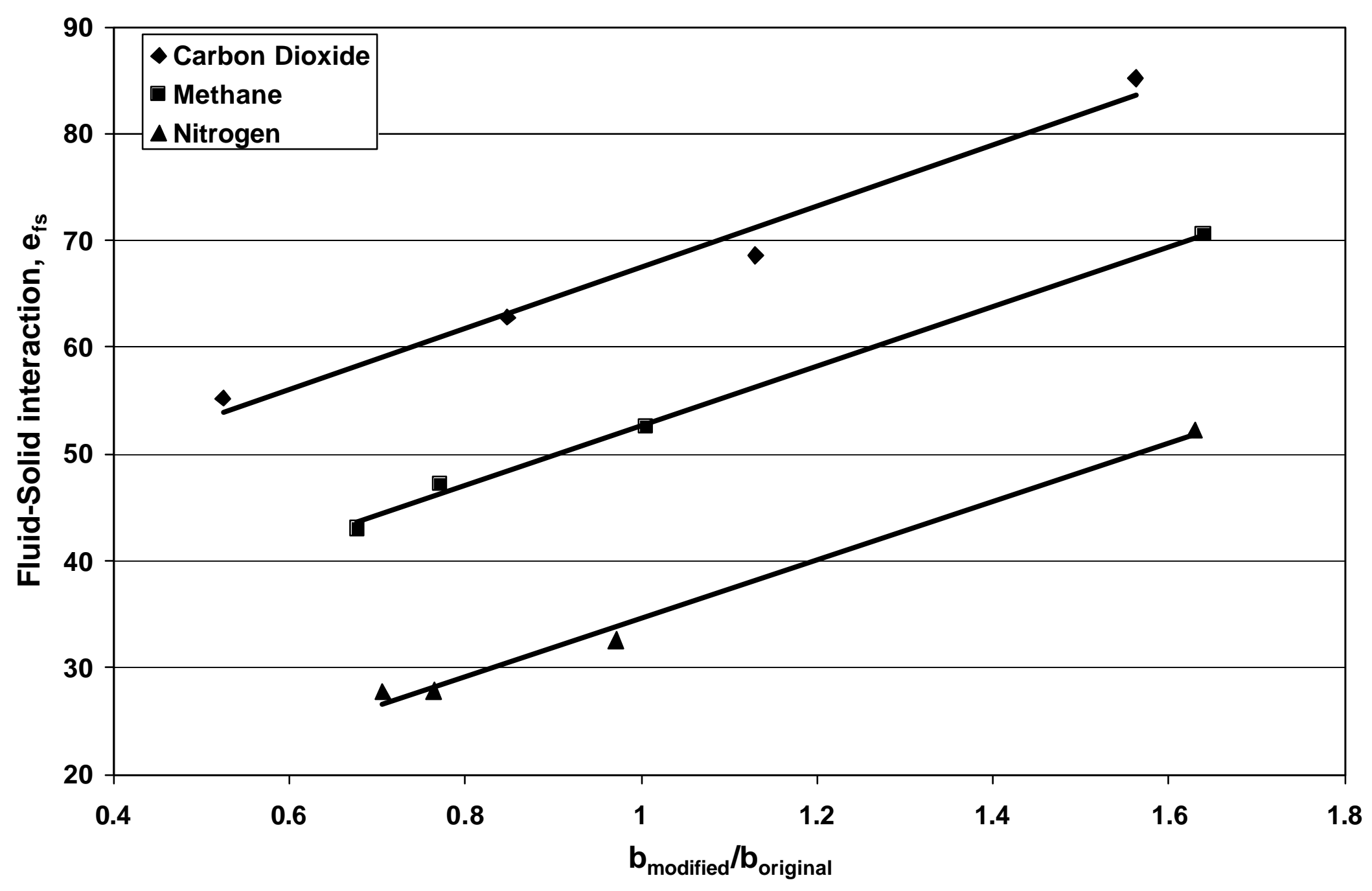


Figure 48. Predicted Total Absolute Adsorption for Methane/Carbon Dioxide on Illinois- 6 Coal at $115^{\circ} \mathrm{F}$ : ZGR and LRC Models

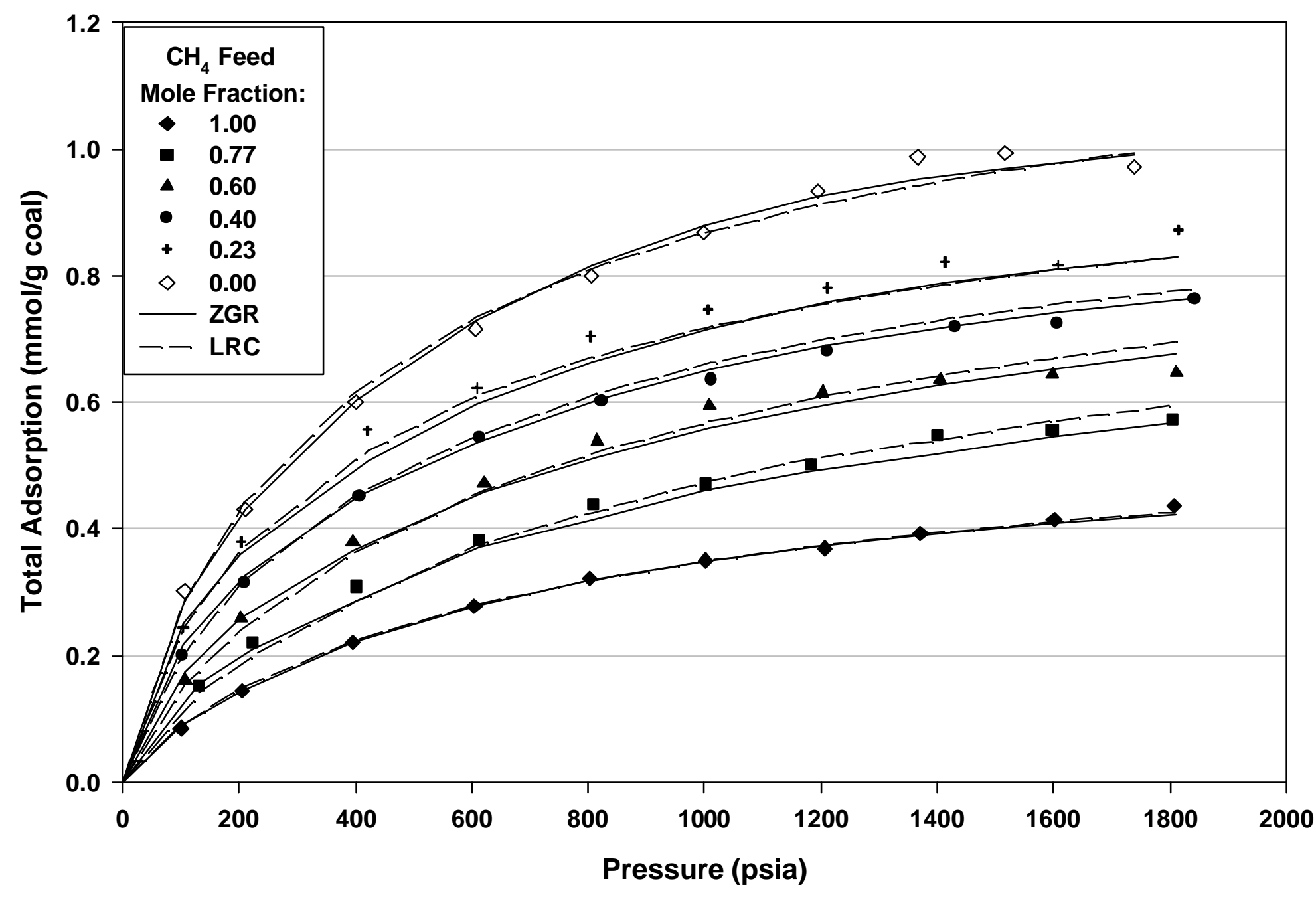


Figure 49. Predicted Methane Absolute Adsorption for Methane/Carbon Dioxide on Illinois-6 Coal at $115^{\circ} \mathrm{F}$ : ZGR and LRC Models

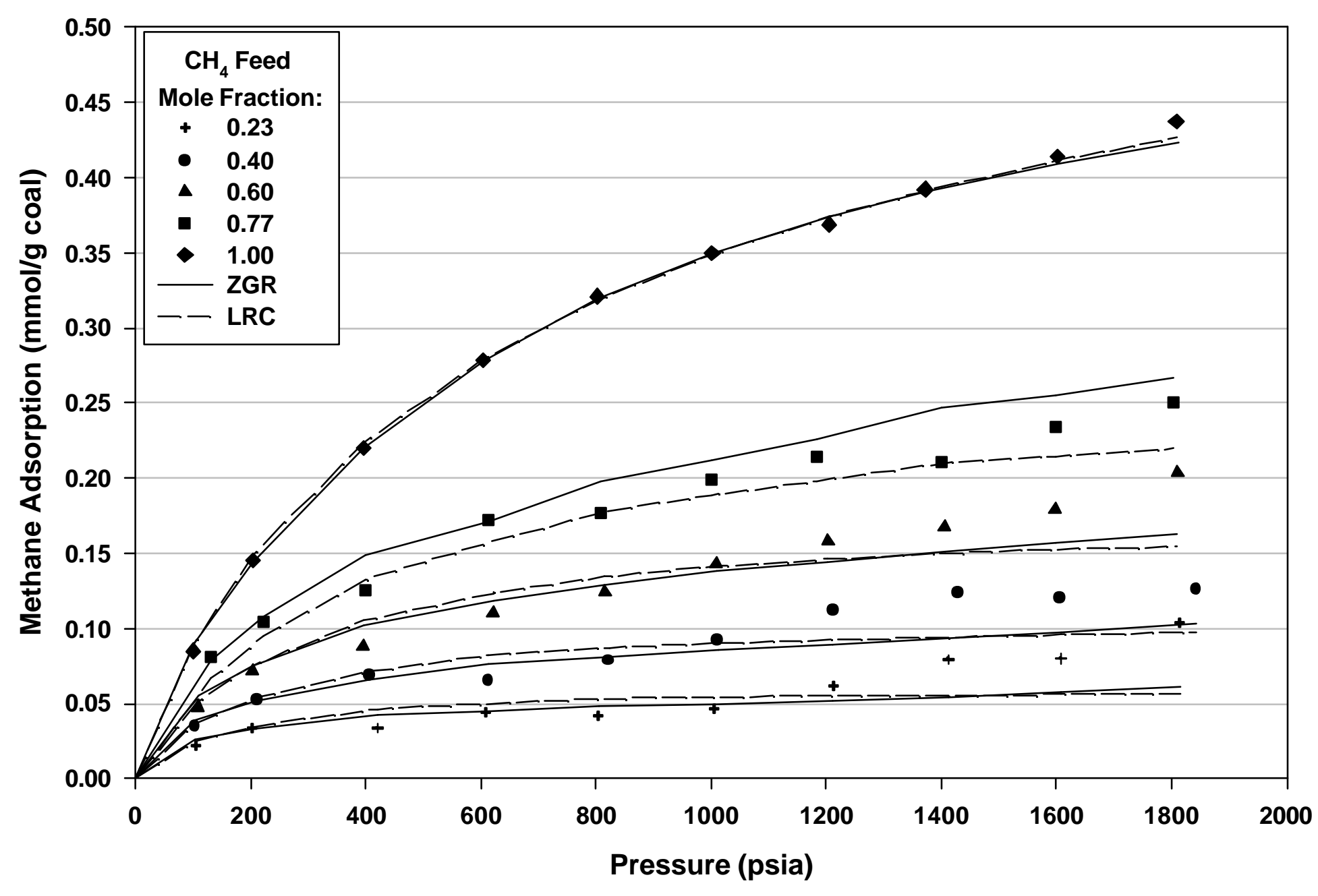


Figure 50. Predicted Carbon Dioxide Absolute Adsorption for Methane/Carbon Dioxide on Illinois- 6 Coal at $115^{\circ} \mathrm{F}$ : ZGR and LRC Models

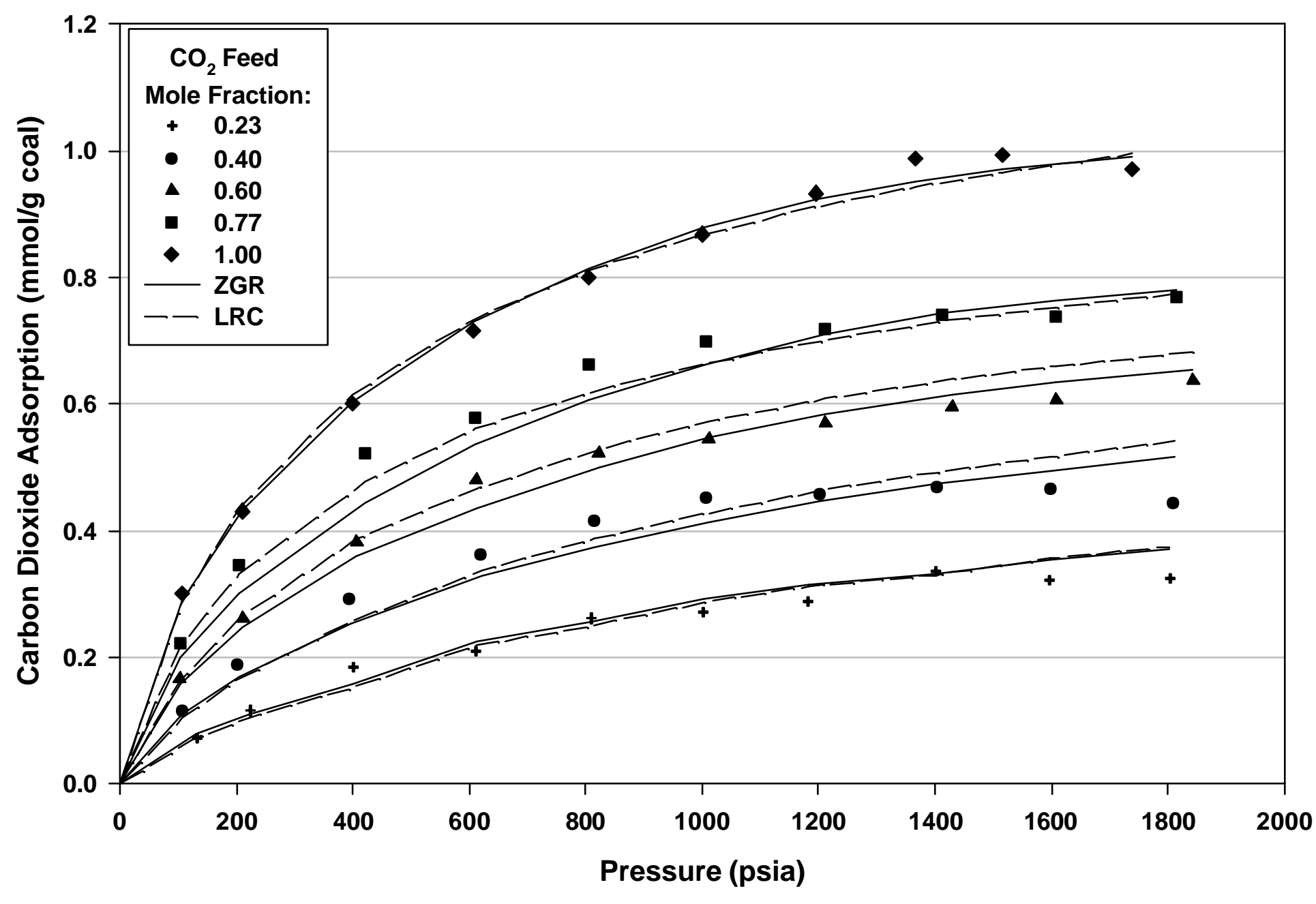


Figure 51. Predicted Total Absolute Adsorption for Methane/Carbon Dioxide on Illinois- 6 Coal at $115^{\circ} \mathrm{F}$ : ZGR Model

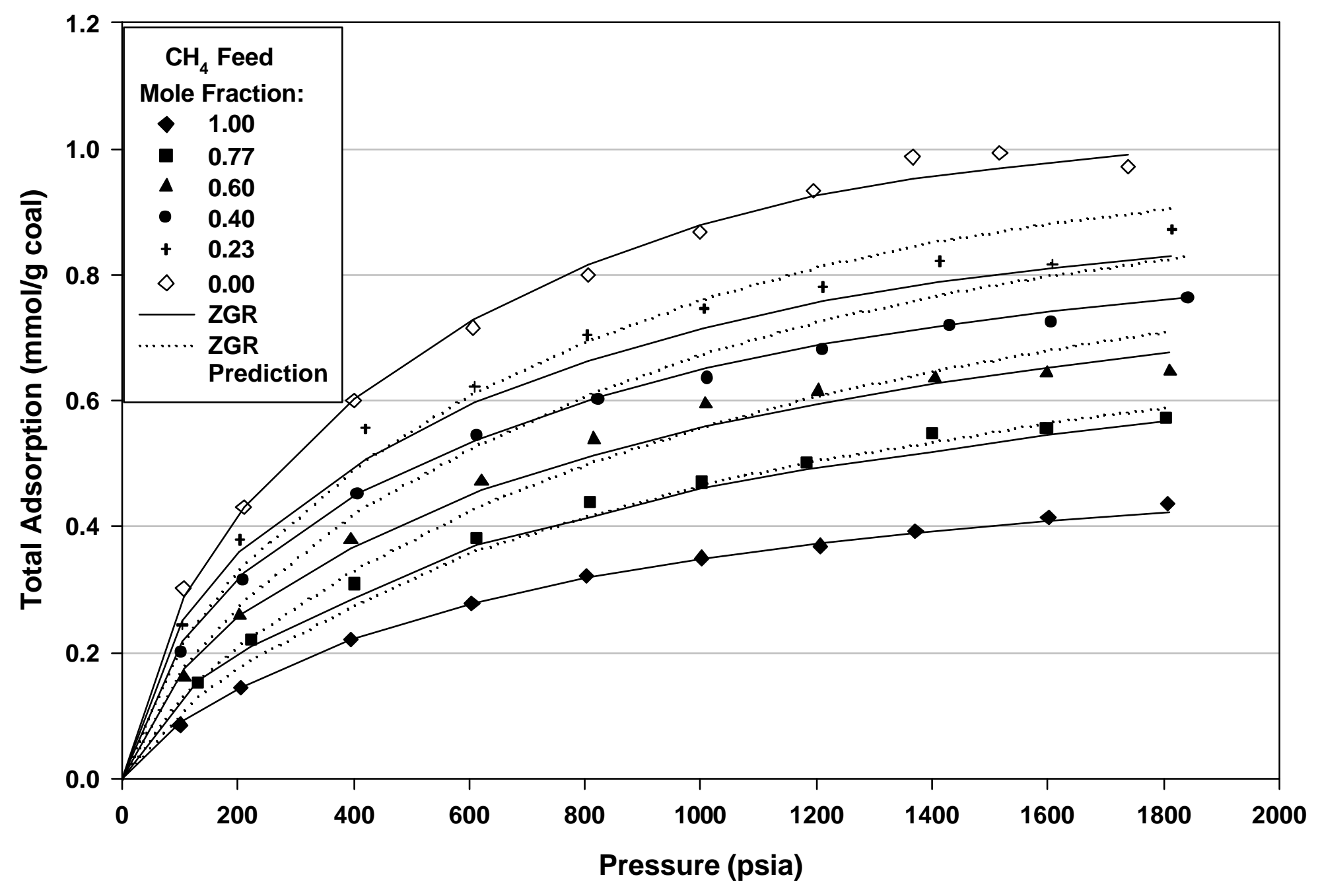


Figure 52. Predicted Methane Absolute Adsorption for Methane/Carbon Dioxide on Illinois-6 Coal at $115^{\circ} \mathrm{F}$ : ZGR Model

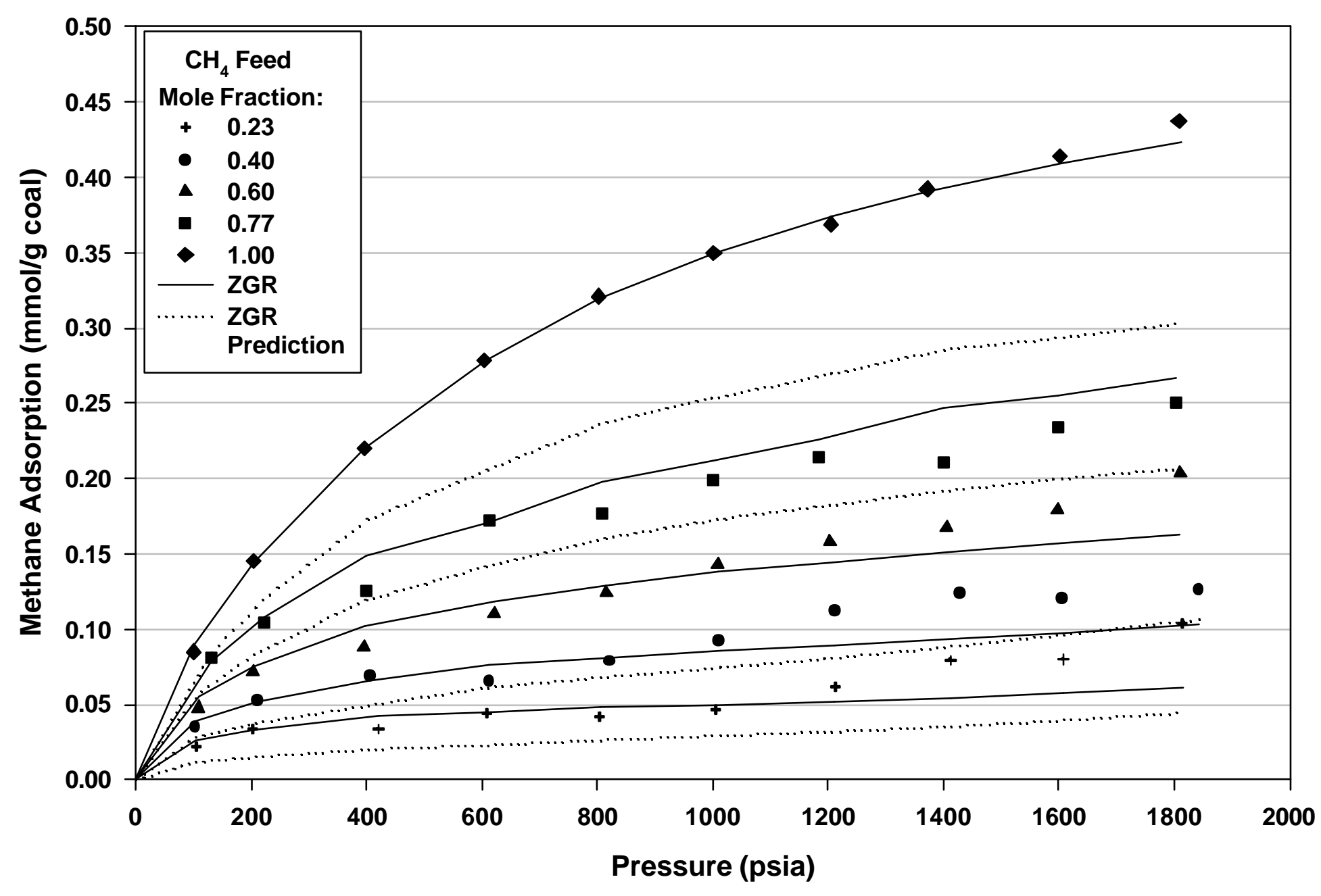


Figure 53. Predicted Carbon Dioxide Absolute Adsorption for Methane/Carbon Dioxide on Illinois-6 Coal at $115^{\circ} \mathrm{F}$ : ZGR Model

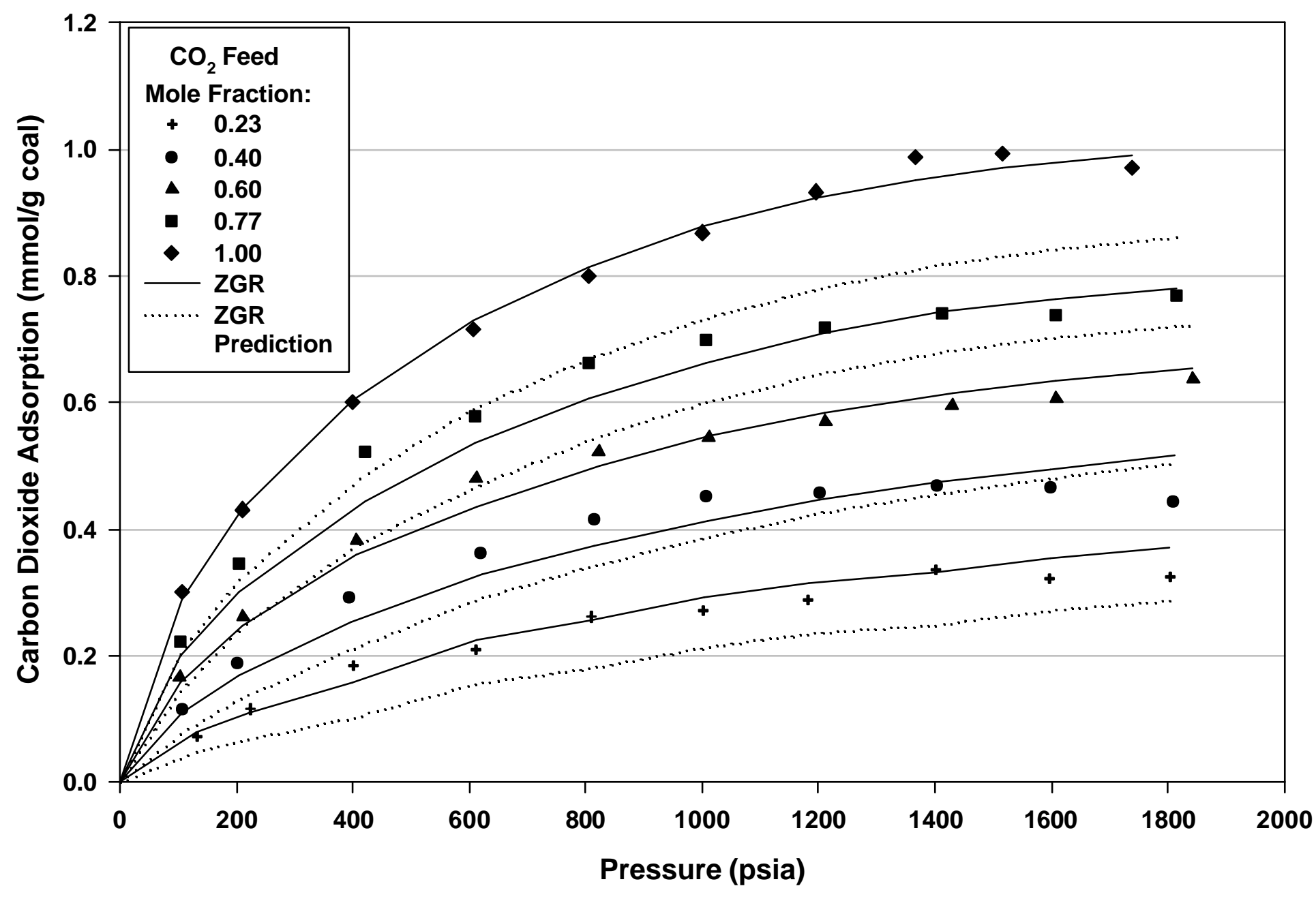

